\title{
Fuel Cycle Technologies 2014 Achievement Report
}

\author{
Idaho National Laboratory
}

January 2015

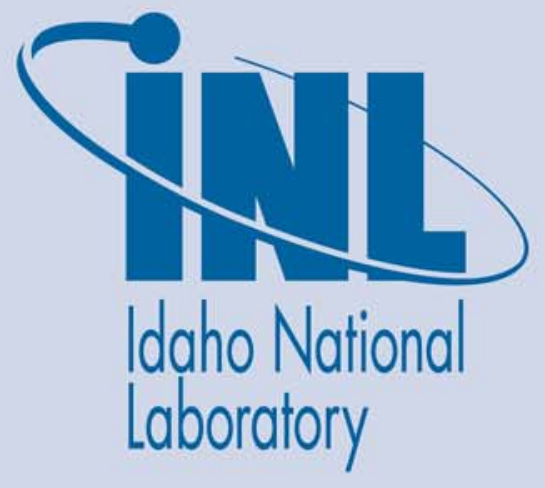




\section{DISCLAIMER}

This information was prepared as an account of work sponsored by an agency of the U.S. Government. Neither the U.S. Government nor any agency thereof, nor any of their employees, makes any warranty, expressed or implied, or assumes any legal liability or responsibility for the accuracy, completeness, or usefulness, of any information, apparatus, product, or process disclosed, or represents that its use would not infringe privately owned rights. References herein to any specific commercial product, process, or service by trade name, trade mark, manufacturer, or otherwise, does not necessarily constitute or imply its endorsement, recommendation, or favoring by the U.S. Government or any agency thereof. The views and

opinions of authors expressed herein do not necessarily state or reflect those of the U.S. Government or any agency thereof. 


\title{
Fuel Cycle Technologies Yearly Accomplishments Report
}

\author{
January 2015 \\ Idaho National Laboratory \\ Idaho Falls, Idaho 83415 \\ http://www.inl.gov
}

INL/EXT-15-34061

\author{
Prepared for the \\ U.S. Department of Energy \\ Office of Nuclear Energy, Fuel Cycle Technologies \\ Under DOE Idaho Operations Office \\ Contract DE-AC07-05ID14517
}





\section{CONTENTS}

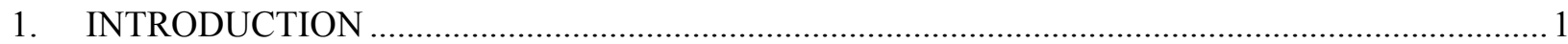

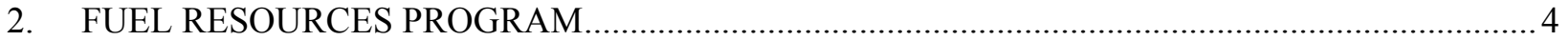

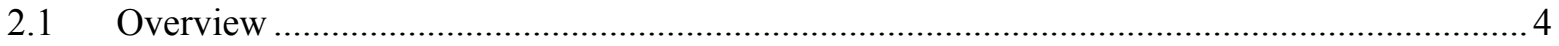

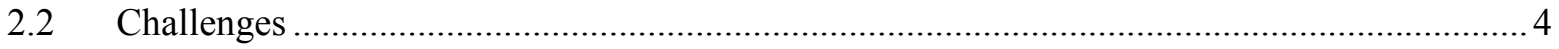

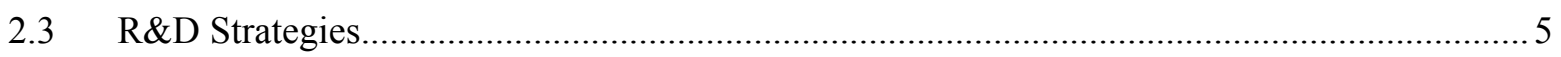

2.4 Major Research and Development Activities.................................................................. 5

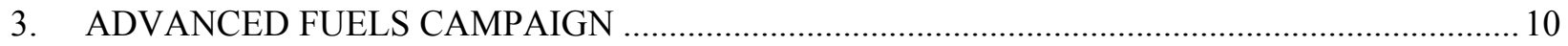

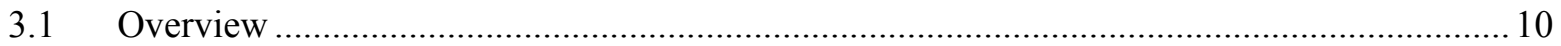

3.2 Advanced LWR Fuel Systems Development ................................................................ 11

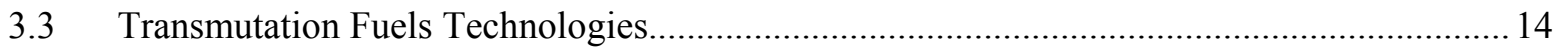

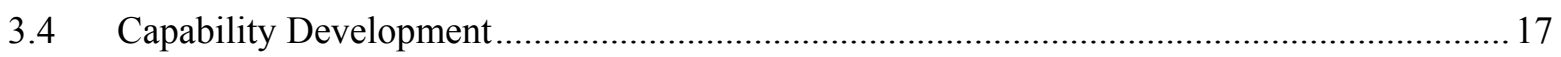

4. NUCLEAR FUELS STORAGE AND TRANSPORTATION PROGRAM ....................................20

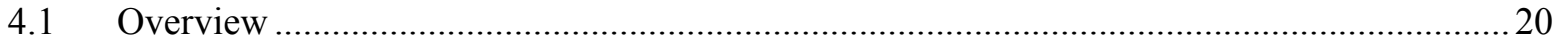

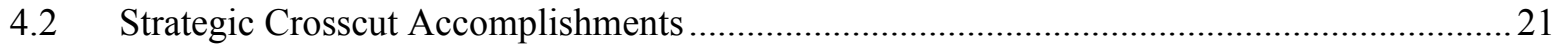

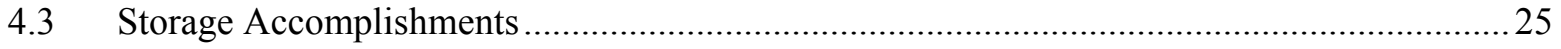

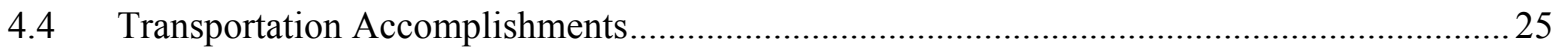

5. MATERIAL RECOVERY AND WASTE FORM DEVELOPMENT CAMPAIGN ........................28

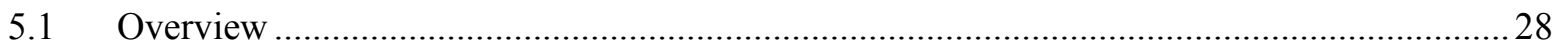

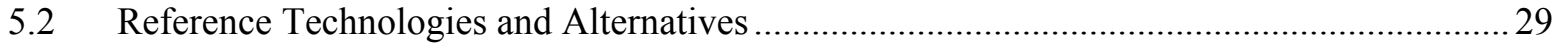

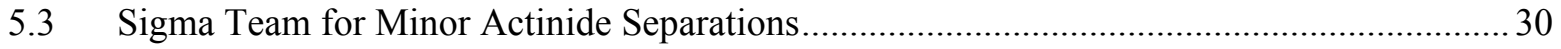

5.4 Sigma Team for Off-Gas Capture and Immobilization ................................................... 30

5.5 Fundamental Science and Methods, Modeling, and Simulation .......................................... 30

5.6 Advanced Waste Form Characterization.............................................................................. 30

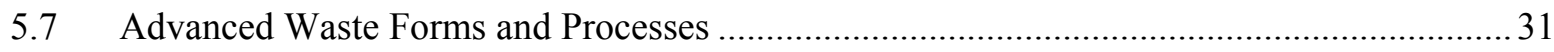

$5.8 \quad$ Domestic Electrochemical Separations Technologies....................................................... 31

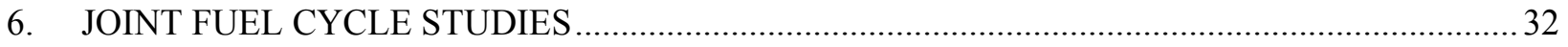

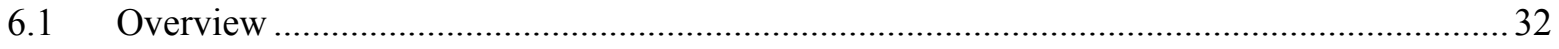

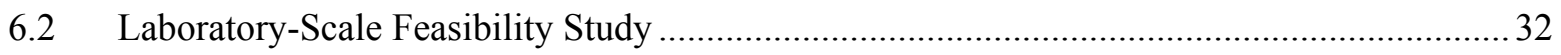

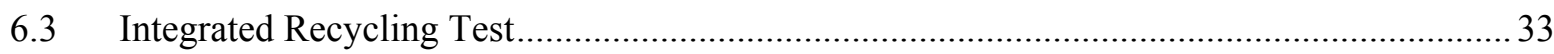

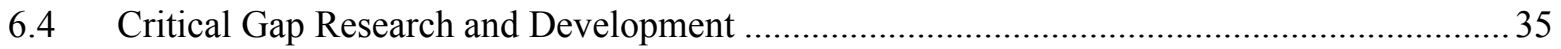

7. USED FUEL DISPOSITION RESEARCH AND DEVELOPMENT CAMPAIGN ........................38

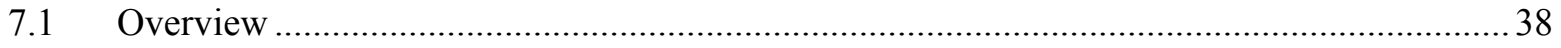

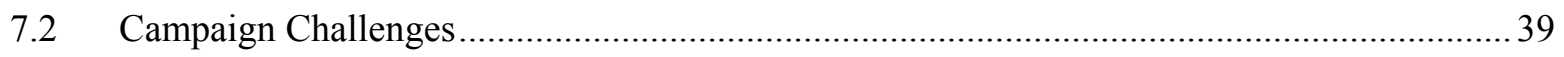




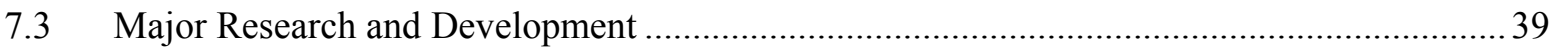

7.4 Storage and Transportation Accomplishments................................................................ 40

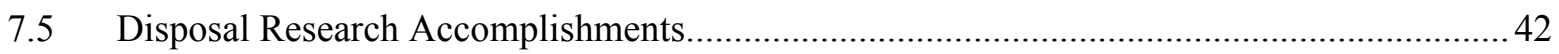

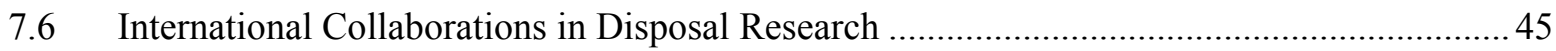

8. MATERIAL PROTECTION, ACCOUNTING, AND CONTROL TECHNOLOGIES PROGRAM46

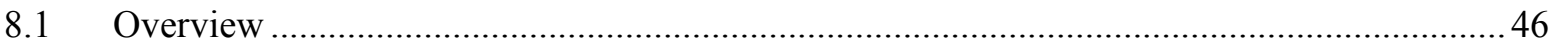

8.2 Major Research and Development Activities.................................................................. 47

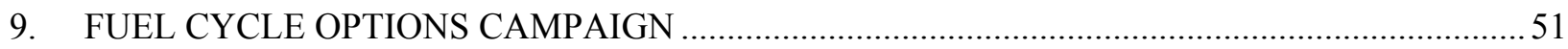

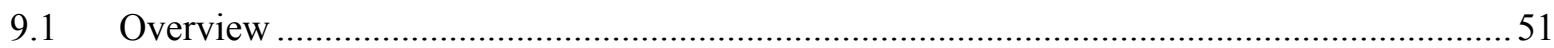

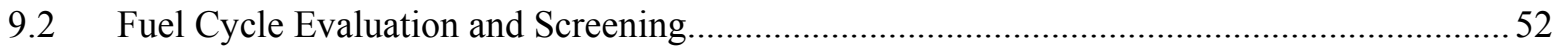

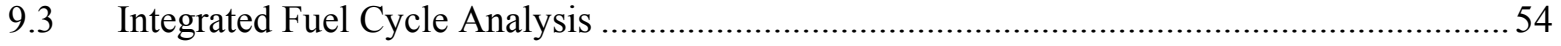

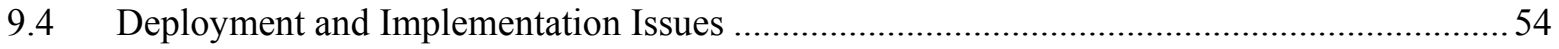

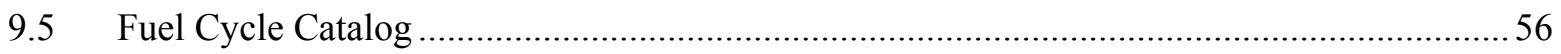

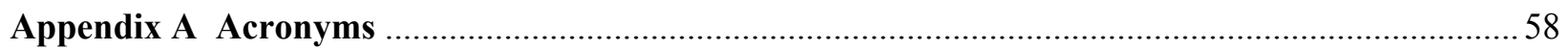




\section{FIGURES}

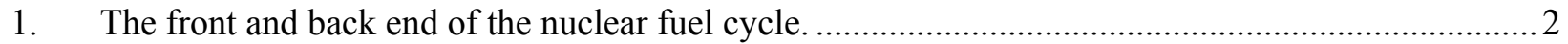

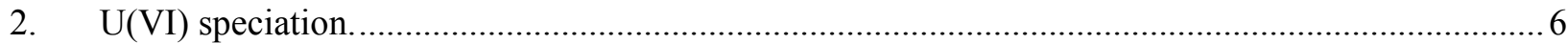

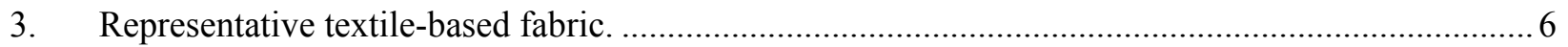

4. RIGP-ATRP hybrid method (A), direct ATRP method (B) ................................................

5. Time-series measurements of uranium adsorption capacity determined using column (left panel) and flume exposure (right panel) studies for different form ulations of the amidoxime-based adsorbent AF1 produced by ORNL. Data have been normalized to a salinity of $35 \mathrm{psu}$. 8

6. Time series measurements of adsorbent capacity for three different temperatures with the ORNL adsorbent AI8. Lines drawn through the data points were generated with a one-site ligand saturation model. Data were normalized to a salinity of $35 \mathrm{psu}$. 8

7. Temperature dependence on adsorption capacity for the ORNL adsorbents $38 \mathrm{H}$ (left panel), AF1 (middle panel) and AI8 (right panel). Data were normalized to a salinity of $35 \mathrm{psu}$. 8

8. Uranium production cost scenarios for ORNL AF 1 adsorbent with capacity at $20^{\circ} \mathrm{C}$ as predicted by PNNL measurements and one-site ligand saturation model.

9. Volumetric view of temperature distribution in ATF-1 experiment hardware with a threshold of $300-450 \mathrm{C}$

10. An AREVA fuel pellet and digital radiography of welded capsule assemblies............................. 12

11. Digital radiography of GE capsule assemblies and a fuel pellet. ................................................... 12

12. Digital radiography of Westinghouse capsule assemblies and a fuel pellet.................................. 13

13. Radiograph of ORNL ATF-1 rodlets after completion of fabrication prior to delivery. Length of

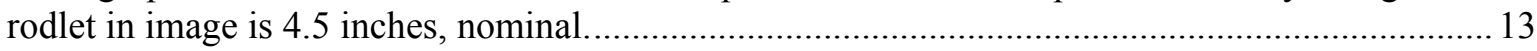

14. Macroscopic photographs of specimens after exposure to steam at a variety of temperatures......... 14

15. Left: Hot Uniaxial Press insert loaded with reaction crucible and reagents. Middle: Close up of magnesium oxide crucible nested $\mathrm{n}$ a stainless steel crucible nested in the furnace insert. Right: Removal of neptunium metal button.

16. Schematic and photo of the GACS configured for gravity casting. Note- the linear actuator has been removed for the photo.

17. Legacy AFC-1 material: (Left) Archive slug which can be used as-is for further characterization and Right) remaining casting heel pieces which can be re-cast into a usable sample...................... 16

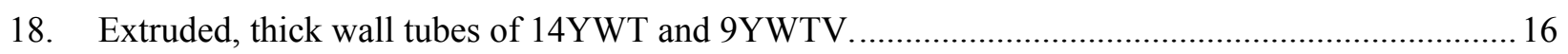

19. TN-106 cask containing the FUTURIX-FTA experiment in the HFEF Truck Lock .......................17

20. Micro compression testing on irradiated materials. ................................................................. 17

21. TCM measures local changes in thermal conductivity. The left side illustrates measurement of the Kapitza resistance of an individual, highly characterized interface ............................................ 18

22. Fresh Fuels Glovebox in MFC's Analytical Lab: (a) West side view; (b) East side view............... 19

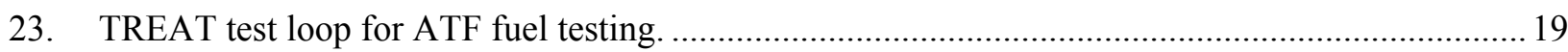

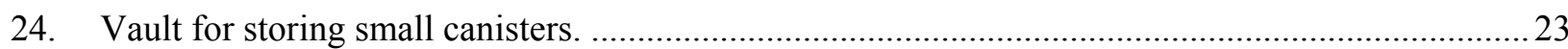




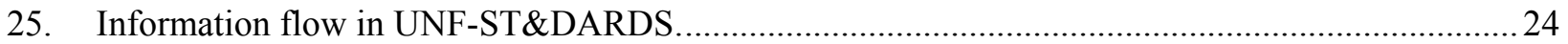

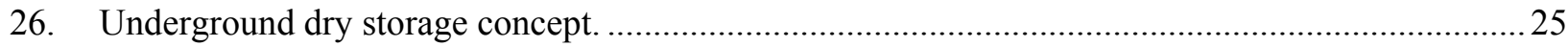

27. U.S. Navy AAR S-2043 compliant rail car with cask (not for transport of commercial UNF) ........27

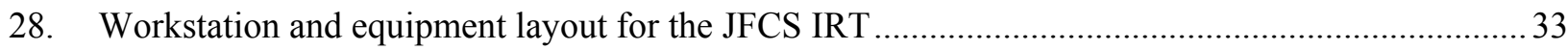

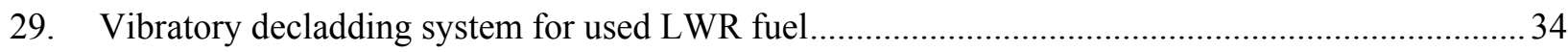

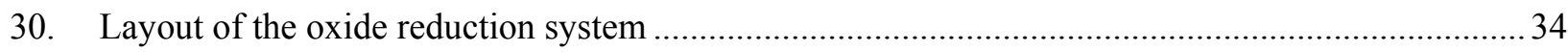

31. Internal components for uranium counter gravity casting (left) and gravity casting (right) .............35

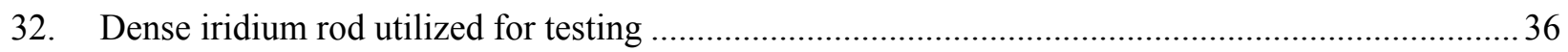

33. $\mathrm{UO}_{2}$-coated crucible after repeated melts with metallic uranium ................................................ 36

34. Summary timeline for Storage and Transportation Research activities. ......................................... 40

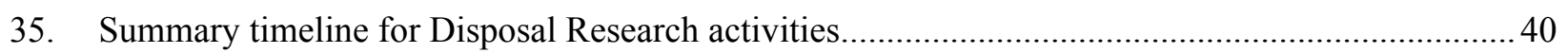

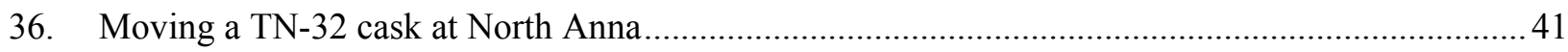

37. Cyclic Integrated Reversible-bending Fatigue Tester in Hot Cell ................................................. 41

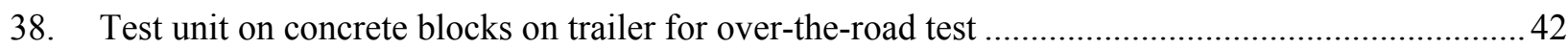

39. Representative disposal concepts investigated by the Used Fuel Disposition R\&D Campaign. ...... 43

40. Underground field tests of radionuclide transport in crystalline rock at the Grimsel test site in

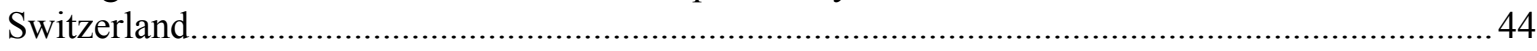

41. Representative results of generic disposal system modeling for a reference case mined

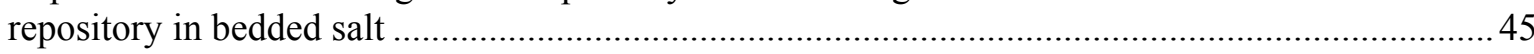

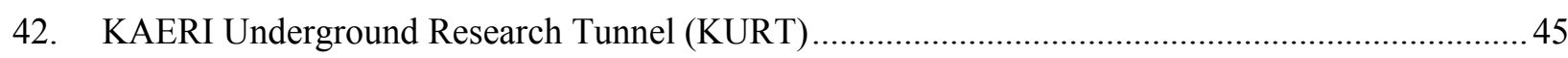

43. Level/density sensor testing equipment for molten salt tests have demonstrated the ability to measure density with $<1 \%$ accuracy, while level measurements were made with $2 \%$ accuracy...... 48

44. In-situ monitoring technology for prompt determination of actinide concentrations in a molten

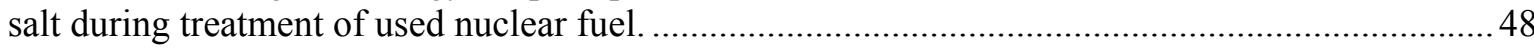

45. Radiation signatures (neutron and gamma-ray) are being developed for electrochemical processing to enable advanced monitoring techniques.

46. Experimental design for the determination of the spent fuel ratio, which is currently poorly understood and an important factor in evaluating security of interim storage concepts.

47. H-Canyon sampling hardware and associated model to support the field testing of the Multi-

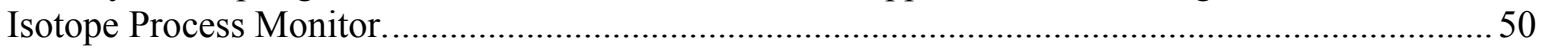

48. Benefit versus challenge using equal criteria tradeoff factors ................................................... 53

49. An example of the timing of transition to a new fuel cycle using recycle in SFRs for a total generating capacity of $100 \mathrm{GWe}$.

50. Comparison of the probability distributions for the levelized cost of electricity at equilibrium for EG01 (today's U.S. fuel cycle) and EG23 (one of the most promising groups) at a 5\% discount rate.

51. Global and U.S. electricity generation in the $450 \mathrm{ppm}$ scenarios $(\mathrm{EJ} / \mathrm{yr})$. ..................................56

52. Image of the home page of the Nuclear Fuel Cycle Catalog......................................................... 56 


\section{TABLES}

1. Identified attributes for the most promising fuel cycle options 53

2. Included groups considered most-promising in Evaluation Group EG23 
This page left intentionally blank 


\section{Fuel Cycle Technologies Program Yearly Accomplishments Report}

\section{INTRODUCTION}

The Fuel Cycle Technologies (FCT) program supports the Department of Energy's (DOE's) mission to: “Enhance U.S. security and economic growth through transformative science, technology innovation, and market solutions to meet our energy, nuclear security, and environmental challenges." Goal 1 of DOE's Strategic Plan is to innovate energy technologies that enhance U.S. economic growth and job creation, energy security, and environmental quality. FCT does this by investing in advanced technologies that could transform the nuclear fuel cycle in the decades to come. Goal 2 of DOE's Strategic Plan is to strengthen national security by strengthening key science, technology, and engineering capabilities. FCT does this by working closely with the National Nuclear Security Administration and the U.S. Department of State to develop advanced technologies that support the nation's nuclear nonproliferation goals.

DOE's Strategic Plan supports the President's Climate Action Plan. The Climate Action Plan is intent on cutting carbon pollution in America by deploying clean energy. Two ways of doing this are to "[unlock] longterm investment in clean energy innovation" and "invest in a range of energy technologies, including emerging nuclear technologies." The Climate Action Plan also calls on the U.S. to lead international efforts to address global climate change. A key aspect of this is to "promote the safe and secure use of nuclear power worldwide through a variety of bilateral and multilateral engagements." FCT promotes the continued development of clean nuclear energy in the short term through research and development (R\&D) into advanced nuclear fuel concepts for this generation of light water reactors and to lay the groundwork for decision

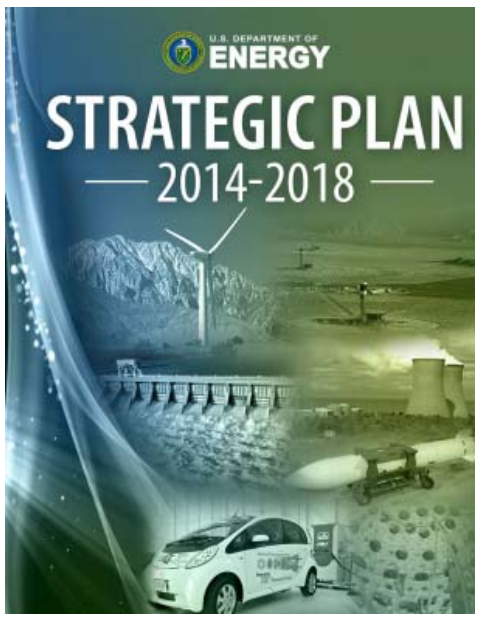
makers to implement a waste management system for used nuclear fuel and high-level radioactive waste. In the long term, FCT conducts R\&D on advanced sustainable fuel cycle technologies.

The mission of FCT is to (1) conduct R\&D and other activities related to used nuclear fuel (UNF), nuclear waste management, and disposal issues and (2) conduct $R \& D$ related to advanced sustainable fuel cycle technologies that have the potential to improve resource utilization and energy generation, reduce waste generation, enhance safety, and limit proliferation risk. In addition, the program is laying the groundwork for implementing the Administration's strategy on the management of spent nuclear fuel (SNF) and high-level radioactive waste (HLW). The program employs a long-term, science-based approach to foster innovative, transformational technology solutions to achieve this mission. Advancements in fuel cycle technologies and solutions support the enhanced availability, affordability, safety, and security of nuclear-generated electricity in the U.S. 
The nuclear fuel cycle consists of acquiring the uranium resources and fabricating fuel on the "front end," using that fuel to produce heat and electricity in reactors, and then storing and disposing of the used fuel on the "back end." This is the "once-through" fuel cycle currently being developed in the U.S. The back end could also include recycling used fuel in various ways to produce new fuel. FCT is conducting R\&D on advanced technologies covering all aspects of the front end and the back end of the nuclear fuel cycle. FCT also works closely with other programs in the Office of Nuclear Energy that focus on advanced reactor technology development. FCT employs an integrated systems approach in fuel cycle technology development because technologies employed in one aspect of the fuel cycle will impact the performance throughout other aspects of the fuel cycle. This is accomplished through systems analyses, engineering, and integration (see Figure 1).

\section{Front End}

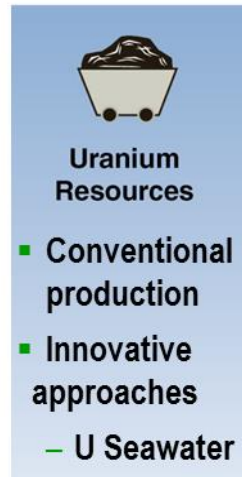

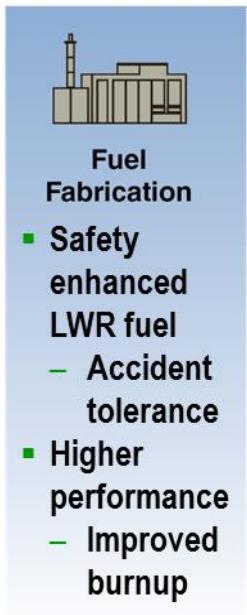

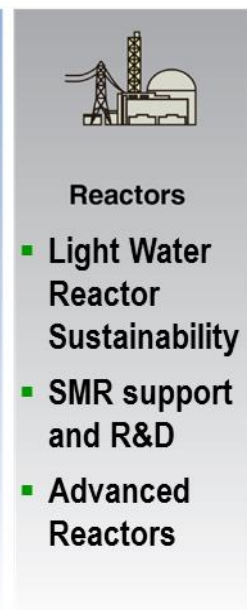

\section{Back End}

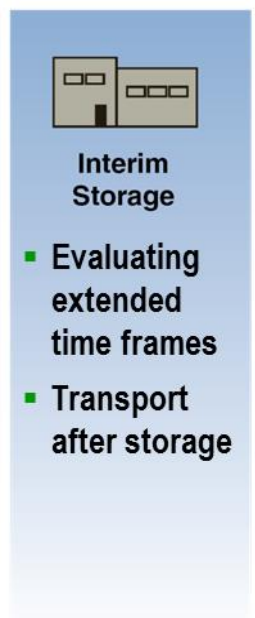

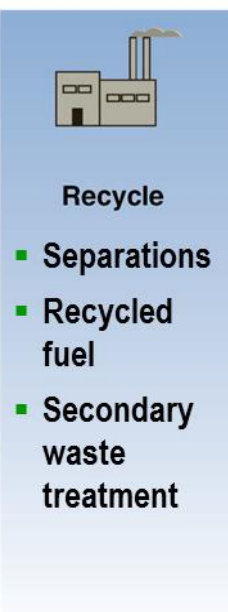

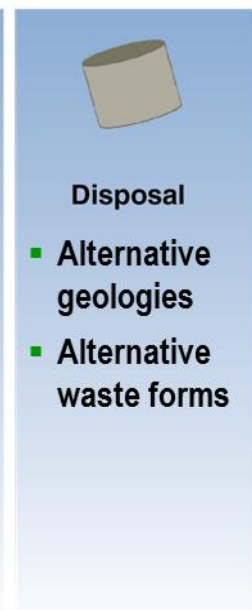

$\leftarrow---------S a f e g u a r d s$ and Security By Design------------ $\rightarrow$

Optimize through Systems Analysis, Engineering, and Integration

Figure 1. The front and back end of the nuclear fuel cycle.

FCT R\&D consists of eight technical campaigns that correspond to the parts of the nuclear fuel cycle that are illustrated above. The rest of this report is organized according to these technical campaigns.

\section{Front End}

1. Fuel Resources works to ensure that economic nuclear fuel resources remain available. The campaign is currently investigating the viability of recovering uranium from seawater. FCT also supports the Department's uranium management policies.

2. Advanced Fuels conducts near-term $R \& D$ of advanced light water reactor (LWR) fuel and longterm R\&D of metallic transmutation fuel. The campaign also develops advanced capabilities to support a science-based approach to fuel development. 


\section{Back End}

3. Nuclear Fuel Storage and Transportation lays the groundwork and develops options for decision makers on the design of an integrated waste management system with special emphasis on a consolidated storage facility and associated transportation activities.

4. Material Recovery and Waste Form Development researches advanced fuel cycle separation and waste management technologies that improve current fuel cycle performance and enables a sustainable fuel cycle with minimal processing, waste generation, and potential for human diversion.

5. Joint Fuel Cycle Studies collaborates with the Republic of Korea to assess the technical and economic feasibility and nonproliferation acceptability of electrochemical recycling for managing used fuel.

6. Used Fuel Disposition R\&D identifies alternatives and conducts scientific research and technology development to enable storage, transportation, and disposal of used fuel and wastes generated by existing and future fuel cycles.

\section{Integrating Campaigns}

7. Materials Protection, Accounting and Control Technologies develops the technologies and analysis tools to support the next generation of nuclear materials management and safeguards for future fuel cycles.

8. Fuel Cycle Options analyzes complex fuel cycle system options, assesses their overall performance under various scenarios, and improves the understanding of the interdependencies between subsystems and their associated technologies. 


\section{FUEL RESOURCES PROGRAM}

Stephen Kung, DOE; Costas Tsouris, ORNL; Gary Gill, PNNL; and Linfeng Rao, LBNL

\subsection{Overview}

\subsubsection{Mission}

The Fuel Resources Program seeks to identify and implement actions to ensure that economic nuclear fuel resources remain available. The program evaluates nuclear fuel resources and develops recovery technologies to enable a sustainable fuel cycle through increasing the fuel resources. Priority attention in the near term focuses on developing the technology for extraction of uranium from seawater.

\subsubsection{Objectives}

- Develop advanced adsorbent materials that can simultaneously enhance uranium sorption capacity, selectivity, kinetics, and materials durability to reduce the technology cost and uncertainties.

- Develop a molecular-level understanding of the coordination modes, sorption mechanisms, and kinetics of uranium extraction.

- Design and synthesize functional ligands for extraction of uranium from seawater with higher capacity, selectivity, and stability.

- Investigate advanced high-surface-area hybrid supports for separation of uranium from seawater that could lead to a major breakthrough.

- Develop marine testing methods to evaluate the extraction efficiency of uranium from seawater from polymeric and high-surface-area hybrid supports.

- Develop sorbents with enhanced durability and recyclability.

- Assess the cost and energy return on investment for extraction of uranium from seawater with polymeric adsorbents.

\subsubsection{Key Fiscal Year 2014 Deliverables}

- Completed new adsorbent materials for marine testing to demonstrate $4.5 \mathrm{~g}-\mathrm{U} / \mathrm{kg}$ adsorbent.

- Completed laboratory evaluation and issued a report on the impact of temperature on uranium sorption.

\subsection{Challenges}

- Low concentration of uranium in seawater environment (3.3 ppb).

- Graft the chelating agents onto polymers or high-surface-area materials and retaining their selectivity, capacity, recyclability, and kinetics for uranium extraction.

- Understand the primary variables that impact the technology cost. 


\subsection{R\&D Strategies}

The R\&D strategy is to take advantage of recent developments in high-performance computing, advanced characterization instruments, and nanoscience and nanomanufacturing technology to enable technical breakthroughs. The technology-driven, science-based R\&D efforts are focused on:

- Simulating and predicting structural and functional relationships using modern computational tools

- Applying advanced characterization tools to understand dynamic chemical processes at the atomic and molecular levels

- Synthesizing novel nanoscale adsorbent materials with architectures and functionality tailored for specific chemical performance.

\subsection{Major Research and Development Activities}

Program Coordination and Integration provides technical coordination and integration support to the campaign, including working group and review meetings, program reporting and international collaborative activities.

- Held two program meetings (one in January and the other in July) to review progress and future plans. All researchers funded under the program gave presentations of their activities.

- Hosted an information exchange meeting with the Japan Atomic Energy Agency (JAEA) researchers to support the DOE Civil Nuclear Energy R\&D Working Group. JAEA visitors toured research and marine testing facilities at Oak Ridge National Laboratory (ORNL) and Pacific Northwest National Laboratory (PNNL).

- Sponsored a meeting with the Chinese Academy of Sciences (CAS) at ORNL in May 2014 to review current program activities from each country. This collaboration supports the DOE-CAS Nuclear Energy Sciences and Technology Cooperative agreement.

- Ligand Design, Thermodynamics, and Kinetics activities seek to increase the uranium adsorbent capacity through the development of novel adsorbents that contain chelating sites with higher uranium binding affinity and selectivity than that exhibited in the current amidoxime-based adsorbents. A combined theoretical and experimental approach has been pursued (1) to better understand how current amidoxime-based adsorbents function; (2) to identify novel chelating agents on the computer using state-of-the-art de novo structure-based design methods; (3) to synthesize, characterize, and evaluate the performance of promising candidates in the laboratory; and (4) to develop synthetic methods to allow chelate attachment to polymeric and high-surfacearea materials. 
- The Ligand Design subtask presented the highest suggested uranyl binding ligand yet using a bisamidoxime ligand with a calculated binding affinity higher than the previously reported bisimidedioximes. Polymers were generated that allow anchoring the ligands onto a polymeric support for marine testing.

- Thermodynamic studies of the interaction between $\mathrm{Ca}(\mathrm{II}) / \mathrm{Mg}$ (II) and the triscarbonato uranyl species have been conducted, and results (Figure 2) indicate that, at the seawater $\mathrm{pH}$ (8.2), the neutral species $\mathrm{Ca}_{2} \mathrm{UO}_{2}\left(\mathrm{CO}_{3}\right)_{3}(\mathrm{aq})$ accounts for $58 \%$ of the total uranium in solution, $\mathrm{CaUO}_{2}\left(\mathrm{CO}_{3}\right)_{3}{ }^{2-}$ and $\mathrm{MgUO}_{2}\left(\mathrm{CO}_{3}\right)_{3}{ }^{2-}$ $18 \%$ each, and $\mathrm{UO}_{2}\left(\mathrm{CO}_{3}\right)_{3}{ }^{4-}$ only $6 \%$. In contrast, more than $97 \%$ of $\mathrm{U}(\mathrm{VI})$ would exist as $\mathrm{UO}_{2}\left(\mathrm{CO}_{3}\right)_{3}{ }^{4-}$ if the formation of $\mathrm{Ca} / \mathrm{Mg}$ complexes with $\mathrm{UO}_{2}\left(\mathrm{CO}_{3}\right)_{3}{ }^{4-}$ was neglected.

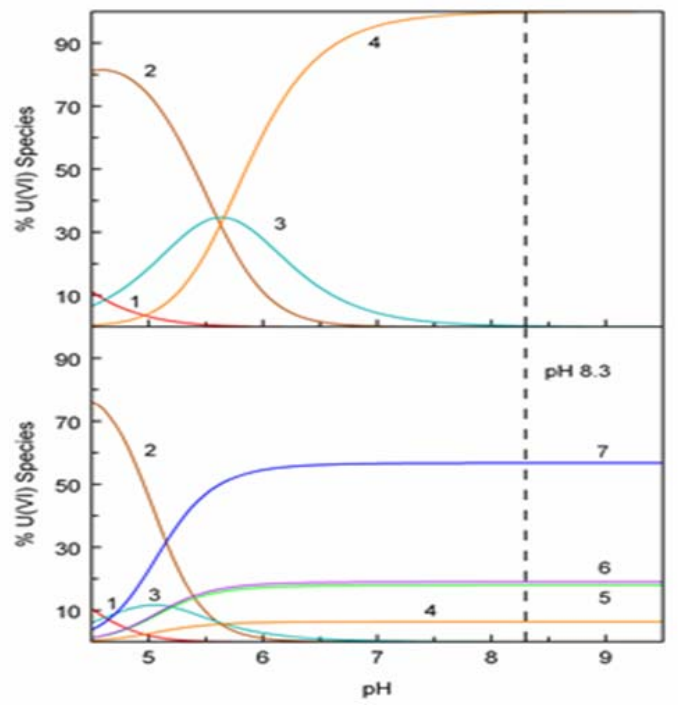

Figure 2. U(VI) speciation in the absence (upper) and presence (lower) of $0.01 \mathrm{M} \mathrm{Ca(II)} \mathrm{and} 0.053 \mathrm{M}$

$\mathrm{Mg}(\mathrm{II}) . C_{\mathrm{U}}=1.4 \times 10^{-8} \mathrm{M}, C_{\text {carbonate }}=0.0023 \mathrm{M}$. $1-\mathrm{UO}_{2}{ }^{2+}, 2-\mathrm{UO}_{2}\left(\mathrm{CO}_{3}\right)(\mathrm{aq})$,

3 - $\mathrm{UO}_{2}\left(\mathrm{CO}_{3}\right)_{2}{ }^{2-}, 4-\mathrm{UO}_{2}\left(\mathrm{CO}_{3}\right)_{3}{ }^{4-}$,

$5-\mathrm{CaUO}_{2}\left(\mathrm{CO}_{3}\right)_{3}{ }^{2-}, 6-\mathrm{MgUO}_{2}\left(\mathrm{CO}_{3}\right)_{3}{ }^{2-}$,

$7-\mathrm{Ca}_{2} \mathrm{UO}_{2}\left(\mathrm{CO}_{3}\right)_{3}(\mathrm{aq})$.

Advanced Adsorbent Development by Radiation Induced Graft Polymerization (RIGP) and Atom-

Transfer Radical Polymerization (ATRP) focus on increasing the adsorption capacity by increasing the surface area of the fiber adsorbents and optimizing the polymerization conditions and degree of grafting. Work on the RIGP method builds on the studies of the JAEA, which focuses on preparing amidoximebased polymers by RIGP of acrylonitrile with hydrophilic monomers on various trunk polymers. In our work, much of the effort focuses on increasing the capacity by optimizing the large number of experimental variables in the RIGP, including the electron beam irradiation conditions, the graft polymerization conditions and the choice of monomers, the amidoximation conditions, and the alkaline conditioning of the grafted fibers. ATRP focuses on generating polymeric fiber adsorbents via a chemical-grafting approach. The use of ATRP offers several tunabilities, including controllable composition and degree of polymerization (length of graft chains), which can be either increased to a much higher degree of grafting or controlled to the exact degree of grafting for the best performance. The resulting adsorbents by both methods are tested for their capacity to bind uranium from seawater in marine tests at Marine Sciences Laboratory of the Pacific Northwest National Laboratory (MSL/PNNL).

A wide range of braided and textile-based fabric candidates were

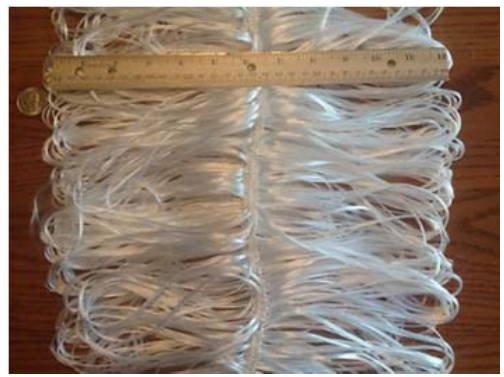
manufactured, and promising fabric candidates were selected for Figure 3. Representative textile-based fabric. amidoximation, potassium-hydroxide conditioning, and laboratory screening studies prior to sending samples to PNNL for seawater studies (see example in Figure 3). 
Braided adsorbents have been manufactured and uranium adsorption capacities ranging from 3.0 to $3.6 \mathrm{~g}$ $\mathrm{U} / \mathrm{kg}$-adsorbent have been successfully demonstrated in marine testing at PNNL.

New families of polyethylene-based fiber adsorbents have been developed. Uranium capacities greater than $4.5 \mathrm{~g}-\mathrm{U} / \mathrm{kg}$ adsorbent have been demonstrated after marine testing at PNNL.

The ATRP method has been introduced to prepare tunable polymeric fiber adsorbents of adjustable grafting density and chain length (Figure 4a). Direct ATRP successfully achieved high capacity at $5.4 \mathrm{~g}-\mathrm{U} / \mathrm{kg}$ ads (Figure $4 \mathrm{~b}$ ) and fast kinetics in seawater tests.

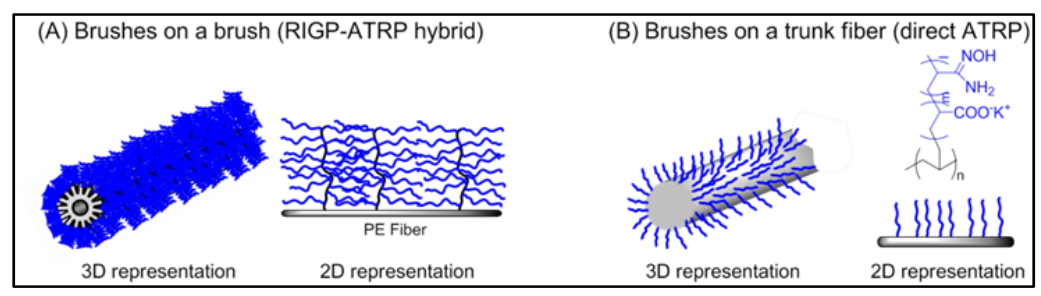

Figure 4. RIGP-ATRP hybrid method (A), direct ATRP method (B).

Advanced Nanomaterials Synthesis activities seek to take advantage of the high surface areas of nanoporous materials $\left(>1000 \mathrm{~m}^{2} / \mathrm{g}\right)$ to generate a new class of high-capacity adsorbents that can be functionalized with ligands to selectively bind uranium. This approach toward a nanostructured alternative to polyethylene fibers focuses on two classes of material: (1) carbon-based nanostructures and (2) polymeric nanostructures. A key focus and challenge in this work is to increase the grafting yields.

A mesoporous ATRP initiator was generated for the first time and utilized as a polyacrylonitrile (PAN) support to extract uranium from seawater. Batch seawater testing suggested fast kinetics and moderately high capacity.

Marine Testing and Materials Durability activities address issues associated with the deployment of uranium adsorbent materials in the marine environment. To achieve this goal, the work focuses on two main tasks: (1) a marine testing program to characterize the adsorbent capacity and adsorption rate with natural seawater and (2) a research effort to assess the durability of adsorbent materials in marine conditions, in particular adsorbent reuse, toxicity, and biological fouling.

- Adsorbent Capacity and Adsorption Rate: A new formulation of the amidoxime-based adsorbent produced by ORNL referred to as AF1, has been characterized using both column and flume exposure methods. The two different exposure methods yielded very similar results for adsorption capacity. The ORNL AF1 adsorbent has a 17\% higher adsorbent capacity at 56 days of exposure than the previous ORNL 38H adsorbent investigated last year (Figure 5 and Figure 6). 

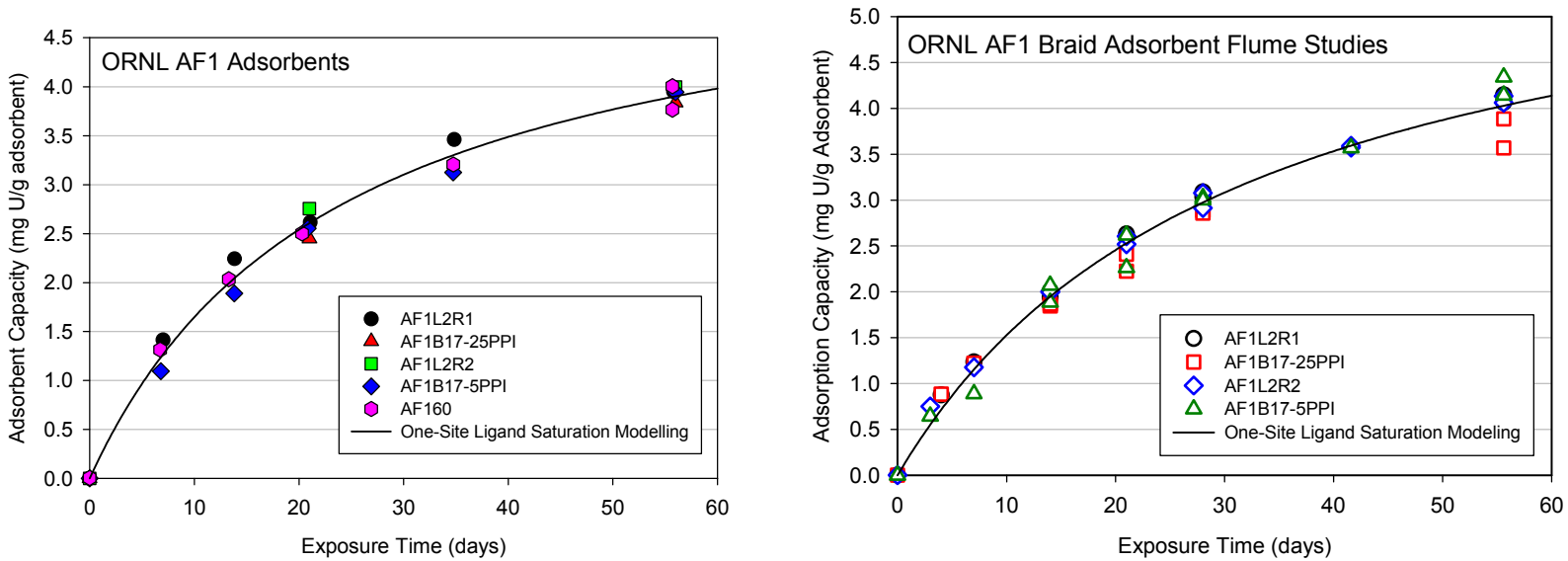

Figure 5. Time-series measurements of uranium adsorption capacity determined using column (left panel) and flume exposure (right panel) studies for different formulations of the amidoxime-based adsorbent AF1 produced by ORNL. Data have been normalized to a salinity of 35 psu.

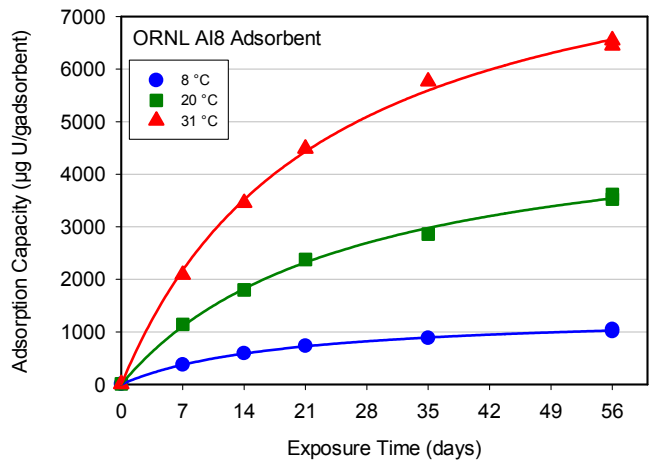

Figure 6. Time series measurements of adsorbent capacity for three temperatures with the ORNL adsorbent AI8. Lines drawn through the data points were generated with a one-site ligand saturation model. Data were normalized to a salinity of 35 psu.

- Temperature Dependence: Time-series experiments were conducted with three separate formulations of the ORNL amidoxime-based polymeric adsorbent $(38 \mathrm{H}, \mathrm{AF} 1$ and AI8) to assess the impact of temperature on adsorption capacity. All three adsorbents showed higher adsorption capacities as a function of temperature (Figure 7).
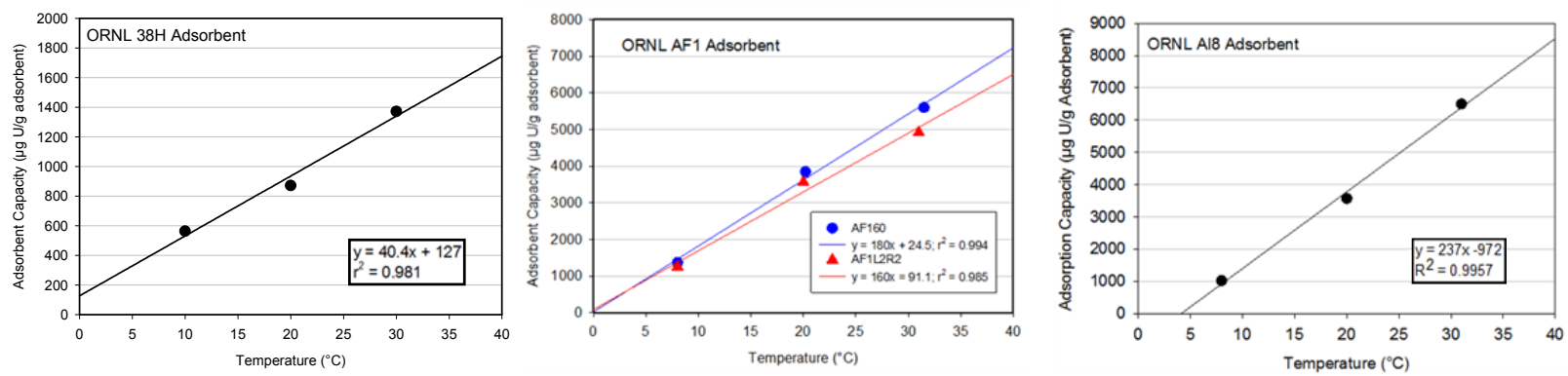

Figure 7. Temperature dependence on adsorption capacity for the ORNL adsorbents 38H (left panel), AF1 (middle panel) and AI8 (right panel). Data were normalized to a salinity of 35 psu. 
Modeling and Cost Analysis focuses on (1) mechanistic modeling of the micro-scale processes that control uranium uptake, (2) macroscopic hydrodynamic modeling and marine deployment assessment, and (3) cost and energy return on investment for the major steps in the adsorbent fabrication and grafting, mooring at sea and recovery, and elution and purification of the braided polymeric adsorbent.

- Uranium Adsorption Modeling: A kinetic model determined the rate limiting mechanism of uranium uptake. Results have shown that, in the presence of a flow velocity higher than $2 \mathrm{~cm} / \mathrm{s}$, uranium uptake is reaction limited due to the competition of amidoxime with bicarbonate ions.

- Marine Deployment Assessment: An assessment of the impact of the deployment of a braided adsorbent farm on current flow in the coastal ocean suggested that the impact was minor, less than a $10 \%$ reduction in current flow would result at the braid density used in the literature.

- Cost Analysis: Marine-test data from PNNL, including the capacity-to-temperature dependence, were incorporated into the models used in cost analysis. Using the ORNL AF1 adsorbent, the 60day uranium uptake in $20^{\circ} \mathrm{C}$ water is close to $4 \mathrm{~g} \mathrm{U} / \mathrm{kg}$ adsorbent (Figure 8). Given six uses of the adsorbent with a $5 \%$ loss in capacity upon each reuse, the uranium production cost is slightly above $\$ 600 / \mathrm{kg}$ U. The cost declines for uranium adsorption in $30^{\circ} \mathrm{C}$ water, where the capacity is approaching $6 \mathrm{~g} \mathrm{U} / \mathrm{kg}$ adsorbent after 60 days, and decreases further if the adsorbent is reused up to 14 times.

- Cost of Uranium Produced by Novel Adsorbents: A preliminary assessment of the uranium production cost associated with two novel adsorbents developed at ORNL based on the ATRP method yielded uranium production costs in the range of $\$ 500-600 / \mathrm{kg} \mathrm{U}$ for the first adsorbent and over $\$ 1,000 / \mathrm{kg} \mathrm{U}$ for the second adsorbent.

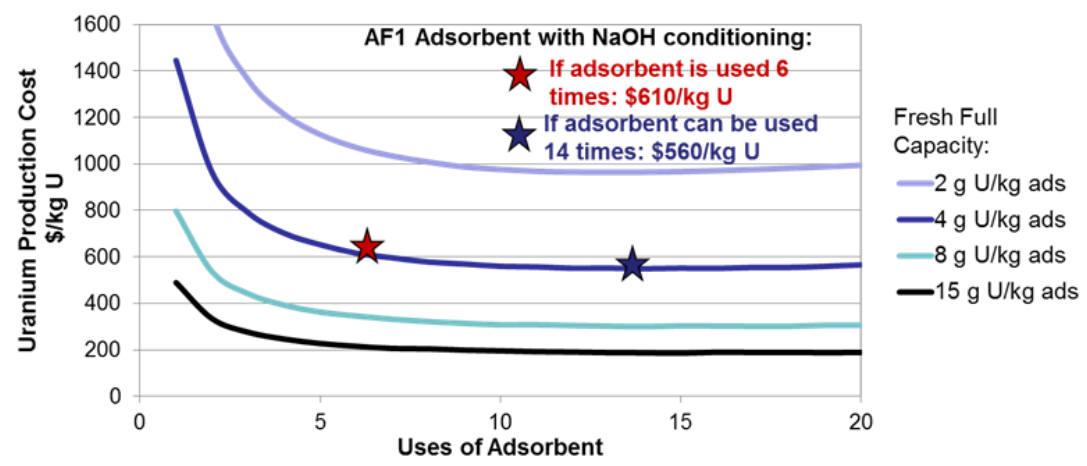

Figure 8. Uranium production cost scenarios for ORNL AF1 adsorbent with capacity at $20^{\circ} \mathrm{C}$ as predicted by PNNL measurements and one-site ligand saturation model. 


\section{ADVANCED FUELS CAMPAIGN}

\subsection{Overview}

\section{J. Carmack, Shannon Bragg-Sitton, and Lori Braase, Idaho National Laboratory}

\subsubsection{Campaign Mission}

The mission of the Advanced Fuels Campaign (AFC) is to perform research, development, and demonstration (RD\&D) activities for advanced fuel forms (including cladding) to enhance the performance and safety of the nation's current and future reactors; enhance proliferation resistance of nuclear fuel; effectively utilize nuclear energy resources; and address the longer-term waste management challenges associated with used nuclear fuels. This includes development of a state-of-the art RD\&D infrastructure to support the development of advanced fuel systems using a "goal-oriented science-based approach."

\subsubsection{Campaign Objectives}

The AFC has been given the specific responsibility to develop advanced nuclear fuel technologies for the Fuel Cycle R\&D program. The current focus is on the following:

- Advanced Light Water Reactor (LWR) Fuels with enhanced accident tolerance, improved performance, and reduced waste.

- Transmutation Fuels for transmutation with enhanced proliferation resistance and resource utilization.

- Capability Development such as separate effects testing for modeling and simulation data generation, advanced in-pile instrumentation, characterization, and postirradiation examination (PIE) techniques.

- Advanced Fuel Performance Modeling and Simulation is a primary need for development of advanced fuel systems. The AFC maintains a close connection with the development of a multiscale, multi-physics fuel performance code infrastructure under the Nuclear Energy Advanced Modeling and Simulation (NEAMS) program.

\subsubsection{Key Fiscal Year 2014 Deliverables}

The Accident Tolerant LWR Fuel (ATF) research effort made significant progress in FY 2014 through completion of Phase 1A activities by the three industry-led Funding Opportunity Announcement (FOA) awards and initiation of Phase 1B for two additional years of activity. These projects are integrated into the DOE laboratory funded research, development, and infrastructure activities in AFC with the university NEUPs and university-led IRPs. In addition, ATF fabrication support resources were established and demonstrated at Oak Ridge National Laboratory (ORNL), Idaho National Laboratory (INL), and Los Alamos National Laboratory (LANL). Research quantities of ATF compositions were fabricated, demonstrating the capability to support industry FOA fuel fabrication needs as well as the capability to fabricate novel ATF fuel compositions. Design of the initial irradiation of ATF concepts, designated as the ATF-1 test series, was completed. The ATF-1 experiment will be inserted in ATR in FY 2015. The experiment includes fuel concepts from Westinghouse, AREVA, General Electric, and from the national laboratories. Irradiation will continue over the next two years. 
The Transmutation Fuels area achieved a major goal in FY 2014 with the successful return of the FUTURIX-FTA experiment from the French CEA Phenix reactor. The FUTURIX-FTA fuel experiment contains four pins of transmutation fuel, two pins of metallic fuel, and two pins of nitride fuel. The results of PIE will allow direct comparison of similar data obtained through fuel testing in the ATR. In addition, revision 6 of the AFCI Materials Handbook was issued.

\subsection{Advanced LWR Fuel Systems Development}

Researchers across AFC have been investigating a number of potential fuels and cladding technologies to improve fuel system performance in both normal and accident conditions. Significant progress has been made on establishing oxidation, corrosion, and materials property characterization capabilities and techniques that can be used to assess the performance of potential advanced LWR fuel technologies. In addition, AFC has been preparing for the first irradiation of ATF technologies in ATR in FY 2015.

As-built projected temperature calculations were performed on the ATF capsules using the BISON fuel performance code. BISON is an application of INL's Multiphysics Object-Oriented Simulation Environment (MOOSE), which is a massively parallel finite element-based framework used to solve systems of fully-coupled nonlinear partial differential equations. Both 2D and 3D models were set up to examine cladding and fuel performance. As-built axial and radial dimensions were measured on each rodlet tube using a Coordinate Measurement Machine (CMM). The CMM data were directly imported into the BISON model and 3D temperature profiles were calculated. Figure 9 shows the preliminary BISON results for one of the ATF-1 concepts. The as-built 3D temperature profiles can then be used to determine if the rodlet clad temperatures (axial and azimuthal) are within the desired test range for the ATF concept design.

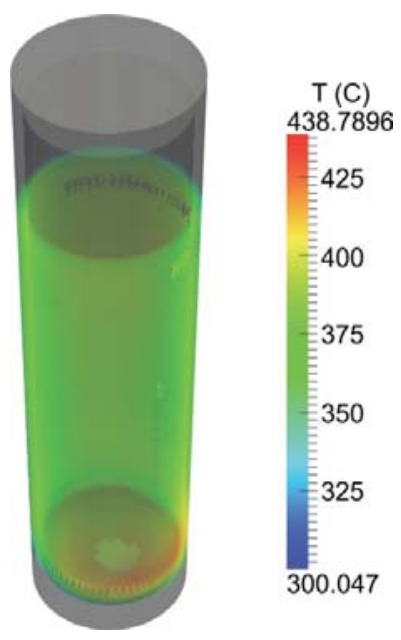

Figure 9. Volumetric view of temperature distribution in ATF-1 experiment hardware with a threshold of 300 - $450 \mathrm{C}$.

\subsubsection{Industry ATF Concepts}

Industry-led R\&D activities are supported by awards made in 2012 under a DOE Funding Opportunity Announcement. In FY 2014, each research team provided either fuel or cladding samples for irradiation in INL's ATR, completing the FOA Phase 1A scope. Rodlets and capsules were completed and assembled in late summer 2014 for irradiation in 2015. This irradiation test series is referred to as “ATF-1." In September 2014 all three FOA's were selected to continue development of their concepts in 
Phase 1B, allowing for additional development and testing prior to the planned downselection/prioritization of ATF concepts in late 2016.

\section{AREVA}

The AREVA R\&D team is designing both fuel and cladding concepts for enhanced performance and accident tolerance. AREVA ATF-1 rodlets include modified $\mathrm{UO}_{2}$ fuel fabricated at the University of Florida via Spark Plasma Sintering (SPS) techniques. Fuel is encased standard Zr-alloy cladding for the initial ATR drop-in test. Figure 10 shows an AREVA fuel pellet and digital radiography of welded capsule assemblies.
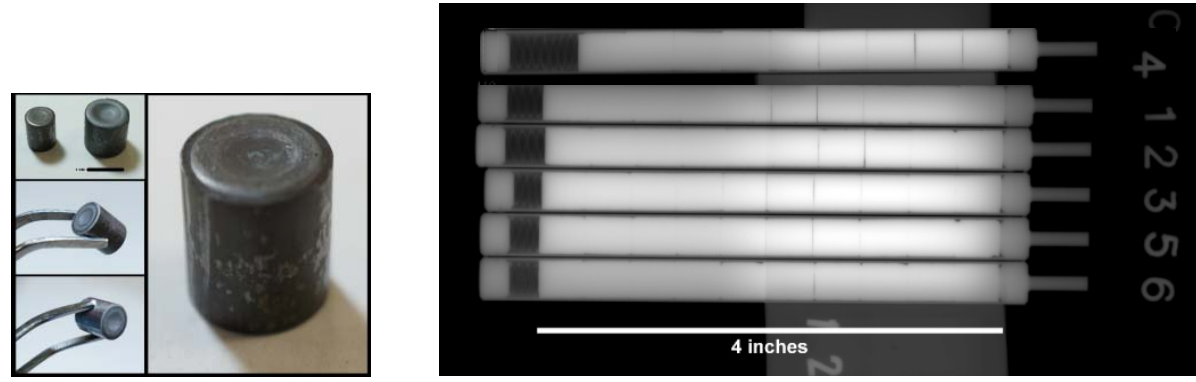

Figure 10. An AREVA fuel pellet and digital radiography of welded capsule assemblies.

\section{General Electric Global Research}

The GE Global Research and Global Nuclear Fuels team includes the University of Michigan and LANL. The GE team is investigating the replacement of Zr-alloy cladding with advanced steels, such as FeCrAl alloys (APMT), which offer a number of benefits in beyond design-basis accident conditions. Improved properties under normal conditions may provide sufficient benefit to mitigate the increased neutron absorption characteristics of these materials. Figure 11 shows the digital radiography of GE capsule assemblies and a fuel pellet.
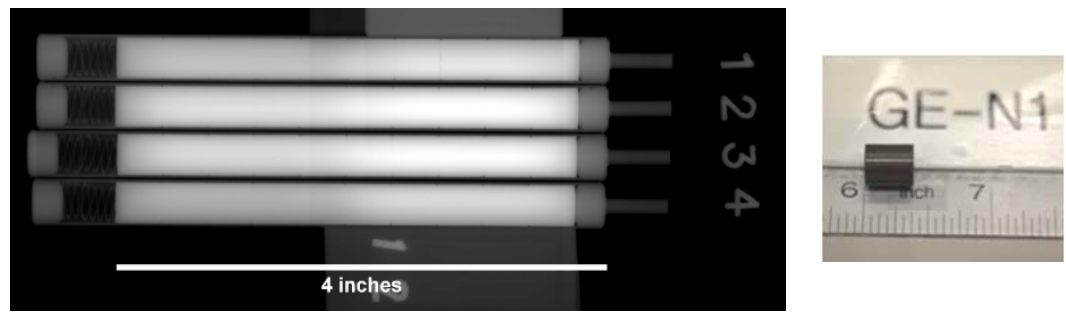

Figure 11. Digital radiography of GE capsule assemblies and a fuel pellet.

\section{Westinghouse}

The Westinghouse Electric Company LLC consortium includes General Atomics (GA), Edison Welding Institute (EWI), the University of Wisconsin (UW), LANL, INL, Texas A\&M University (TAMU), the Massachusetts Institute of Technology (MIT) and Southern Nuclear Operating Company (SNOC). Fuel development is conducted by INL for $\mathrm{U}_{3} \mathrm{Si}_{2}$, LANL for UN, and TAMU for waterproofed UN (using $\mathrm{U}_{3} \mathrm{Si}_{2}$ additives). Figure 12 show the digital radiography of Westinghouse capsule assemblies and a fuel pellet. 

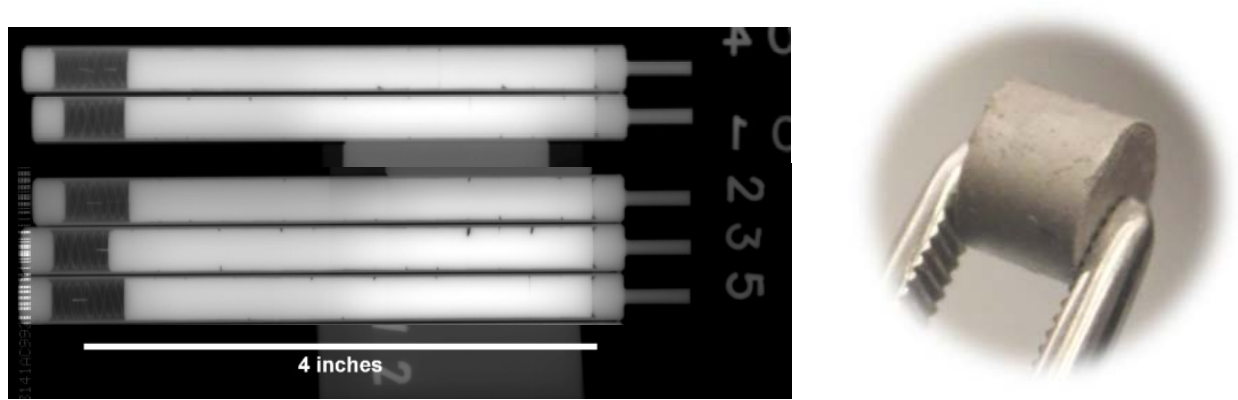

Figure 12. Digital radiography of Westinghouse capsule assemblies and a fuel pellet.

\subsubsection{Engineering ATF FeCrAl Clad: Processing and Environmental Effects}

\section{K. A. Terrani, L. L. Snead, Y. Yamamoto, B. A. Pint, K. G. Field, Oak Ridge National Laboratory}

FeCrAl classes of alloys are promising candidates as near-term ATF cladding materials for LWR fuel assemblies. The body-centered cubic (bcc) structure of these alloys, stabilized up to the melting point due to presence of Al, offers superior corrosion behavior under normal operating conditions compared with historical austenitic stainless steel used as fuel cladding. The combination of $\mathrm{Al}$ and $\mathrm{Cr}$ are a critical composition and offer exceptional oxidation resistance in the high-temperature steam environments all the way to the onset of melt. This significant reduction in oxidation rate compared with $\mathrm{Zr}$ alloys, roughly three orders of magnitude, reduces the heat and hydrogen production during severe accidents, thus providing larger safety margins for LWR cores experiencing beyond design basis accidents. Prospective iron, chromium, aluminum (FeCrAl) alloy cladding was successfully fabricated into a ATF-1 test at the ORNL. Figure 13 shows a radiograph of the ORNL FeCrAl clad fuel rodlets.

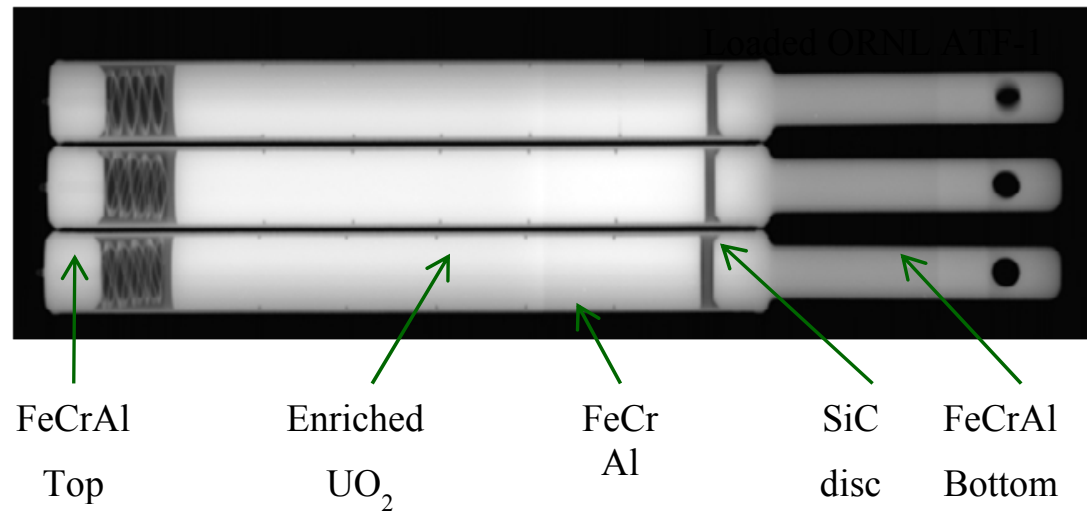

Figure 13. Radiograph of ORNL ATF-1 rodlets after completion of fabrication prior to delivery. Length of rodlet in image is 4.5 inches, nominal. 


\subsubsection{Oxidation Testing (LANL)}

Oxidation testing was conducted on U-Si compounds in air and steam environments to simulate performance under ambient storage and loss of coolant accident (LOCA) conditions, respectively. U-Si compounds, $\mathrm{UO}_{2}$, and $\mathrm{UN}$ that are exposed to air at elevated temperature degrade to a black powder. This effect is not observed until above $250^{\circ} \mathrm{C}$, which is above the temperature where UN degrades. Macroscopic photographs of $\mathrm{U}_{3} \mathrm{Si}_{2}$ and $\mathrm{U}_{3} \mathrm{Si}_{5}$ compared to $\mathrm{UO}_{2}$ after isothermal holds under $75 \%-\mathrm{H}_{2} \mathrm{O} / \mathrm{Ar}$ atmospheres are shown in Figure 14. $\mathrm{U}_{3} \mathrm{Si}_{2}$ fragmented under all test conditions, while $\mathrm{U}_{3} \mathrm{Si}_{5}$ exhibited some evidence of mechanical integrity. $\mathrm{UO}_{2}$ pellets gained mass under the test conditions, but did not degrade after exposure to steam.

\subsection{Transmutation Fuels Technologies}

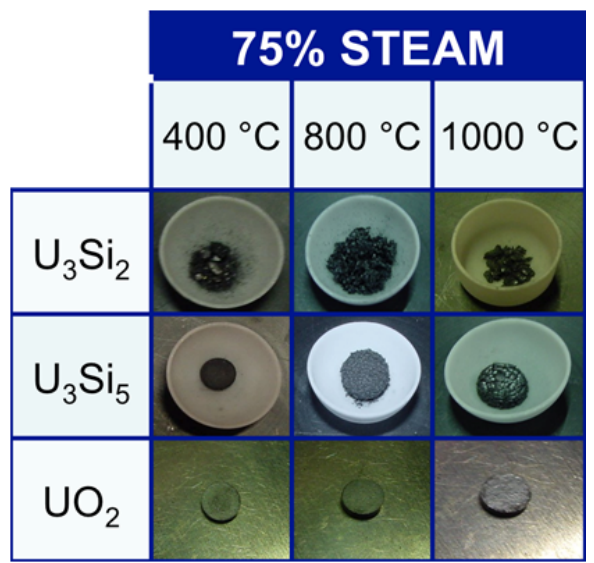

Figure 14. Macroscopic photographs of specimens after exposure to steam at a variety of temperatures

The Transmutation Fuels Technologies program focuses on R\&D to gain a fundamental understanding of metallic transmutation fuels. Priority was on low-loss fabrication methods and capability and on developing a fundamental understanding of the phase, microstructure, and chemical migration behavior of metallic fuel constituents. The desired outcome is to develop an understanding of the key phenomena affecting metallic fuel performance and behavior under irradiation.

\subsubsection{Neptunium Reduction Experiments and Feedstock Purification}

\section{Squires, Idaho National Laboratory}

Neptunium metal is an important constituent of transmutation fuel. Current supplies of pure neptunium metal for fuel fabrication needs are dwindling and it is therefore necessary to develop a technique to supply the metal. A process is under development to directly reduce the oxide to metal using a chemical reduction technique. Below are pictures (Figure 15) showing the furnace set up and the process products including Np metal button.
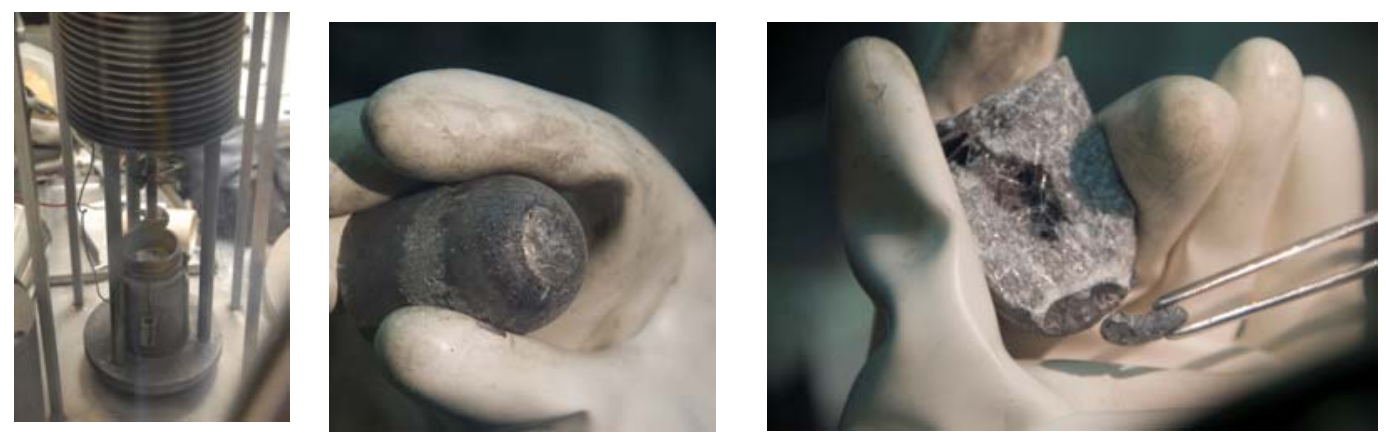

Figure 15. Left: Hot Uniaxial Press insert loaded with reaction crucible and reagents. Middle: Close up of magnesium oxide crucible nested in a stainless steel crucible nested in the furnace insert. Right: Removal of neptunium metal button. 


\subsubsection{AmBB Accomplishments FY 2014}

\section{P. Lessing, Idaho National Laboratory}

Experiments were conducted during FY 2014 to produce good-purity Americium metal for use in tests within the transmutation fuel program. During FY 2014, americium was purified using impure metal obtained from LLNL. The LLNL material contains $5 \% \mathrm{~Np}, \mathrm{O}$, and $5 \% \mathrm{~Pb}$ as major impurities. During distillation in a tantalum tube, Am metal is deposited. All the $\mathrm{Np}$ is left in bottom of tube; using short time/low temperature runs, the $\mathrm{Pb}$ was shown to segregate into outer regions of the solid distillate. The oxide is removed by the reaction $2 \mathrm{La}+3 / 2 \mathrm{O}_{2} \rightarrow \mathrm{La}_{2} \mathrm{O}_{3}$ (left in bottom). Several grams of purified Am were produced.

\subsubsection{Minor Actinide Bearing Metallic Fuel Fabrication}

\section{R. Fielding, Idaho National Laboratory}

The glovebox advanced casting system (GACS) was installed and operated in a minor actinide qualified glovebox. This furnace was designed to provide a flexible casting development platform where both gravity casting into a permanent mold and counter gravity casting into a glass mold could be developed and studied. In addition to casting development the GACS will also be used to study melt properties, americium volatility studies, and general sample fabrication. The furnace was designed to be a flexible platform in which a number of experiments, alloys, and configurations can be run. The modular design of the furnace makes it possible to change out components, such as coils, crucibles, and molds to accommodate a variety of sizes or techniques as required.

The solid model of the GACS as it is currently configured for gravity casting and the installed furnace is shown in Figure 16.

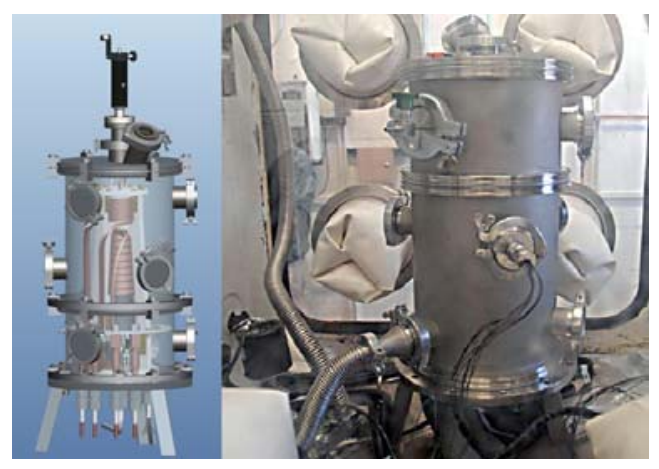

Figure 16. Schematic and photo of the GACS configured for gravity casting. Note- the linear actuator has been removed for the photo.

Minor actinide casting in FY 2014 consisted of two main experiments: first, chemical analysis of previously cast rods to verify axial homogeneity and americium retention; and second, a set of experiments to verify americium retention under casting conditions. Based on the results, americium can be maintained during the casting process if casting is not done under a vacuum environment.

Early in the fiscal year, additional fuel tests were made to supplement the AFC-4A irradiation test. The fuel slugs were cast, machined to final diameter and encapsulated in the standard AFC-OA irradiation hardware. Example metallic fuel cast slugs are shown in Figure 17. 

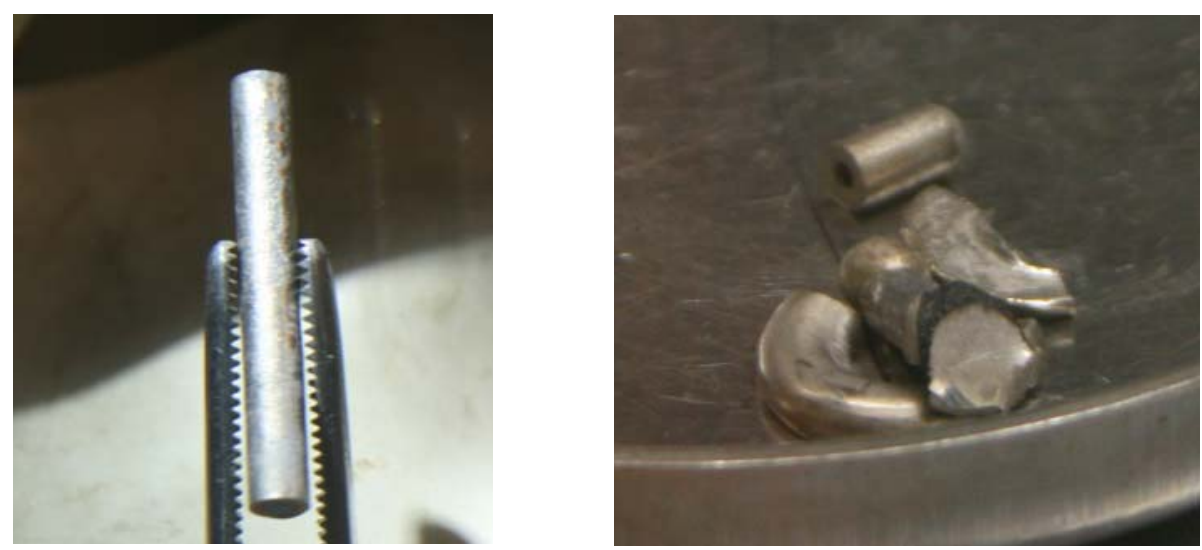

Figure 17. Legacy AFC-1 material: (left) Archive slug which can be used as-is for further characterization and (right) remaining casting heel pieces which can be re-cast into a usable sample.

\subsubsection{Fast Reactor Cladding Development}

\section{S. Maloy, Los Alamos National Laboratory}

Research performed on high-dose irradiated HT-9 was summarized in a new revision of Ch. 18 of the Materials Handbook (Rev. 6). Data included mechanical properties measured on the ACO3 duct after irradiation to $155 \mathrm{dpa}$, which included tensile properties, fracture toughness, and ductile-to-brittle transition temperature. In addition, revised sections were provided on irradiation creep and void swelling. Authors include O. Anderoglu, M. Serrano de Caro, T. Saleh, LANL; M. Toloczko, PNNL; F. Garner, Radiation Effects Consulting; and T.S. Byun, PNNL (formerly at ORNL).

Research was started this fiscal year on developing fabrication methods for ultimately producing thinwall clad tubing from the advanced oxide dispersion strengthened (ODS) ferritic alloys. For the conventional fabrication method involving drawing, swaging, and pilgering, three thick wall tubes were first produced by extruding ball milled powder of ODS 14YWT (14Cr) and ODS 9YWTV (9Cr) over a steel mandrel at $850^{\circ} \mathrm{C}$ at ORNL (see Figure 18). After removing the mandrel and steel can from the enclosed ODS tubes, a tube section of 14YWT and 9YWTV were shipped to PNNL for developing the fabrication

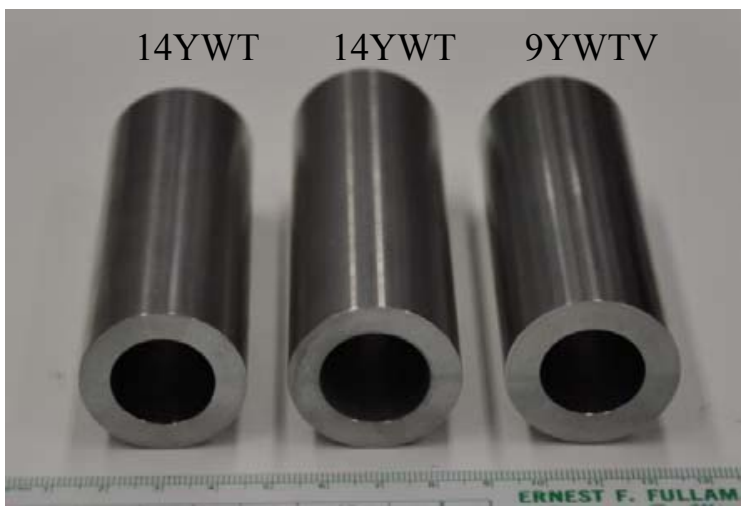

Figure 18. Extruded, thick wall tubes of 14YWT and 9YWTV.

method using swaging and pilgering to reduce the wall thickness and diameter. In another method, the feasibility of solid-state cold spray deposition of ball milled and annealed 14YWT powder is being evaluated for producing thin-wall tubes by the additive manufacturing approach. 


\subsubsection{Irradiation Testing and PIE}

\section{H. MacLean Chichester, Idaho National Laboratory}

Ten years after signing the Implementing Arrangement between DOE and France's CEA to jointly conduct the FUTURIX irradiation experiments in the PHENIX reactor in France, the four pins in the FUTURIX-FTA fuel experiment returned to the U.S. The shipment arrived in South Carolina on July 22 and was received at INL on July 24, 2014 (See Figure 19).

Postirradiation examination of this experiment will begin in FY 2015. Identical fuels were irradiated in ATR in the AFC-1 test series. Results of the AFC-1 and FUTURIX-FTA experiments will be used to evaluate and identify any differences caused by the difference in neutron spectra between PHENIX (a typical fast reactor) and ATR (using a cadmium-lined basket to simulate fast reactor neutron spectrum in a thermal reactor).

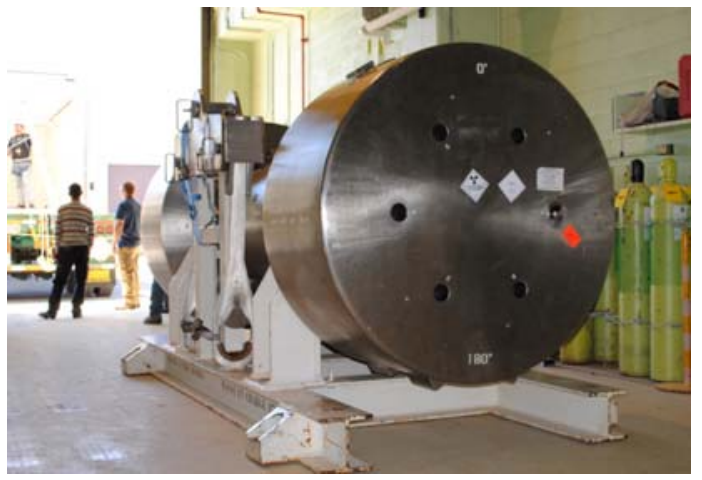

Figure 19. TN-106 cask containing the FUTURIX-FTA experiment in the HFEF Truck Lock

\subsection{Capability Development}

A basic philosophy of AFC is the development and utilization of advanced scientific methods for the research and development of advanced, novel, high performance nuclear fuel systems. The Crosscutting Technologies area is focused on this guiding principal. Performing research on irradiated and highly radioactive fuel materials is difficult, time intensive, and technically challenging. Couple this with the desire to study the microstructural evolution of fuels and materials under irradiation provides the opportunity for the development of advances in nuclear fuels and materials R\&D science. The activities in this technical area are examples of the innovative and creative science and engineering accomplished by the technical scientific and engineering staff.

\subsubsection{Developing Ultra-Small Scale Mechanical Testing Methods and Microstructural Investigation Procedures for Irradiated Materials}

P. Hosemann, A. Minor, D. Chrzan, University of California at Berkeley; D. Kaoumi, University of South

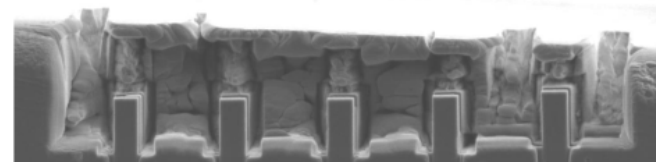
Carolina; Y. Wang, Los Alamos National Laboratory

The development of small-scale mechanical testing in combination with microstructural investigation is of great interest to the nuclear materials community. Reducing the sample size reduces the amount of radioactive material, therefore creating the ability to gain mechanical properties on ion beam irradiated samples. Moreover, such studies promise a range of benefits including cost reduction, fundamental insight in structure-property relationships, increased statistics on less sample material, and reinvestigation of prior irradiated and tested reactor

Figure 20. Micro compression testing on irradiated samples. Small-scale materials testing on sub-sized 
samples has been available for over two decades; however, the introduction of micro-compression testing in 2001, based on focused ion beam sample manufacturing, allowed testing on "orders of magnitude" smaller samples of irradiated materials (Figure 20). New methods are being developed to evaluate irradiated materials, such as micro-mechanical testing in extreme environments. The goal is to find a parameter reflecting ductile-to-brittle transition temperature (DBTT) on a micro scale.

\subsubsection{Development of the Thermal Conductivity Microscope}

\section{Hurley, Idaho National Laboratory}

The Thermal Conductivity Microscope (TCM) is designed to operate in a radiation hot cell environment via remote control manipulation. The TCM provides micron-level thermal property information that is commensurate with microstructure heterogeneity (Figure 21). The development of the TCM connects closely with INL's larger PIE effort to provide new validation metrics for fundamental computational material science models.

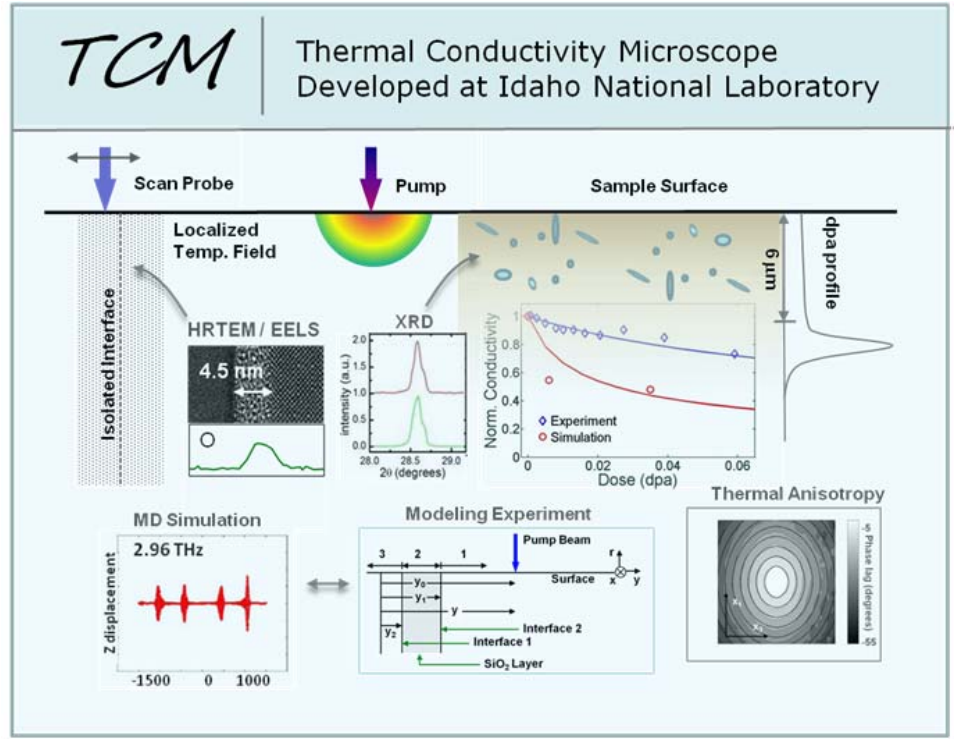

Figure 21. TCM measures local changes in thermal conductivity. The left side illustrates measurement of the Kapitza resistance of an individual, highly characterized interface. The right side demonstrates the use of the TCM to measure the conductivity of a thin surface layer damaged by energetic ions.

\subsubsection{Thermophysical Properties Testing in the Fresh Fuels Glovebox}

\section{Papesch, Idaho National Laboratory}

The fresh fuels glovebox located at MFC in the Analytical Laboratory was installed this year (Figure 22). This glovebox is an inert atmosphere box containing a variety of characterization instruments that will be used to support transuranic fuel and materials characterization for AFC irradiation testing and ATF fabrication and testing. 


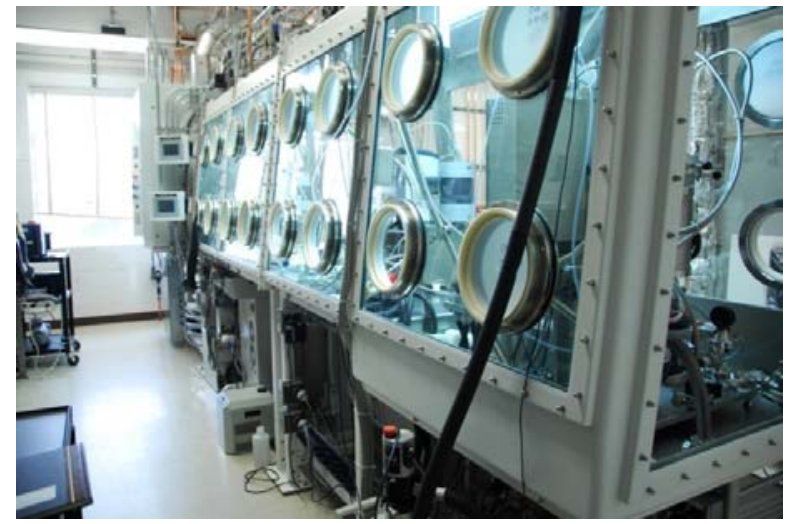

(a)

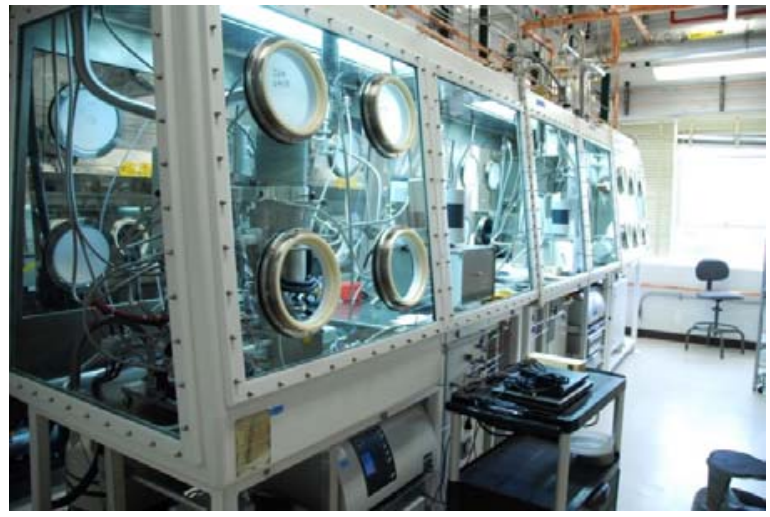

(b)

Figure 22. Fresh Fuels Glovebox in MFC's Analytical Lab: (a) West side view; (b) East side view.

\subsubsection{TREAT Transient Testing Preparation}

\section{Wachs, Idaho National Laboratory}

A transient testing research program is being developed to support assessment of ATF designs being proposed for LWR applications. Accident tolerant fuels are defined as fuel systems that, when compared to existing Zircaloy clad $\mathrm{UO}_{2}$ designs, can tolerate loss of active cooling while maintaining or improving the fuel performance during normal operations, operational transients, design-basis events, and beyond design-basis events. ATF concept evaluation must be completed in time to support insertion of an ATF lead rod assembly into a commercial power reactor by 2022 . To enable this goal, transient testing of ATF fuels under both overpower (e.g. Reactivity Initiated Accident (RIA) simulation) and undercooling (e.g. Loss of Coolant Accident (LOCA simulation) conditions must begin shortly. This series of ATF transient tests have been termed ATF-3.

In parallel to the effort to resume operations at TREAT, the transient testing strategy to support ATF concept screening, development, and qualification is being developed. A proposal for the first set of transient experiments has been prepared for discussion with the ATF concept design leads. These tests emphasize assessment of the relative performance of the fuel designs under various enthalpy additions anticipated under pulse and ramp conditions.
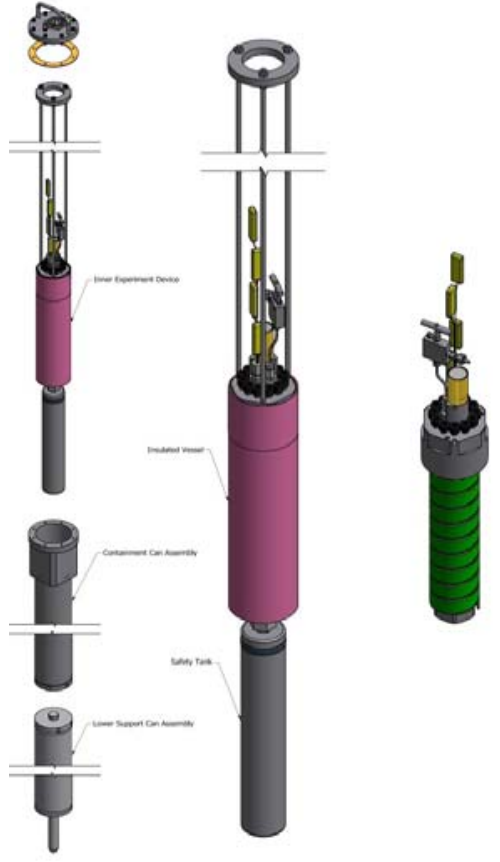

Figure 23. TREAT test loop for ATF fuel testing. 


\section{NUCLEAR FUELS STORAGE AND TRANSPORTATION PROGRAM}

\subsection{Overview}

In 2010, the Secretary of Energy chartered the Blue Ribbon Commission (BRC) on America's Nuclear Future to conduct a comprehensive review and recommend a plan of action for the management and disposal of the nation's used nuclear fuel (UNF) and high-level waste (HLW). In January of 2012, the BRC issued a report to the Secretary of Energy, which included a number of recommendations. In January of 2013, the Administration released its Strategy for the Management and Disposal of Used Nuclear Fuel and High-Level Radioactive Waste (Strategy), which serves as a statement of Administration policy regarding the importance of addressing the disposition of UNF and HLW; lays out the overall design of a system to address the issue; outlines the reforms needed to implement such a system; and represents the Administration's response to the BRC recommendations.

In coordination with the development of the Administration's Strategy, DOE established the Nuclear Fuels Storage and Transportation (NFST) Program on October 1, 2012. The mission of the NFST is to lay the groundwork for implementing interim storage, including associated transportation, per the Administration's Strategy, and to develop a foundation for a new nuclear waste management organization. The purpose of the NFST is to make progress on this important national issue, within existing legislative and budgetary authorizations, while the Administration and Congress work together on legislative changes to the nuclear waste management program. An over-arching goal is to develop options for decision-makers on the design of an integrated waste management system.

The objective of the NFST is to develop and begin implementation of an integrated plan to (1) implement interim storage; (2) improve the overall integration of storage as a planned part of the waste management system; (3) prepare for the large-scale transportation of spent nuclear fuel (SNF) and high-level radioactive waste (HLW), with an initial focus on removing used nuclear fuel (UNF) from the shutdown reactor sites; and (4) develop foundational information, resources, and capabilities needed to support the aforementioned objectives and future implementation of decisions and actions. An over-arching goal is to develop options for decision-makers on the design of an integrated waste management system.

\subsubsection{Near-Term Objectives}

- Develop and maintain an integrated plan to accomplish the Strategy goals;

- Improve integration of storage as a planned part of the waste management system, including evaluating standardization of dry cask storage systems;

- Develop and evaluate design options for an integrated waste management system;

- Develop and apply systems analyses to provide quantitative estimates of system impacts of utility actions and inform future decisions;

- Prepare for the large-scale transportation of UNF and HLW, with an initial focus on removing UNF from the shutdown reactor sites; and

- Establish and maintain a unified and integrated UNF database and analysis system to characterize the input to the waste management system. 


\subsubsection{Long-Term Objectives ${ }^{1}$}

- Site, design and license, construct, and begin operations of a pilot interim storage facility (ISF) with an initial focus on accepting UNF from shutdown reactor sites

- Develop transportation infrastructure and capabilities to facilitate the acceptance of UNF at a pilot ISF

- Site and license a larger ISF with sufficient capacity to provide flexibility in the waste management system and allow for acceptance of enough UNF to reduce expected government liabilities.

The NFST activities are aligned with the key principles that underpin the BRC recommendations and are prioritized and executed such that they will provide a foundation for a new nuclear waste management organization. NFST activities are divided into four major topical areas: (1) Consent-Based Siting of an ISF, (2) Storage, (3) Transportation, and (4) Strategic Crosscuts.

\subsection{Strategic Crosscut Accomplishments}

Strategic Crosscut activities includes developing a decision analysis/decision support framework; developing a dynamic simulation modeling capability for use in the analysis of alternative implementation of strategies and plans; developing and applying waste management systems analysis capabilities and data; evaluating opportunities for standardization in the waste management system; characterizing and assessing existing and projected used fuel inventory and storage and transportation systems; assessing previous experience on siting nuclear facilities; evaluating public preferences related to consent-based siting of waste management facilities; and developing and maintaining a collaborative web-based used fuel storage, transportation and disposal, data and document access system.

\subsubsection{Project Management}

- Completed the "Nuclear Fuels Storage and Transportation Planning Project (NFST): Near-Term Implementation Plan" that describes the high-level milestones necessary to meet the Administration's Strategy goals for siting, designing, licensing, constructing, and beginning operations of both a pilot ISF and a larger ISF regardless of whether they are implemented by DOE or another organization. Major implementation milestones that must be achieved to deploy consolidated UNF interim storage were identified and sequenced. For the purposes of planning and consistent with the Administration's Strategy, it is assumed that an ISF would be deployed in phases with a pilot ISF that accepts UNF loaded into canisters from shutdown reactor sites first, followed by a larger ISF that would service the remainder of the U.S. nuclear reactor fleet.

- Prepared a publication entitled "Characteristics of Commercial Spent Nuclear Fuel: Distributed, Diverse, and Changing with Time," that was featured on the cover of the January-March 2014 edition of Radwaste Solutions, a publication of the American Nuclear Society.

- Attended and participated in the IAEA Technical Working Group on Fuel Cycle Options and Spent Fuel Management annual meeting, Vienna, Austria, April 28th-30th, 2014.

\footnotetext{
${ }^{1}$ Per the Administration's Strategy, legislation is required to enable full implementation of the longerterm objectives.
} 
- Visited the Boiling Water Reactor Hope Creek Nuclear Generating Station in Lower Alloways Creek Township, New Jersey August 18-22 to observe a spent fuel cask loading. Met with dry cask storage project experts at the plant and witnessed fuel transfer, canister welding, canister drying, stack up, canister transfer, and heavy haul transport operations. Information from the visit is being used to support the development of an integrated nuclear waste management system.

- Participated in several conferences and workshops to communicate NFST's mission, objectives, plans, and activities to various stakeholders, including the following.

- Nuclear Waste Technical Review Board's technical workshop on the Impacts of Dry-Storage Canister Designs on Future Handling, Storage, Transportation, and Geologic Disposal of Spent Nuclear Fuel (November 18-19) and Fall 2013 Meeting (November 20)

- Nuclear Waste Strategy Coalition meeting (November 13)

- Institute of Nuclear Materials Management 29th Spent Fuel Seminar (January 13-15). Presented "Nuclear Fuels Storage and Transportation Planning Project (NFST) Overview."

- Nuclear Energy Institute's Used Fuel Management Conference (May 6-8). Participated on the panel for the Shutdown Plant Caucus.

- Institute of Nuclear Materials Management annual meeting (July 20-24). Presented “Overview of the Department Of Energy's Nuclear Fuels Storage and Transportation Planning Project."

\subsubsection{Waste Management Systems Analyses}

The NFST is conducting integrated waste management system architecture analyses to support the future deployment of a comprehensive system for managing UNF from shutdown and operating reactors, Greater-than-Class C low-level radioactive waste generated during the decommissioning of nuclear power plants, and DOE-managed UNF and HLW. Integrated approaches for transportation, storage, and disposal in the waste management system are being evaluated, with an emphasis on providing flexibility to respond to evolving waste management policy and direction.

- Completed the initial collection and compilation of data for use in waste management system analyses. This includes reactor site UNF management, ISF UNF management, transportation logistics, and UNF disposal canister packaging parameters. The compiled data was used to populate the NFST's Unified Database (discussed below) and is the first compilation of waste management system analysis data.

- Evaluated alternative acceptance priority strategies for accepting UNF from reactor sites and the potential impacts of these strategies on at-reactor UNF management and on the design and operation of an ISF and assessed the impact of accelerating the transfer of UNF from at-reactor pool to dry storage on the waste management system,

- Evaluated transportation routes to determine generic ISF locations for use in waste management system architecture analyses

- Developed process flow diagrams and node descriptions that describe the various material flow operations contained within the waste management system architecture. 
- Participated in the development of a waste management system interaction matrix and an informal working meeting with a limited number of U.S. Nuclear Waste Technical Review Board (NWTRB) members and the NWTRB staff, and a U.S. Nuclear Regulatory Commission (NRC) representative, at the NWTRB offices in Arlington VA, April 24th.

- Initiated development of the Next Generation Systems Analysis Model that (1) is more readily sustainable and maintainable in the future, (2) is flexible for use by a broader set of users, (3) takes advantage of advanced simulation techniques, such as agent-based simulation, (4) leverages existing logistics and transportation simulation models developed for other applications, and (5) links with the Used Nuclear Fuel Storage, Transportation \& Disposal Analysis Resource and Data System (UNF-ST\&DARDS) system currently under development (discussed below).

\subsubsection{Execution Strategy Analysis}

The NFST completed development of a dynamic simulation modeling capability for use in the analysis of alternative implementation of strategies and plans. This effort provided an approach and tool for ongoing performance assessment of the evolving project plan/strategy that takes into account significant assumptions, risks, and uncertainties throughout the project life cycle.

The Execution Strategy Analysis (ESA) capability provides a comprehensive, fully integrated systems planning process and tool that ties together the implementation options at a high level to identify and examine alternative strategies for achieving project objectives. The ESA tool is helping to develop sound, risk-informed business practices and communicate/defend future program execution decisions to multiple stakeholders.

\subsubsection{Data and Document Access}

The NFST continued the development and maintenance of a collaborative UNF document and data access system, the Centralized Used Fuel Resource for Information Exchange (CURIE; curie.ornl.gov). CURIE provides ready access and use of UNF data, reports, and tools to support the NFST activities. It also maintains reactor- and site-specific information, displayed on a map, related to dry and wet storage in the United States. In addition to supporting the NFST, CURIE is a national resource accessible to industry, vendor, federal, and laboratory partners, as well as other stakeholders. To date, over 3,300 documents have been loaded onto CURIE, many of which are accessible to the public. Along with documents, CURIE also maintains a calendar, image galleries, and the Siting Experience Database, which was a BRC near-term recommendation.

\subsubsection{Standardization and Integration}

The NFST is evaluating standardization options within the nuclear waste management system with the initial focus to better integrate storage into the waste management system. In FY 2014, an initial assessment was completed to quantify the impacts of

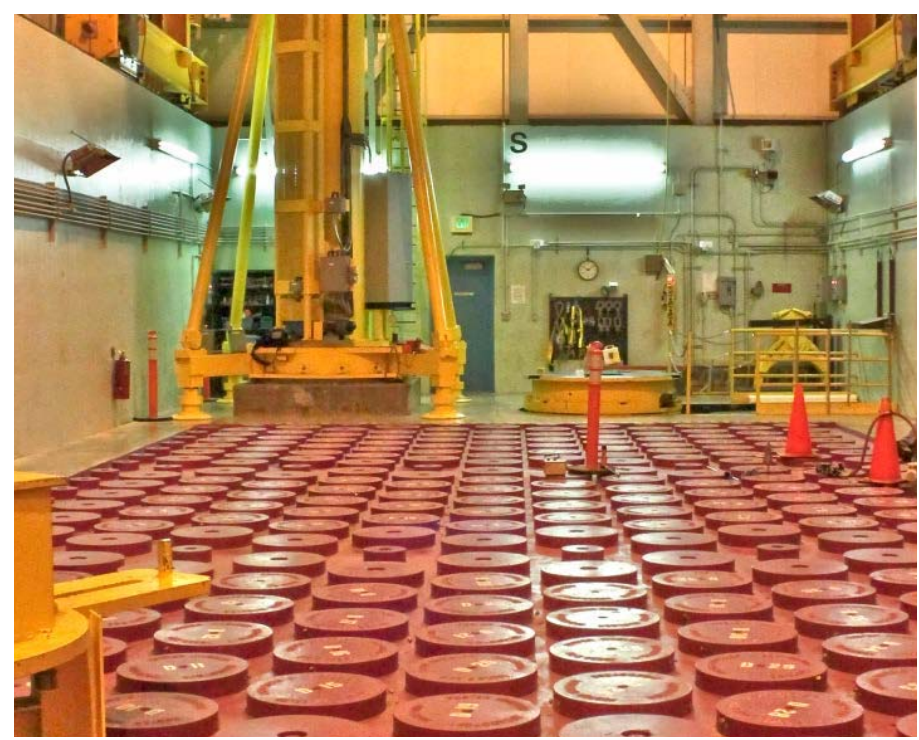

Figure 24. Vault for storing small canisters. 
incorporating standardized canister systems as the means to better integrate storage into the waste management system. The NFST initially focused on the potential impacts of loading smaller, standardized canister systems at reactors before the repository waste package requirements were known compared to the current industry practice of loading large, dual-purpose (storage and transportation) canisters (Figure 24). In support of this and future assessments, a number of accomplishments were achieved.

- Presented "Integrating Standardization into the Nuclear Waste Management System" at the U.S. NWTRB fall meeting in Washington D.C. on November 20, 2013.

- Presented "Implications of Repackaging Used Nuclear Fuel" at the U.S. NWTRB Technical Workshop on "the Impacts of Dry-Storage Canister Designs on Future Handling, Storage, Transportation, and Geologic Disposal of Spent Nuclear Fuel in the U.S." in Washington D.C. on November 18, 2013.

- Awarded a contract to EnergySolutions to conduct generic design studies of small standardized transportation, aging and disposal canister systems suitable for different potential disposal media.

- Awarded a contract to

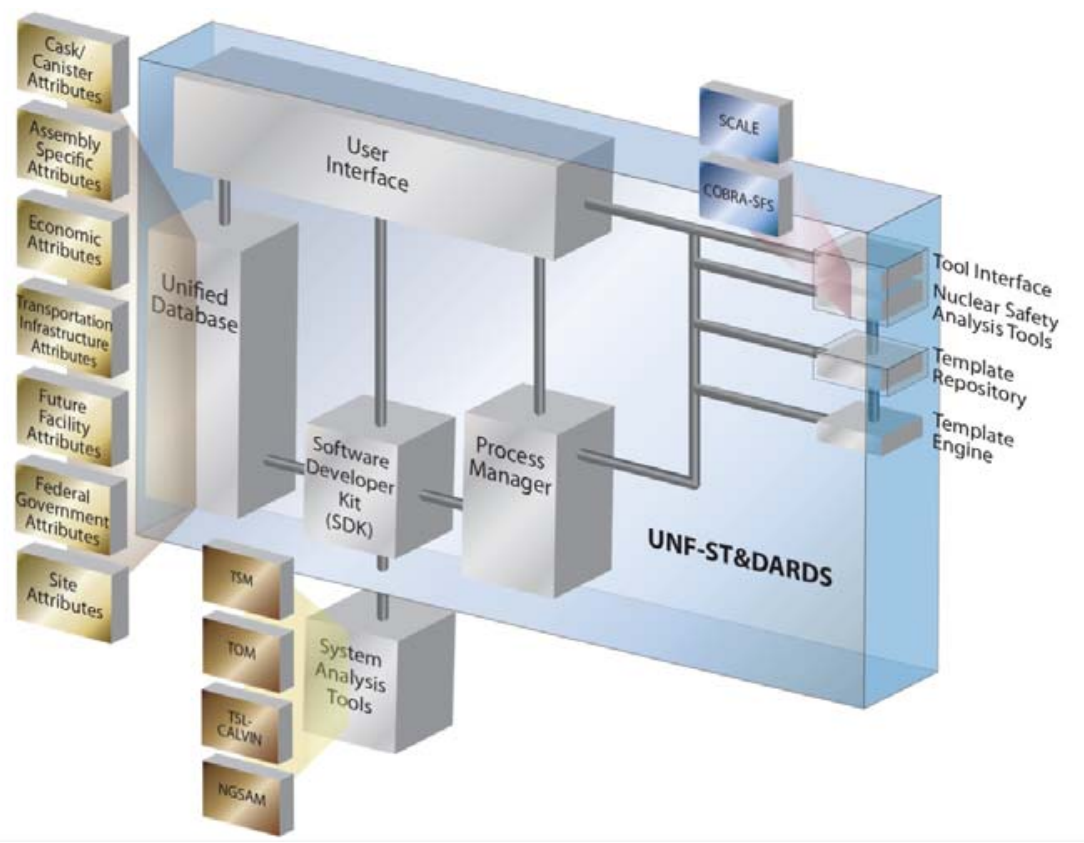

Figure 25. Information flow in UNF-ST\&DARDS. EnergySolutions to provide information on the operational requirements and impacts related to implementation of standardized canister systems at operating reactors and to identify innovative approaches to reduce related impacts.

\subsubsection{UNF Characterization and Assessment}

UNF Characterization and Assessment accomplishments include (1) establishing a unified, comprehensive UNF database and integrated analysis system, referred to as UNF-ST\&DARDS, (2) characterization of the input to the waste management system; provide a credible, controlled data source for key information; assess issues and uncertainties related to the extended storage and transportability of loaded canisters; support safety confidence and R\&D prioritization; and (3) provide a foundational data and analysis capability (Figure 25).

The UNF-ST\&DARDS is the foundation of an invaluable national archive that can track the mechanical and nuclear properties of all commercial UNF throughout the back end of the fuel cycle, and provides the framework to support future storage, transportation, repackaging, and disposal licensing analysis needs. 


\subsection{Storage Accomplishments}

NFST has initiated a number of activities to help lay the groundwork for implementing interim storage per the Administration's Strategy. The Strategy calls for an initial pilot ISF with priority given to the shutdown reactor fuel in dualpurpose canisters (DPCs). The Strategy also describes a larger ISF with sufficient capabilities to begin reducing the government's liabilities. Therefore, the design and operation of a larger ISF will depend on spent fuel management practices, acceptance queues, and may ultimately require both dry and wet systems (Figure 26). Consistent with the BRC

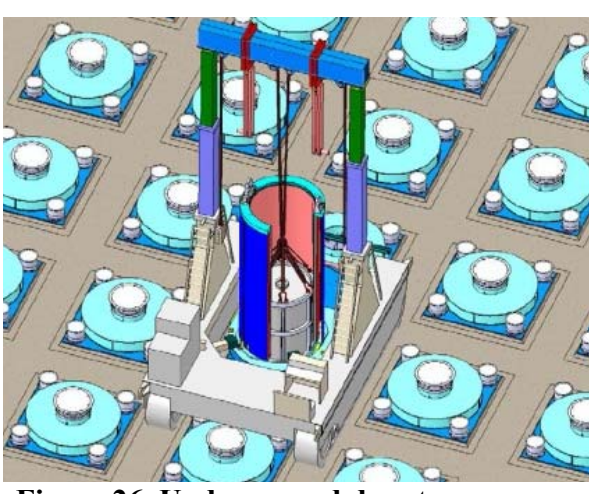

Figure 26. Underground dry storage concept. recommendations and the Strategy, a future ISF would be deployed in phases, utilizing modular design concepts for expanded functional capabilities, capacity, and throughput as appropriate. NFST is developing a range of design information for use in evaluating ISF deployment as part of an integrated waste management system.

- Awarded a contract (Advice and Assistance contract, Task Order 18) to Chicago Bridge and Iron to develop design concepts for the Receipt and Storage of UNF in Dual Purpose Canisters and examine alternative cask handling methods and facility configurations.

- Completed an initial study for the receipt and storage of UNF as individual assemblies (or "bare fuel"). Storage concepts examined include (1) pool storage in high-density storage racks, (2) UNF transfer to a mechanical seal (bolted) canister and subsequent storage in a below-grade vault, and (3) UNF transfer to welded canister and subsequent storage in a passively cooled concrete vertical overpack.

\subsection{Transportation Accomplishments}

Key NFST Transportation accomplishments include significant interaction with stakeholders including the four state regional groups (SRGs) and tribal representatives, which involved providing funding and collaborating to develop a Nuclear Waste Policy Act (NWPA) Section 180(c) policy implementation exercise and revision of the draft National Transportation Plan; development of a proposed route selection methodology and deployment of the Stakeholder Tool for Assessing Radioactive Transportation routing tool; continued evaluation of issues and associated required actions necessary to remove used fuel from shut-down reactor sites; and development of a system requirements document for development of a cask railcar that is compliant with the Association of American Railroads (AAR) S-2043 standard and subsequent posting of a Request for Information and Sources Sought notification in FedConnect for development of compliant railcars.

\subsubsection{Institutional}

- Continued developing the National Transportation Plan, which is a key planning document that outlines roles and responsibilities of the shipper, states, tribes, local officials, and industry to support shipment of UNF from waste producer sites. A draft version of the National Transportation Plan developed in FY 2013 was submitted to the SRGs and tribal partners and other stakeholders for review and comment. It was also presented at the National Transportation 
Stakeholders' Forum. The comments received from three of the four SRGs, tribes and other stakeholders were incorporated into a revision to the draft National Transportation Plan.

- Section 180(c) of the NWPA requires DOE to provide technical assistance and funds to states and tribes for training in support of UNF transportation. A NWPA 180(c) Policy Implementation Exercise was developed, in collaboration with the SRGs and Tribes, which will simulate the funding portion of the $180(\mathrm{c})$ process.

- Completed a report that proposes a transportation route selection process methodology that takes into account all applicable regulations, guidance documents that are available and germane, and lessons learned from past successful spent fuel and other large-scale radioactive material shipping campaigns. The proposed methodology also includes opportunities for stakeholder input and collaboration.

- Participated in several meetings and tele-conferences with stakeholders including the National Transportation Stakeholders' Forum (May, Minneapolis), SRG Core Group Meeting (August, Denver), Western Interstate Energy Board's Transportation of Spent Nuclear Fuel and HighLevel Radioactive Waste annual meeting (September, California), as well as several other meetings and webinars.

\subsubsection{Operational}

- Completed a revision of the evaluation of removing the UNF and Greater-than-Class C low-level radioactive waste inventory from the shut-down sites. The revision included 12 shutdown sites (Big Rock Point, Connecticut Yankee, Crystal River, Humboldt Bay, Kewaunee, La Crosse, Maine Yankee, Rancho Seco, San Onofre, Trojan, Yankee Rowe, and Zion).

- Performed a site visit to the shutdown Kewuanee Nuclear Power Plant and surrounding area, including the existing railroad and waterway infrastructure in near-site communities that could be used for spent fuel transportation operations in the future.

- Deployed the Stakeholder Tool for Assessing Radioactive Transportation routing tool which uses geographical information system (GIS) data and software to identify potential transportation routes from sites of interest.

- Completed a report that documents the application of automated radiation source term calculations and dose rate analyses of as-loaded transportation packages for four loaded NACInternational UMS transport packages.

- Developed a report on the relative ease of de-inventorying each of the 12 shutdown sites that considered a number of different factors and graded each of the sites on those factors to allow for a comparison of the ease and difficulty of removing the spent fuel from each of the sites.

- Developed a template for reports on the initial site-specific de-inventorying implementation plans for the shutdown sites. This report was subsequently used to develop a generic statement of work for industry contracts for development of these site-specific plans. 


\subsubsection{Hardware}

Transportation hardware includes all physical items necessary for operation of the UNF transportation system: transportation casks and railcars to carry them, other transportation conveyances such as heavy-haul trailers and barges, and ancillary equipment such as lifting devices and cask cradles. A key component is the design, prototype fabrication, testing, and approval of a railcar that meets AAR Standard S-2043 (Figure 27). Because railcar development is expected to take on the order of seven years-including design, prototype fabrication, and extensive testing - it is important that this work proceeds on schedule, so that railcars will be available once a destination has been selected for UNF shipments. A number of

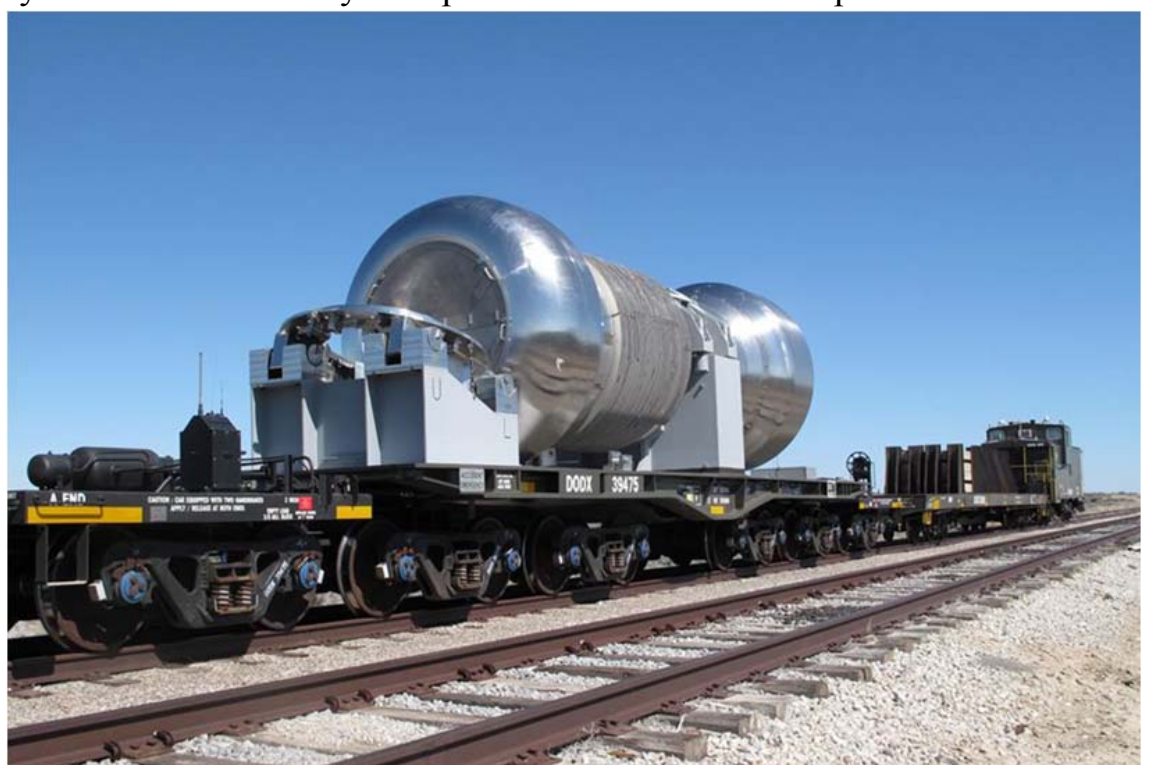

Figure 27. U.S. Navy AAR S-2043 compliant rail car with cask (not for transport of commercial UNF)

activities were completed to advance the development of AAR S-2043 compliant railcars for carrying UNF transportation casks.

- Completed a report on the history and requirements of the AAR Standard S-2043 that summarized the requirements of the standard, compared the requirements to those for other types of railcars, discussed analysis methods used in the development of such railcars, and documented the experiences the U.S. Navy and Private Fuel Services have had in the development of complaint railcars

- Developed a system requirement document for the cask railcar

- Published a Request For Information regarding rail car design and testing, evaluated responses from industry, and established a statement of work. 


\section{MATERIAL RECOVERY AND WASTE FORM DEVELOPMENT CAMPAIGN}

\section{T. A. Todd, Idaho National Laboratory, J. D. Vienna, Pacific Northwest National Laboratory}

\subsection{Overview}

The Material Recovery and Waste Form Development (MRWFD) Campaign under the U.S. DOE Fuel Cycle Technologies (FCT) Program is responsible for developing advanced separation and waste form technologies to support the various fuel cycle options defined in the DOE Nuclear Energy Research and Development Roadmap, Report to Congress, April 2010. This section provides a highlight of the results of the R\&D efforts performed within the MRWFD Campaign in FY 2014. Each subsection contains a high-level overview of the activities and key results, produced during the fiscal year. More detailed accomplishments are available in the 2014 MRWFD Accomplishments Report (Braase \& May, FCRDMRWFD-2015-00004).

This section briefly outlines the campaign mission, objectives and challenges and highlights key technical accomplishments made during FY 2014. The campaign continued to utilize an engineering drivenscience-based approach to maintain relevance and focus. There was increased emphasis on development of technologies that support near-term applications that are relevant to the current once-through fuel cycle.

The MRWFD Campaign management and integration activities included international collaboration activities (France, China, Russia, Japan, European Union, and the International Atomic Energy Agency [IAEA]), integration of MRWFD Campaign activities with other FCRD campaigns, (Advanced Fuels, Used Fuel Disposition, Fuel Cycle Options, and Material Protection, Accountancy and Control Technology), and integration with DOE Office of Environmental Management.

Technical accomplishments are reported under the following R\&D categories:

- Reference Technologies and Alternatives

- Sigma Team for Minor Actinide Separations

- Sigma Team for Off-Gas Capture and Immobilization

- Fundamental Science and Methods, Modeling, and Simulation

- Advanced Waste Form Characterization

- Advanced Waste Forms and Processes

\section{Mission}

Develop advanced fuel

cycle separation and

waste management

technologies that improve

current fuel cycle

performance and enable a sustainable fuel cycle, with reduced processing, waste generation, and potential for material diversion.

- Domestic Electrochemical Separation Technologies

- Fuel Resources.

\subsubsection{Mission}

Material Recovery and Waste Form Development, formerly Separations and Waste Forms, applies expertise and technical capabilities to a wide array of applications. This campaign now also leverages its 
expertise by working with others in areas such as environmental remediation, national security missions, as well as civilian nuclear applications. The mission of MRWFD is to:

Develop advanced fuel cycle separation and waste management technologies that improve current fuel cycle performance and enable a sustainable fuel cycle, with minimal processing, waste generation, and potential for material diversion.

Mission implementation is outlined in the Campaign Implementation Plan, issued in November 2012. A revision will be made following issuance of a new Nuclear Energy Roadmap, expected in FY 2015 and the recent issuance of the Fuel Cycle Options Evaluation and Screening Study (FCRD-FCO-2014000106).

\subsubsection{Objectives}

- Develop technologies that support the current once-through fuel cycle and have near-term potential application.

- Develop a fundamental and practical understanding of methods for the separation of uranium and transuranic elements from used fuel.

- Develop a fundamental and practical understanding of the factors affecting performance of advanced waste forms.

- Develop and demonstrate enabling technologies to separate and immobilize gaseous fission products from used nuclear fuel.

- Demonstrate predictable performance of advanced waste forms with greatly improved durability and waste loadings.

\subsubsection{Challenges}

- Separation of minor actinides from lanthanides.

- Capture and immobilization of off-gas constituents of used fuel, including iodine, krypton, tritium and potentially carbon in a cost-effective manner.

- Development of separation technologies and waste forms is very interrelated to the types of fuels being processed, the types of fuels being fabricated, and the reactors used to burn recycled fuels.

- Achievement of advanced separation and immobilization processes in a cost effective manner.

\subsection{Reference Technologies and Alternatives}

This activity is developing and evaluating mass balances to enable objective comparison of technology performance for new separation technologies. These mass balances also help identify technology gaps, where research and development are needed. Additionally, this activity supports development of on-line monitoring tools, evaluation of solvent degradation mechanisms, and development of tritium removal technologies (for open and closed fuel cycle applications). The focus in FY 2014 was on demonstrating the use of on-line monitors to measure the $\mathrm{pH}$ evolution during Trivalent Actinide - Lanthanide Separation by Phosphorous reagent Extraction from Aqueous Komplexes (TALSPEAK-like processes and the closed loop $\mathrm{NO}_{2}$ oxidation of sim-fuel at low temperature. In addition, the closed fuel cycle case study was updated and the closed fuel cycle waste management strategy was developed. The MRWFD Campaign has initiated a collaboration with the European Union Framework 7 SACSESS program (Safety of Actinide Separation Processes). 


\subsection{Sigma Team for Minor Actinide Separations}

This activity is developing more robust and simplified approaches for separating minor actinides to enable future fuel cycles that transmute minor actinides for improved resource and waste management. There is a large international effort in nearly every fuel cycle country working on this difficult chemical separation and the FCT program is making significant progress on the development of cost-effective methods of separating the minor actinides from used fuel. In FY 2014, the first ever bench-scale demonstration was completed of tandem oxidation of Am and solvent extraction, in centrifugal contactor equipment. Two improved methods for effective Am oxidation and stabilization were developed: silver catalyzed ozone oxidation and copper (III) periodate. A conceptual flowsheet of Actinide-Lanthanide Separation (ALSEP) and a fundamental understanding of TALSPEAK-like processes were developed.

\subsection{Sigma Team for Off-Gas Capture and Immobilization}

This activity is needed to enable licensing of any new fuel treatment facility to meet current regulations. The capture of iodine at very high decontamination factors is required and iodine has a very long half-life, so immobilization is important to reducing the source term in a geologic repository. Krypton (Kr) capture will be needed if processing fuel less than 30 years old. Tritium may also require capture. It is very important to understand the behavior of the entire off-gas system, to avoid cross-contamination of sorbents (e.g., iodine on tritium or krypton sorbent). For FY 2014, a process was developed to mitigate coadsorption of tritium and iodine, the $\mathrm{Kr}$ capacity was increased in capture materials, research was initiated on organic iodide capture, and the economics were evaluated of metal-organic-frameworks (MOF) for near room-temperature capture of $\mathrm{Kr}$.

\subsection{Fundamental Science and Methods Development Modeling and Simulation}

This activity is utilizing new tools and research methods to understand the fundamental properties of extraction systems. These fundamental properties are the basis for understanding any separation process from a science-based approach rather than an empirical approach, which has been the typical approach used in the past. A greater understanding of the fundamental properties (such as thermodynamics, kinetics, effects of radiation on chemistry) will enable the development of more robust processes and also support future models that allow for a predictive capability of process performance. In FY 2014, the structure of phosphorous bonding sites was measured using X-ray absorption spectroscopy. The effects of alpha radiation were assessed on the stability of solvent extraction ligands. In addition, an initial model was developed for non-ideal mixing in the TALSPEAK system.

\subsection{Advanced Waste Form Characterization}

This activity develops sufficient understanding of waste form degradation behavior to predict radionuclide release over geologic timescales. This fundamental understanding is required to optimize waste form chemistry and support disposal system performance assessment. In 2014, a database was created of glass corrosion characteristics that lead to accelerated corrosion. An expression for coupled glass corrosion and alteration product precipitation was developed, as well as an initial alloy waste form corrosion rate model. The performance characteristics of ancient analog glasses were measured. 


\subsection{Advanced Waste Forms and Processes}

These activities are necessary for the immobilization of waste streams from the advanced separation processes, including advanced aqueous and electrochemical processes. These waste forms are designed to improve the performance over current waste forms, such as borosilicate glass, over geologic time frames. Higher performance can be achieved by utilizing glass ceramic or ceramic waste forms. Any new waste form must be processed in production-scale continuous processing equipment. Ceramic containing waste forms must be processed at higher temperatures than glass waste forms; therefore, standard joule-heated melters are not adequate. Investigation of cold crucible induction melters for processing advanced waste forms is in progress. The goal of this work is to significantly reduce the cost of waste treatment, storage, transportation and disposal, while improving performance. In FY 2014, a proof-of-principle melter test was performed with ceramic waste forms, and a reference ceramic waste form was developed that immobilizes HLW. An analysis was completed on the impact of oxide layer formation on cladding recycle kinetics. A composition variation study was initiated for glass ceramic HLW forms.

\subsection{Domestic Electrochemical Separations Technologies}

This activity is developing technologies to enhance performance and reduce waste volumes in the treatment of fast reactor fuels. This technology is suited to treatment of metallic fuels for recycle of transuranics. In FY 2014, a trade study was performed on salt waste management, and a proof-ofprinciple test was performed on selective ceramic membrane separations of $\mathrm{CsCl}$. In addition, a $\mathrm{kg}$-scale unit for uranium/transuranic (U/TRU) codeposition studies was designed and constructed. Salt samples from the Mark IV electrorefiner at the INL Fuel Conditioning Facility were taken for FY 2015 studies in U/TRU codeposition. 


\section{JOINT FUEL CYCLE STUDIES}

\subsection{Overview}

The Joint Fuel Cycle Studies (JFCS) Campaign is chartered to explore the technical and economic feasibility and nonproliferation acceptability of electrochemical recycling for the management of used nuclear fuel. Electrochemical recycling utilizes dry (non-aqueous) processes that allow collection of uranium and group collection of a uranium/transuranium product in compact fuel cycle facilities. The technology offers head-end processes that allow recycling of actinides from oxide fuel, such as used lightwater reactor (LWR) fuel.

The JFCS is a schedule-driven activity with a 10-year duration and divided into three phases. All phases include a range of activities, but each has an area of primary emphasis. The JFCS began in 2011, and the first phase lasted 2 years and focused on the Laboratory-Scale Feasibility Study (LSFS) for electrochemical recycling at small scale with irradiated materials. The second phase lasts 5 years (20132017) with a primary emphasis on the demonstration of reliable and reproducible integrated process operations as well as the recovery of sufficient fuel material for recycled fuel fabrication. The third phase lasts 3 years (2018-2020) and will be focused on validation of recycled fuel fabrication processes, recycled fuel irradiation, and post-irradiation examination. This overview provides highlights of the accomplishments of the JFCS Campaign through FY 2014.

\subsubsection{Key Fiscal Year 2014 Outcomes}

- Completed the design of key equipment for the Integrated Recycling Test, with components moving through the fabrication and testing process.

- Initiated detailed test planning for the Integrated Recycling Test.

- Completed Critical Gap research on the recovery of mixed uranium-transuranium products from low concentration molten salt solutions.

- Implemented the Nuclear Technology Transfer Agreement between the United States and ROK, including training of personnel.

\subsection{Laboratory-Scale Feasibility Study}

The purpose of the LSFS was to evaluate the technical feasibility of the electrochemical process at laboratory scale. This was accomplished through a small-scale study with irradiated materials and existing equipment in a DOE facility. Approximately 100 grams of heavy metal were processed in the Hot Fuel Dissolution Apparatus in Idaho National Laboratory's (INL) Hot Fuel Examination Facility (HFEF).

Some of the prescribed operations in the LSFS had been performed previously at laboratory scale with used fuel, and some operations were performed for the first time. The operations were performed in an integrated manner to allow assessment of the overall process. The LSFS confirmed the feasibility of electrochemical recycling of used LWR fuel. It also provided integrated operating experience that will be addressed in forthcoming critical gap studies and equipment development prior to advancing the subject technology to kilogram scale. 


\subsection{Integrated Recycling Test}

An integrated testing activity at kilogram scale in DOE facilities is planned in order to test electrochemical recycling flowsheets and provide material balance information for an integrated process model. This work is described as the Integrated Recycling Test (IRT), and it is a critical component for the overall goals of the JFCS. The IRT includes the fabrication, irradiation, and post-irradiation examination of metal fuel rodlets produced from recycled LWR fuel. Most operations for the IRT will be performed within the HFEF hot cell of the Materials and Fuels Complex at Idaho National Laboratory. During Phase I (approximately CY-11 through CY-12), the design of process equipment began and fabrication initiated on some components. During Phase IIA (CY-13 through CY 2014) equipment design and fabrication continued. Phase IIB (CY 2015 through CY-17) will focus on the completion, testing, installation, and operation of equipment to recover reusable materials from used LWR fuel. The objective by the end of Phase IIB is the casting of fuel slugs including recycled material for irradiation in the Advanced Test Reactor. The following paragraphs provide additional description of primary equipment components which will be operated during the IRT.

Modular Workstations: The modular workstations will serve as the work platforms for IRT process equipment in HFEF. These include expansion of an existing table at window $11 \mathrm{M}$ in HFEF, a new table to be installed at window $12 \mathrm{M}$, and a smaller intermediate table to be installed between these two tables. These workstations will include integrated balances as well as storage space for tools, equipment, and archived samples. Figure 28 depicts the planed workstation and equipment layout for the IRT in HFEF.

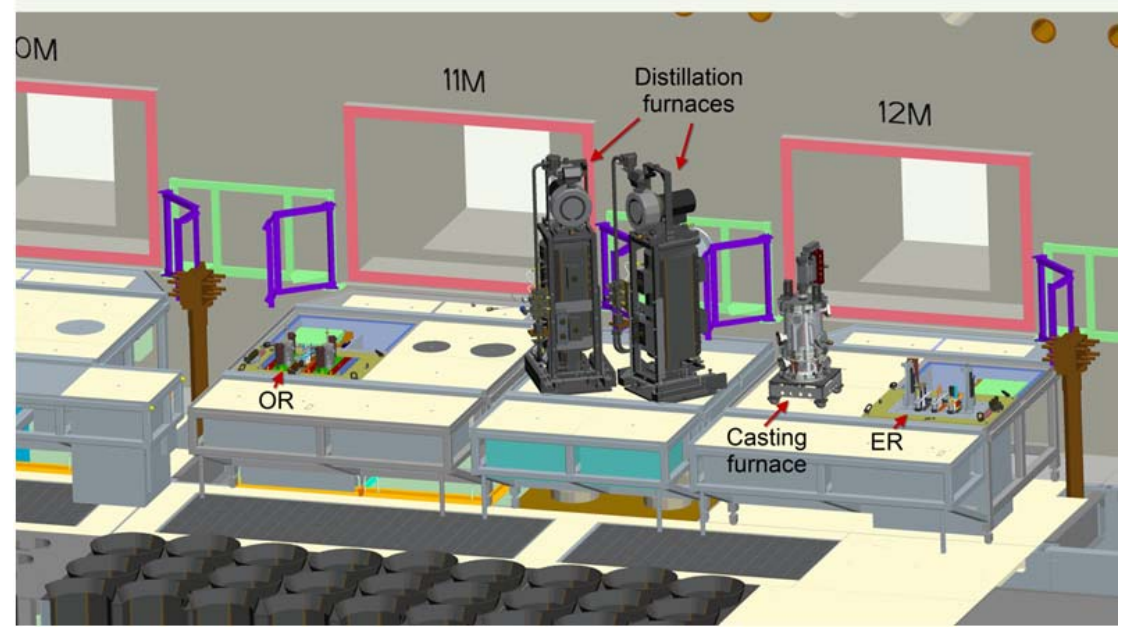

Figure 28. Workstation and equipment layout for the JFCS IRT

Head-End Equipment: The equipment necessary to prepare used nuclear fuel for IRT processing is described as head-end equipment. This includes equipment for decladding, size-reduction, sieving, handling of fines, and material storage. Design of the head-end equipment continued in FY 2014, and has culminated in preliminary design of the vibratory decladding system depicted in Figure 29. 


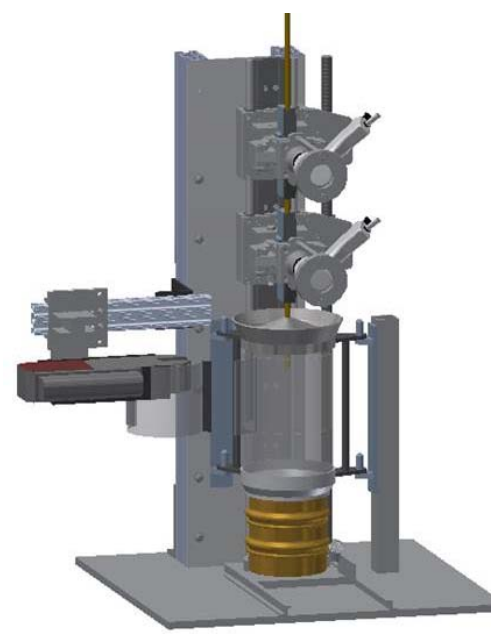

Figure 29. Vibratory decladding system for used LWR fuel

Oxide-Reduction System: The oxide reduction system electrolytically reduces oxide fuels to produce a metallic product that is suitable for further electrochemical recycling. Design and fabrication of the oxide reduction system continued during FY 2014. The system layout on the $11 \mathrm{M}$ table is depicted in Figure 30.

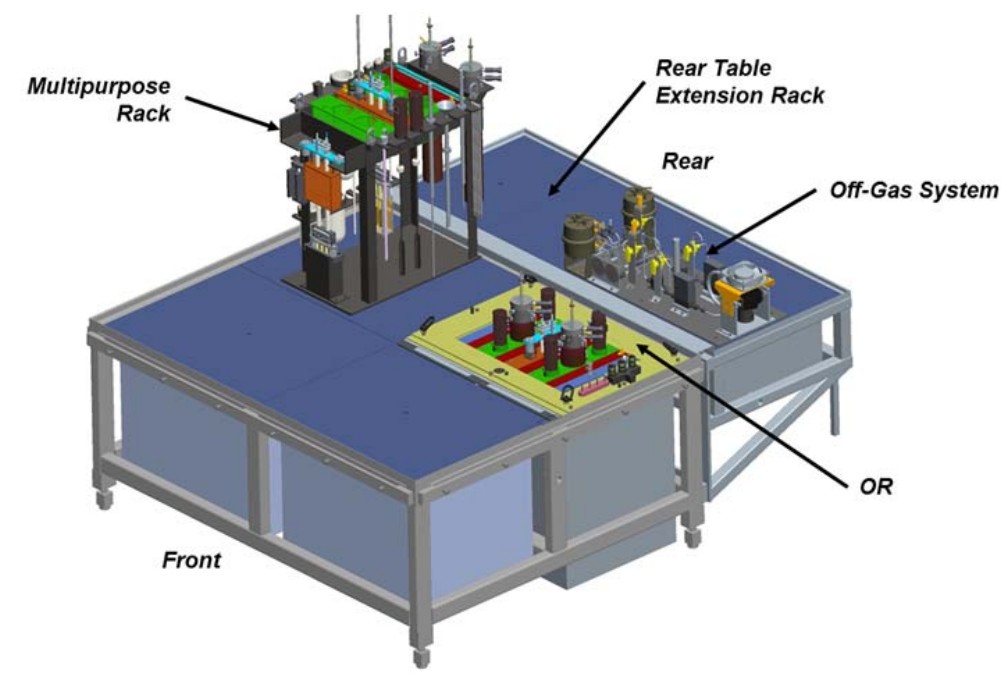

Figure 30. Layout of the oxide reduction system

Electrorefiner System: The purpose of the electrorefiner is to separate TRU elements and fission products from the reduced fuel and accumulate those elements and products in the electrorefiner salt. Purified uranium is collected, and periodically group recovery is performed for uranium and transuranium elements through a liquid cadmium cathode. Major electrorefiner components are currently in the fabrication process.

Distillation System: The distillation module is used to distill salts and/or cadmium from products that originate from the oxide reduction or electrorefining modules. Two separate distillation systems will be installed to accommodate the variety of operations. The distillation systems have been designed, fabricated, and initial testing performed.

Fuel Fabrication Equipment: Recovered actinide materials from the JFCS will be used to fabricate fuel rodlets for irradiation in the Advanced Test Reactor. A casting furnace has been designed, fabricated, and 
initial testing performed. Crucibles and molds are heated electromagnetically, and Figure 31 provides a photograph of the two primary internal assemblies.

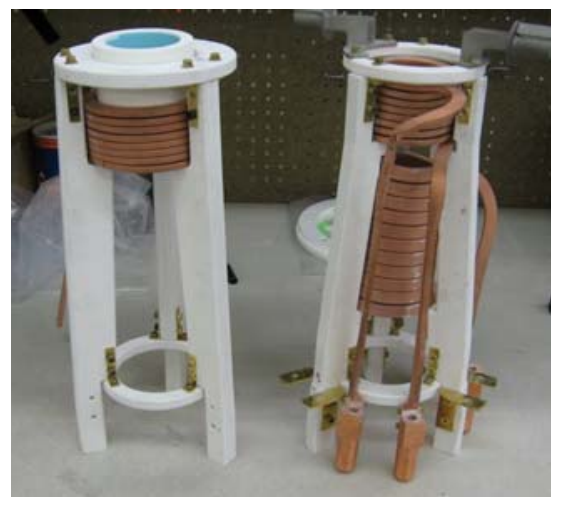

Figure 31. Internal components for uranium counter gravity casting (left) and gravity casting (right)

\subsection{Critical Gap Research and Development}

A range of research and development was performed in FY 2014 to provide fundamental knowledge necessary to prepare for the IRT, close process modeling gaps, and to develop and demonstrate improved processes that are critical to confirm the feasibility of a commercial-scale process. Significant accomplishments from each research activity are briefly summarized below:

Lithia Monitoring: In the oxide reduction process, $\mathrm{Li}_{2} \mathrm{O}$ serves as the oxide ion transport species. Experience has demonstrated that successful performance of the electrolytic reduction process requires that the $\mathrm{Li}_{2} \mathrm{O}$ concentration be maintained within a particular range. A real-time method for monitoring the concentration of $\mathrm{Li}_{2} \mathrm{O}$ is being developed, and will be a valuable element to deployment of electrochemical recycling.

Oxide Reduction: During the oxide reduction process for the LSFS, one significant issue observed was corrosion and salt transport to the heat shields immediately above the platinum anode. To address these issues, the IRT equipment has been designed with a shrouded anode and salt trap. An oxygen monitoring instrument will be included in the offgas system to provide real time feedback of electrolysis conditions. Neither the salt trap nor oxygen monitoring equipment have been previously demonstrated, but must be fully functional when installed. Iterations toward the anode assembly were fabricated and tested in a nonradiological molten salt system.

Anode Material Selection and Design: Platinum has served as the primary anode material for much of the development of the electrolytic reduction process for used uranium oxide fuel. Iridium and graphite are two alternative materials that could function in place of platinum, and testing continued to examine their performance (Figure 32). One particular issue of concern is behavior of these materials in the presence of tellurium and iodine, two fission products with potentially deleterious effects. 


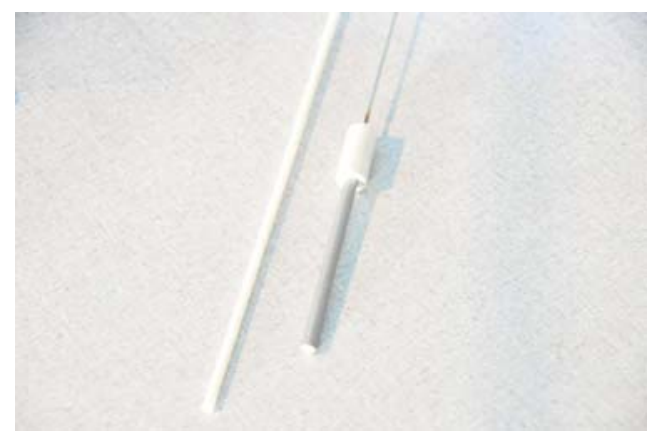

Figure 32. Dense iridium rod utilized for testing

Salt Metal Separations: Testing continued of an innovative laboratory-scale system for salt/metal separation. This is a semi-continuous system for separating salt at elevated temperatures without vacuum. The technology is being adapted for testing with salt-coated uranium dendrites in a radiological glovebox.

Uranium Electrorefining: A prototype of the IRT uranium product harvesting approach is being tested with molten salt and uranium dendrites. Experience gained will allow design enhancements to be identified prior to installation of remote equipment.

Low Transuranic (TRU)/Uranium (U) LCC Operations: In order to recover uranium/transuranium/rare earth products in the necessary rapid time frame for the IRT, it is desired to perform liquid cadmium cathode (LCC) operations at low concentration of transuranium elements in the salt. Few data are available for LCC operations at such low concentrations and challenges may occur. In addition to supporting the near-term IRT, elucidation of LCC performance at low transuranium concentrations is important to manage the TRU inventory for long-term electrorefiner operations. A series of LCC experiments were performed in the Hot Fuel Dissolution Apparatus in FY 2014 to explore these issues.

High Temperature Materials: A number of distillation and melting operations are required for the IRT. One challenge is that current crucible materials for melting operations do not allow the recovery of actinoid holdup. As an example, $\mathrm{ZrO}_{2}$-based drosses react with $\mathrm{Li}_{2} \mathrm{O}$ in the oxide reductions system to form a ternary oxide. $\mathrm{Y}_{2} \mathrm{O}_{3}$ drosses will quantitatively react with $\mathrm{UCl}_{3}$ in the electrorefiner to increase $\mathrm{YCl}_{3}$ concentration in the salt. Materials with potentially improved characteristics are under development. Figure 33 is a photograph of a graphite crucible coated with $\mathrm{UO}_{2}$ following repeated containment of molten uranium. Drosses from such a crucible coating would be recyclable into the process, potentially dramatically reducing crucible losses.

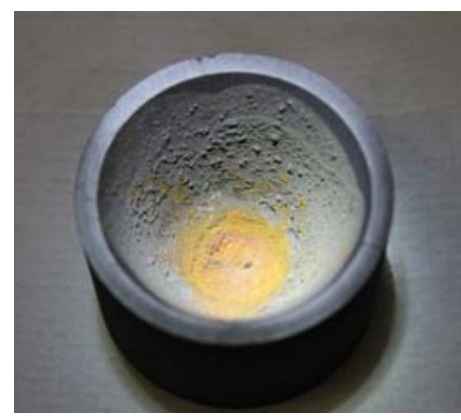

Figure 33. $\mathrm{UO}_{2}$-coated crucible after repeated melts with metallic uranium

Lanthanoid Reduction: The LCC is the current reference method for uranium/TRU product recovery during electrochemical processing. A typical uranium/TRU product consists of uranium, plutonium, 
minor actinides, rare earth elements, cadmium metal, and a small amount of electrorefiner salt. The amount of rare earth elements in the uranium/TRU products may exceed a level acceptable for fuel production. Methods to reduce the rare earth element content of the uranium/TRU products during normal process operations were tested with representative material in the hot cell.

Electrochemical Waste Forms \& Processes: The identification and demonstration of appropriate waste forms and associated production processes are critical to the overall demonstration of the feasibility of electrochemical recycling. These will be demonstrated with fission products during Phase III of the IRT. Activities in FY 2014 continued the investigation and down selection of waste forms.

Fundamental Properties: Thermal properties of molten salt systems are of interest to electrorefiner and oxide reduction operations. Potential situations that need to be avoided during operations include electrolyte freezing at the operating temperature due to changes in the liquidus temperature, and potential phase separation (non-homogenous solution). The stability and homogeneity of the phases can be determined by study of the thermal characteristics of the molten salts as a function of composition. Fundamental data are being collected regarding phase boundaries of oxide reduction and electrorefining salts in both simple and complex operating scenarios.

Fuel Fabrication: During fuel fabrication, several fuel inspections need to occur, including weld inspection and sodium height or bond inspection. While these inspections can be performed several ways for fresh fuels, remote inspection will be required for recycled fuel fabrication at production-scale. Such remote inspections are difficult and require further research and development. Of the available methods, ultrasonic inspection requires fewer electronics in the hot cell and can be implemented with a smaller footprint.

It has been previously observed that failed welds exhibit a certain type of electromagnetic signature during the welding process. This provides the potential to establish a weld qualification technique based on careful monitoring of the electromagnetic signatures during each weld. Activities continued in FY 2014 to develop a database of successful versus failed weld signatures. 


\section{USED FUEL DISPOSITION RESEARCH AND DEVELOPMENT CAMPAIGN}

\subsection{Overview}

The Used Fuel Disposition Research and Development (UFD) Campaign identifies alternatives and conducts scientific research and technology development to enable storage, transportation, and disposal of used nuclear fuel (UNF) and wastes generated by existing and future nuclear fuel cycles. An overarching objective of the campaign is to support the Administration's 2013 Strategy for the Management and Disposal of Used Nuclear Fuel and High-Level Radioactive Waste.

\subsubsection{Near-Term Objectives (2015-2020)}

- Provide technical expertise to inform policy regarding management of UNF and radioactive waste that would be generated under existing and potential future nuclear fuel cycles.

- Develop the technical basis for extended long-term storage of UNF and HLW to identify longterm research and development needs.

- Develop the technical basis for retrievability and transportation of high burnup UNF.

- Develop a comprehensive understanding of the current technical basis for disposal of UNF and high-level nuclear waste in a range of potential disposal environments to identify long-term $R \& D$ needs.

- Develop advanced, predictive computational models, with experimental validation to evaluate UNF performance under normal conditions of storage and transportation and disposal system performance in a variety of generic disposal system concepts and environments.

\subsubsection{Long-Term Objectives (2020-2025)}

- Support the implementation of a full-scale, NRC-licensed confirmatory storage demonstration facility via significant collaboration with industry.

- Develop the technical basis necessary to support eventual transportation of UNF.

- Support implementation of integrated storage, transportation and disposal concepts.

\subsubsection{Key FY 2014 Outcomes}

- Supported the industry storage cask demonstration by actively participating in:

- Support for finalization of the EPRI Test Plan.

- $\quad$ R\&D in support of non-destructive evaluations of the demonstration cask.

- Selection and eventual placement of assemblies to obtain the greatest diversity in cladding and heat exposures during the duration of the test.

- Planning for cask lid design, licensing issues, and approval of final design. 
- Completed cladding bend test on irradiated Zirc-4 and M5 cladding. Results showed that the irradiated fuels can withstand millions of bending cycles at potentially higher than representative loading levels before breaking.

- Tested a surrogate fuel assembly with a 700-mile simulated truck trip on a shaker table followed by 50 miles on a real truck with representative weight to better understand the integrity of high burnup fuel during transport. Results provide further confirmation that stresses and strains seen by the fuel and assembly are well below those predicted to damage cladding or the assembly.

- Completed evaluation of options for permanent geologic disposal of UNF and HLW in support of a comprehensive national nuclear fuel cycle strategy. The evaluation considered the full range of commercial and DOE-managed HLW and UNF concluded that multiple disposal options are available for all existing and currently projected waste forms, with the exception of untreated sodium-bonded fuels, for which additional information is needed.

- Updated analyses of dual-purpose canister (DPC) disposal alternatives indicate that DPC direct disposal could be technically feasible, at least for certain disposal concepts.

- Identified RD\&D needs for evaluating feasibility of deep borehole disposal of small HLW waste forms, providing the foundation for planning a deep borehole field test.

\subsection{Campaign Challenges}

Challenges include providing a sound technical basis for supporting the DOE strategy for managing the back end of the nuclear fuel cycle, including the identification and evaluation of safe and secure options for storage, transportation, and permanent disposal of radioactive wastes resulting from existing and future fuel cycles.

\subsection{Major Research and Development}

Storage and Transportation Research and Development $(R \& D)$ examines three topics: storage, transportation, and security. Storage R\&D focuses on closing technical gaps related to extended storage of UNF, including uncertainties with high-burnup nuclear fuel cladding performance and long-term canister integrity. Transportation R\&D focuses on ensuring transportability of UNF following extended storage, addressing data gaps regarding nuclear fuel integrity, retrievability, and understanding stresses and strains during normal conditions of transport. Security R\&D focuses on questions related to material attractiveness and self-protection due to surface dose rate, which decreases as UNF ages. The UFD campaign participates in the international Extended Storage Collaboration Project, led by the EPRI with input from the DOE, the U.S. Nuclear Regulatory Commission, and programs in multiple other nations.

A major focus in FY 2014 is the start of the High Burnup Dry Storage Cask R\&D Project. This project, led by EPRI under contract to DOE, will conduct a multiyear test to collect data from a UNF dry storage system (located at the North Anna Nuclear Power Plant in Virginia) containing high burnup fuel. The primary goals of the test are to provide confirmatory data for validation of, and potential improvement in, models of the long-term performance of high burnup fuel under typical dry storage conditions. These models will provide key input to future dry storage cask design, support license renewals and new licenses for Independent Spent Fuel Storage Installations, and support transportation licensing for high burnup used fuel. 
NOTE: The following timeline shows approximate target dates (in italics) needed to meet the 2025 deadline set out in the 2013 DOE Strategy.

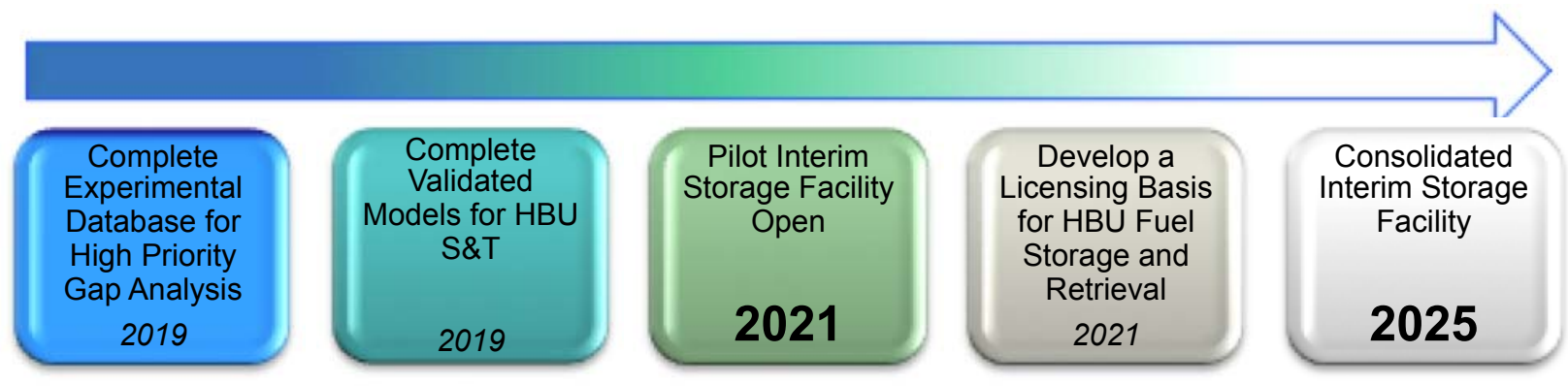

Figure 34. Summary timeline for Storage and Transportation Research activities.

Disposal $\boldsymbol{R} \boldsymbol{\&} \boldsymbol{D}$ focuses on identifying multiple viable geologic disposal options, addressing technical challenges for generic disposal concepts in various host media (e.g., mined repositories in salt, clay/shale, and granitic rocks, and deep borehole disposal in crystalline rock). R\&D goals at this stage are to reduce generic sources of uncertainty that may impact the viability of disposal concepts, to increase confidence in the robustness of generic disposal concepts, and to develop the science and engineering tools needed to select, characterize, and ultimately license a repository. International collaborations are a significant component of the disposal R\&D portfolio, and include: DECOVALEX (Development of Coupled Models and their Validation against Experiments), with participation from multiple nations in Europe and Asia; the Mont Terri underground research laboratory (Switzerland); Colloid Formation Migration (Switzerland); SKB Task Force (Sweden), Salt R\&D (Germany); and crystalline disposal R\&D with Korean Atomic Energy Research Institute (KAERI) Underground Research Tunnel.

NOTE: The following timeline shows approximate target dates (in italics) needed to meet deadlines (in bold) set out in the 2013 DOE Strategy.

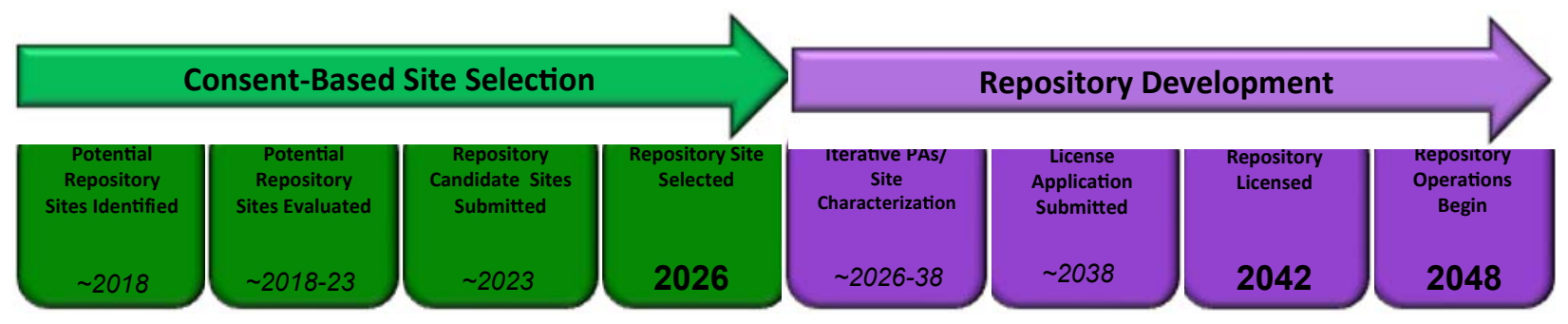

Figure 35. Summary timeline for Disposal Research activities.

\subsection{Storage and Transportation Accomplishments}

Storage and Transportation R\&D has been performed in five areas: Field Demonstration, Experiments, Analysis, Transportation, and Security. Selected work is highlighted here.

\subsubsection{Field Demonstration}

The national laboratories supported the High Burnup Dry Storage Cask R\&D Project by actively participating in finalization of the EPRI test plan, $R \& D$ in support of non-destructive evaluations of cask internals, and planning for receipt, characterization, and laboratory testing of comparable "sister" fuel 
pins during the demonstration phase. Figure 36 shows the transport to the Independent Spent Fuel Storage Installation pad at North Anna of a cask like the one to be used.

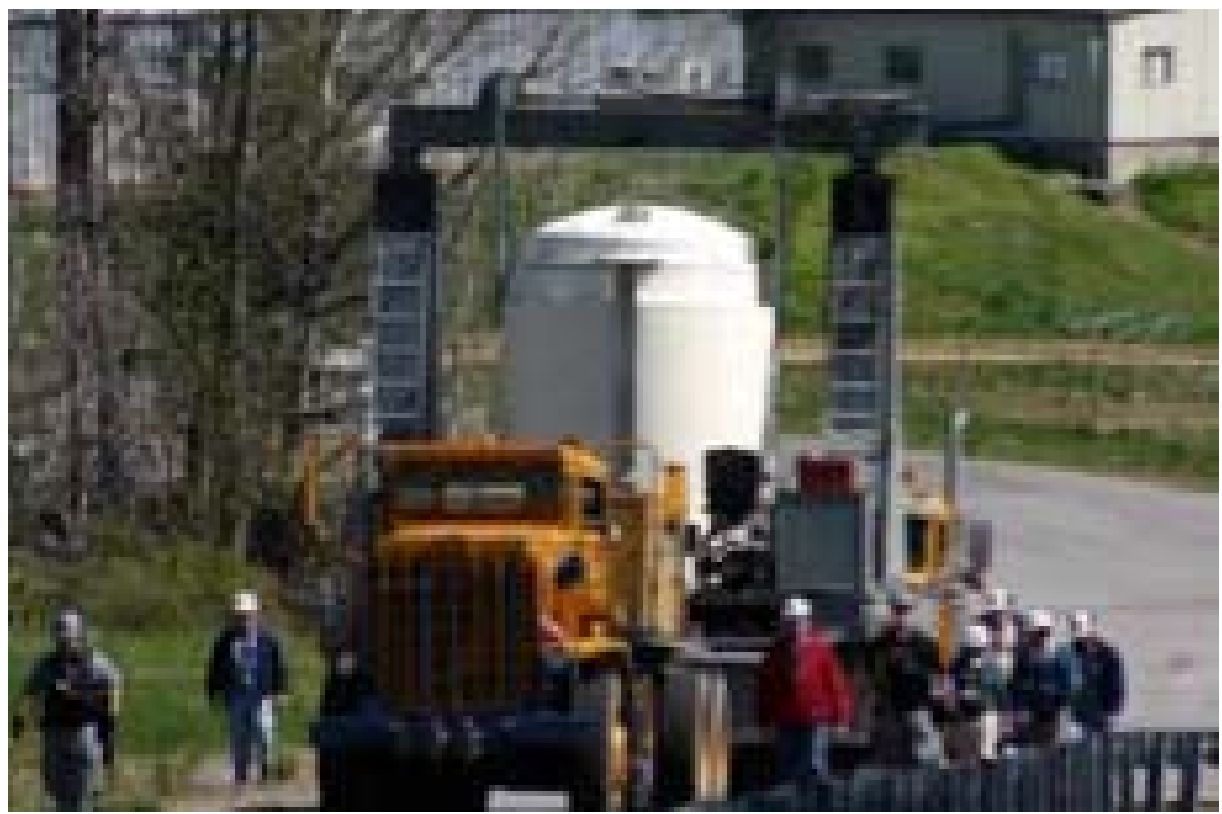

Figure 36. Moving a TN-32 cask at North Anna

\subsubsection{Experiments}

The national laboratories completed cladding bend test on irradiated Zirc-4 and M5 cladding (Figure 37). Results showed that the irradiated fuels can withstand millions of bending cycles at potentially higher than representative loading levels before breaking.

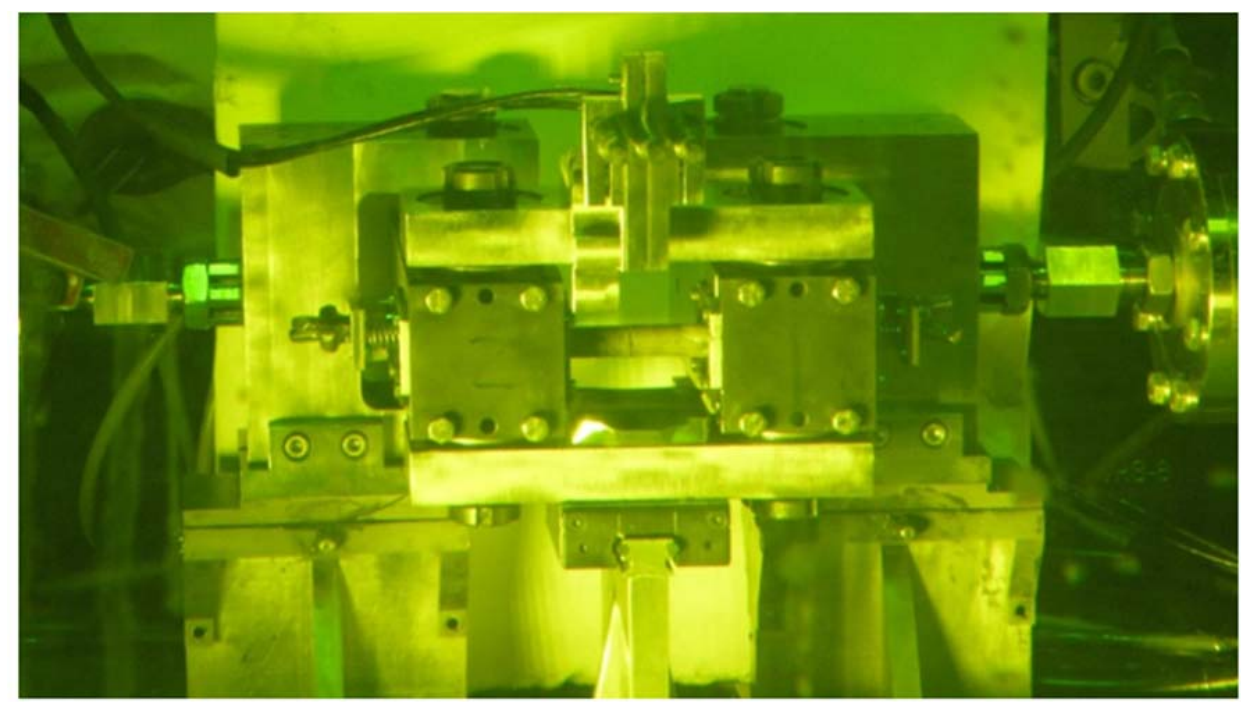

Figure 37. Cyclic Integrated Reversible-bending Fatigue Tester in Hot Cell

(Sample is horizontal rod in center) 
- Cladding from high burnup fuel was tested to see if multiple drying cycles would increase hydride reorientation and increase cladding embrittlement compared to a single drying cycle. Results were mixed, showing the importance of small changes in hoop stress at the point of hydride precipitation.

- Analysis of dust samples collected from the surface of in-service SNF storage canisters.

Preliminary analyses indicate the potential for sufficient chloride at some locations to initiate chloride-induced stress corrosion cracking of the canisters as they cool.

- Purchase of a full-diameter cylindrical mockup of a storage canister with representative welds for future residual stress and corrosion testing.

\subsubsection{Transportation}

The national laboratories tested a surrogate fuel assembly with a 700-mile simulated truck trip on a shaker table followed by 50 miles on a real truck with representative weight to better understand the integrity of high burnup fuel during transport (Figure 38). Results provide further confirmation that stresses and strains seen by the fuel and assembly are well below those predicted to damage cladding or the assembly.

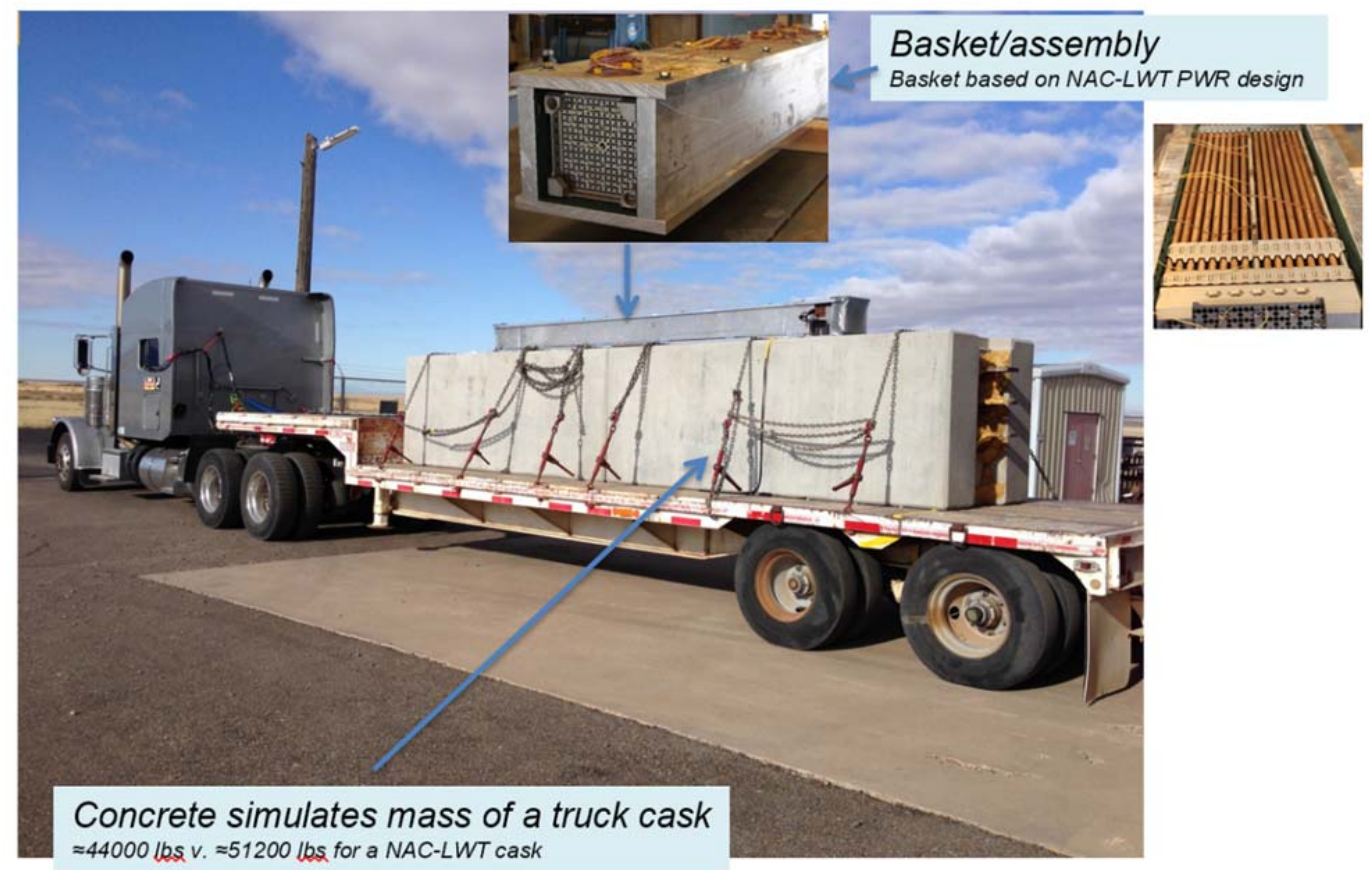

Figure 38. Test unit on concrete blocks on trailer for over-the-road test

\subsection{Disposal Research Accomplishments}

Disposal R\&D has been performed in multiple areas, including analysis of generic mined repository concepts in salt, crystalline rock, and clay/shale rock, as well as deep borehole disposal. Related R\&D had examined the performance of engineered barriers, including the waste form, in various geologic environments, and the feasibility of direct geologic disposal of existing dual-purpose (storage and transportation) canisters currently used for dry storage of used nuclear fuel. Selected work is highlighted here. 


\subsubsection{Evaluation of Disposal Options for the Existing and Projected Inventory of HLW and SNF}

Completing work begun in FY 2013, a multidisciplinary team including members from eight national laboratories, universities, DOE, the U.S. Navy, and private firms concluded that multiple disposal options are available for all existing and currently projected waste forms, with the exception of untreated sodiumbonded fuels, for which additional information is needed. Host media considered included salt, crystalline hard rock and clay/shale rock. Disposal concepts include backfilling upon emplacement (salt) and emplacement of a sorptive backfill either at emplacement or after a ventilation period for mined repositories, and disposal of small waste packages in deep boreholes in crystalline rock (Figure 39).
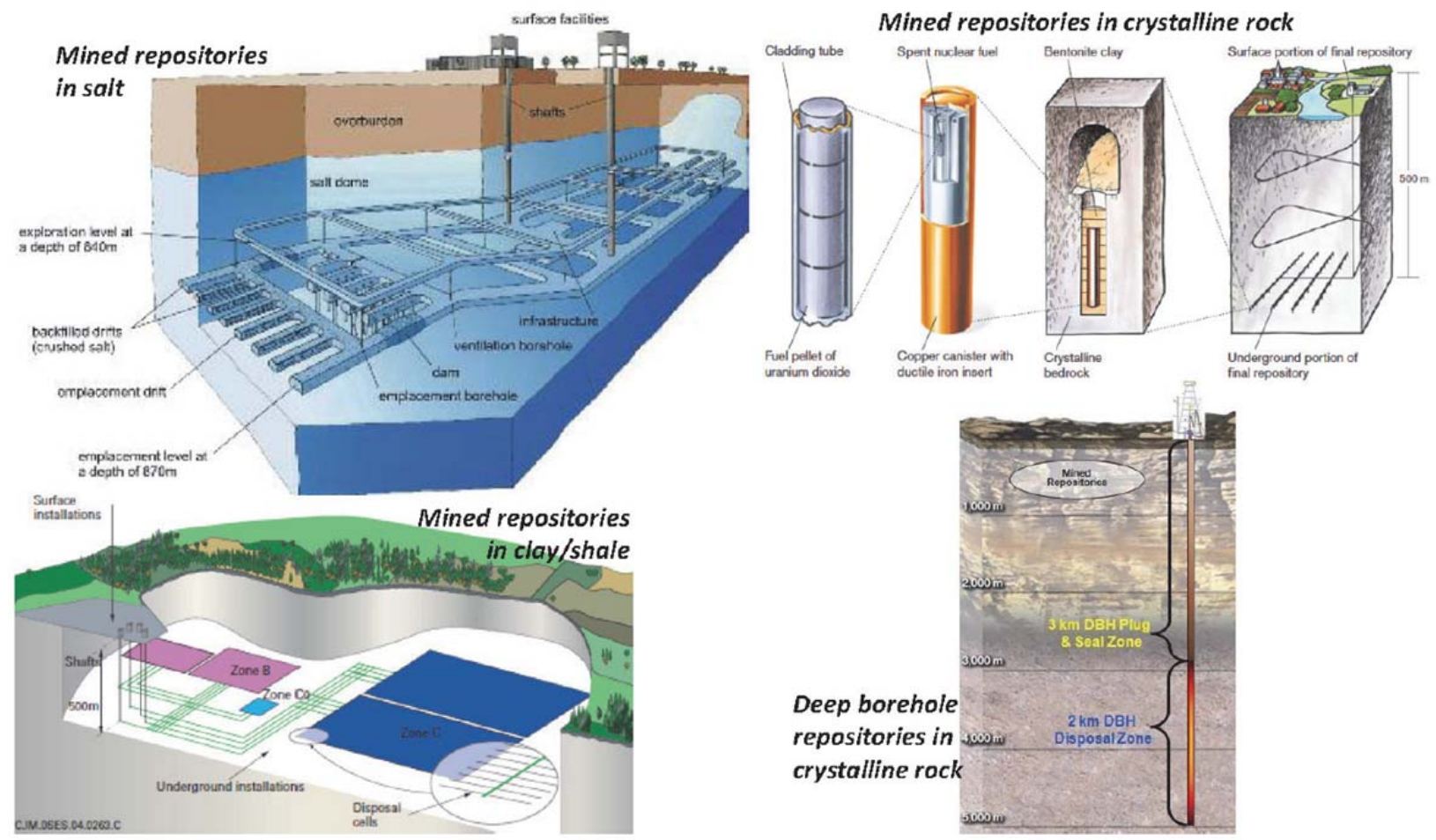

Figure 39. Representative disposal concepts investigated by the Used Fuel Disposition R\&D Campaign.

\subsubsection{Direct Disposal of Dual Purpose Canisters}

FY 2014 investigations support the FY 2013 conclusion that direct disposal of some DPCs is technically feasible, at least for some DPCs, and for some of the disposal concepts depending on the system thermal response, potential for postclosure nuclear criticality, and long-term opening stability. Specific to criticality controls, a key finding is that chloride-rich brines (as might be found in a salt repository) could function as an effective neutron absorber and virtually eliminate the potential for postclosure criticality events.

\subsubsection{Deep Borehole Disposal}

Accomplishments in FY 2014 included completion of a project plan for a deep borehole field test designed to evaluate the feasibility of the deep borehole disposal concept without the use of radioactive 
waste. As planned, the 5-year test will site and drill two boreholes (one small diameter and one large diameter) at the same location to conduct downhole scientific analyses assessing hydrogeochemical conditions and engineering analyses assessing the viability and safety of deep borehole canister emplacement.

\subsubsection{Generic Mined Repository R\&D}

Accomplishments in FY 2014 include:

- Establishment of reference cases for mined repositories in crystalline, clay/shale, and salt host rocks. Reference cases provide a common basis for analysis of representative concepts, and specify the emplacement concept, waste inventory, waste form, engineered barriers including packaging, host rock properties, failure scenarios, and biosphere properties.

- Improved data and models for reactive transport (and actinide sorption/retardation) in fractured rock, building on data from the Grimsel test site in crystalline rock in Switzerland (Figure 40).
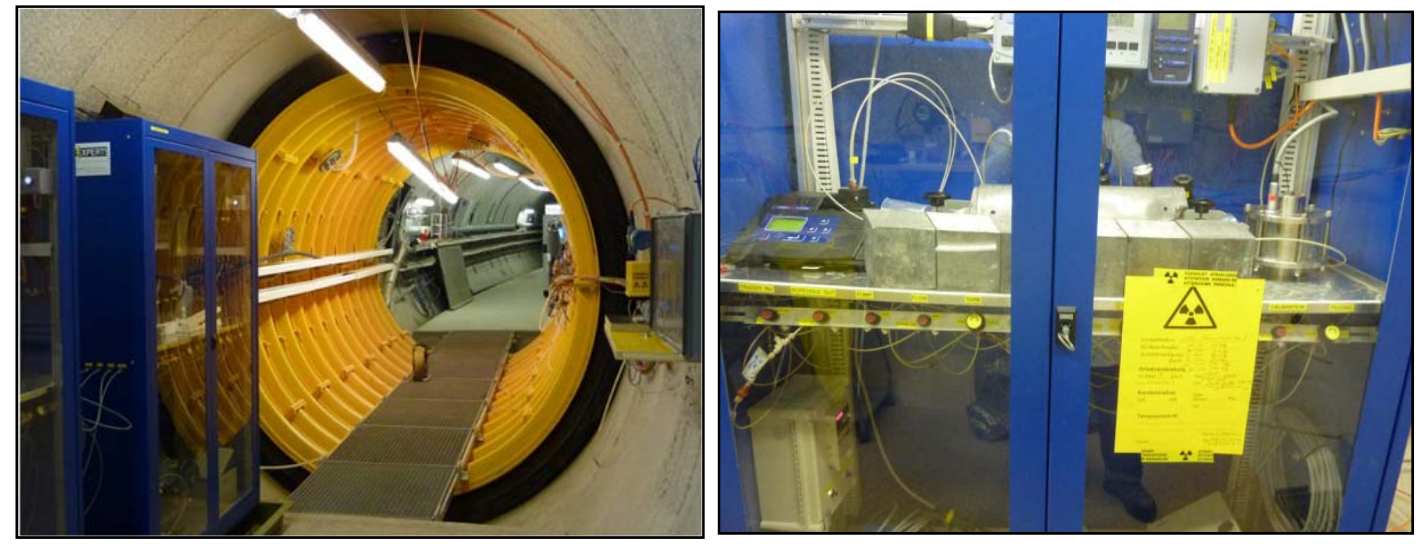

Figure 40. Underground field tests of radionuclide transport in crystalline rock at the Grimsel test site in Switzerland.

- Experimental investigations of the impact of elevated temperatures on material properties of clay, relevant to the performance of both host rock and engineered bentonite backfill.

- Development of generic disposal system modeling capability that employs (1) the highperformance-computing (HPC) capable PFLOTRAN multi-physics code to support the evaluation of repository and subsystem performance in the presence of coupled thermal-hydrologic-chemical (THC) processes, and (2) the HPC-capable uncertainty sampling and propagation code DAKOTA for sensitivity analysis and multi-realization performance assessment. The PFLOTRAN-based modeling capabilities provide multi-physics representations of various coupled processes, including waste degradation, radionuclide mobilization, fluid flow, and radionuclide transport (advection, dispersion, diffusion, sorption, and radionuclide decay and ingrowth) through the engineered barriers and natural barriers to a well location in an overlying aquifer.

The enhanced generic disposal system modeling capability was demonstrated with deterministic and probabilistic simulations of a reference-case repository in bedded salt, as shown in Figure 41. The generic salt repository model included a complex, integrated THC source term (spatially-varying waste degradation across 160 individual waste heat-generating packages, decay heat and thermal effects, and radionuclide solubility and mobility), and fluid movement and radionuclide transport through the engineered backfill, disturbed rock zone, host rock (halite and anhydrite interbeds), and overlying aquifer 
and sediments. In addition to deterministic baseline simulations, sensitivity analyses were performed from 100 realizations with 10 varying parameters.
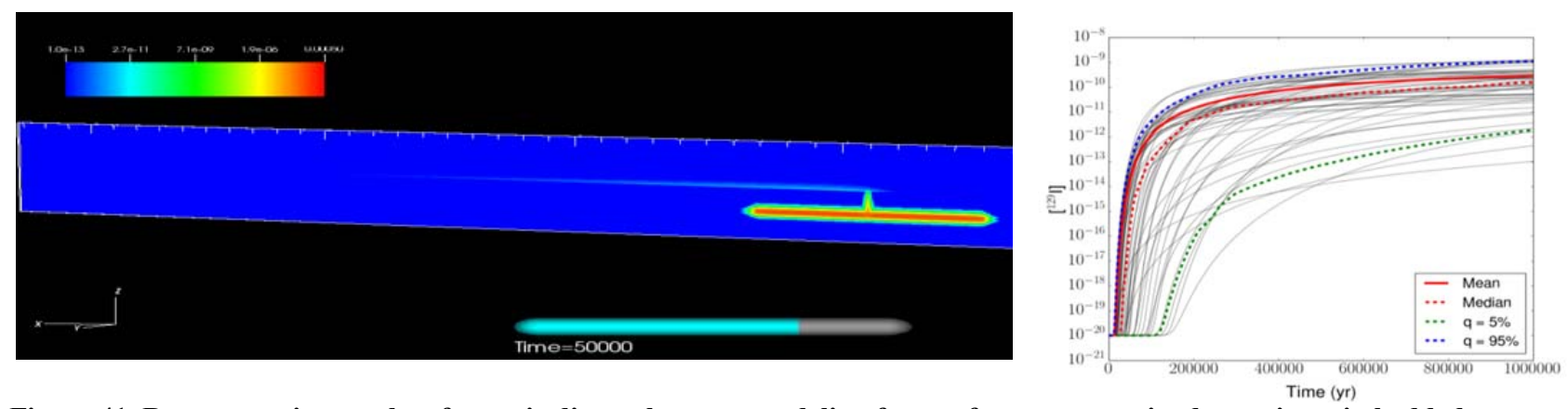

Figure 41. Representative results of generic disposal system modeling for a reference case mined repository in bedded salt. Plots show the estimated mean spatial distribution of the aqueous concentration of I-129 at 500,000 years (left) and the uncertainty in I-129 concentration at the site boundary through time (right).

\subsection{International Collaborations in Disposal Research}

Accomplishments in FY 2014 included collaborative work investigating field tests from underground research facilities in Switzerland (Mont Terri and Grimsel), Sweden (Äspo), Japan (Horonobe), the Czech Republic (Bedrichov Tunnel), and the Republic of Korea's KAERI Underground Research Tunnel (KURT) (Figure 42). Work included completion of nine reports documenting advanced modeling of field tests in the areas of (1) near-field perturbations and engineered barrier system integrity, and (2) fluid flow and radionuclide transport. The campaign also participated in the planning of two major field tests in underground research facilities and has performed related laboratory experiments.

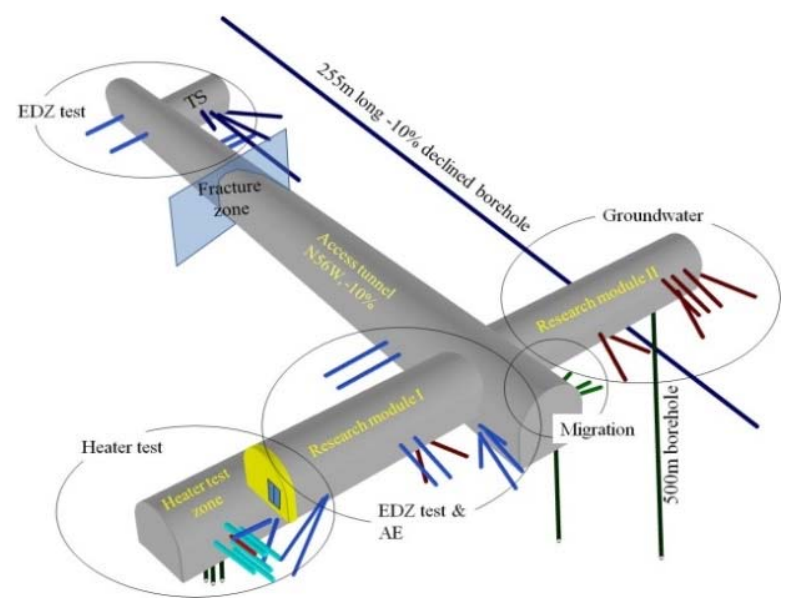

Figure 42. KAERI Underground Research Tunnel (KURT) 


\section{MATERIAL PROTECTION, ACCOUNTING, AND CONTROL TECHNOLOGIES PROGRAM}

\subsection{Overview}

The mission of the Materials Protection, Accounting and Control Technologies (MPACT) campaign is to develop innovative technologies and analysis tools to enable next-generation nuclear materials management for existing and future U.S. nuclear fuel cycles, to manage and minimize proliferation and terrorism risk, and to enhance confidence in and acceptance of nuclear energy.

The existing and future nuclear energy enterprise must prevent, deter, and detect misuse of nuclear materials and associated fuel cycle technologies for both national and global security. While a mature nuclear materials management infrastructure is in place for the existing nuclear energy system, research is needed to support new or improved fuel cycle options as well as the back end of the open fuel cycle.

\subsubsection{Objectives of MPACT campaign}

1. Develop tools, technologies, and approaches in support of used fuel safeguards and security for extended storage, electrochemical processing, and other advanced nuclear energy systems.

2. Develop and demonstrate advanced material control and accounting technologies that would, if implemented, fill important gaps in existing MPACT capabilities.

3. Develop, demonstrate and apply MPACT analysis tools to assess effectiveness and efficiency of MPACT systems and guide R\&D.

4. Perform technical assessments in support of advanced fuel cycle concepts and approaches.

5. Develop guidelines for safeguards and security by design and publish international guidance documents.

\subsubsection{Challenges and Drivers for MPACT Campaign}

1. It is likely that used fuel will be stored for an extended time until an ultimate disposition pathway is available.

2. Future advanced fuel cycle facilities may be larger, more complex and more widespread.

3. Threats, both insider and outsider, may continue to become increasingly sophisticated and capable.

4. Achieving stringent goals for detection timeliness and sensitivity in advanced fuel cycle facilities will be difficult and expensive.

5. Satisfying stringent physical protection requirements in advanced fuel cycle facilities will be expensive.

6. Addressing stakeholder concerns will require positive assurance that risks of nuclear proliferation and terrorism are minimized. 
Technical challenges for the MPACT campaign include:

1. Improve the precision and accuracy nuclear material accountancy measurements, while at the same time improving their timeliness and cost-effectiveness.

2. Expand the scope of detection to include more indicators, taking advantage of existing data where possible and new sources of data where appropriate.

3. Expand and strengthen detection and assessment algorithms to exploit larger data sets and provide results in near-real time.

4. Model and simulate MPACT performance against a wide spectrum of assumed threats and rigorously demonstrate MPACT effectiveness and efficiency in future U.S. nuclear energy systems.

5. Integrate safeguards and security into the design of future nuclear fuel cycle facilities from the earliest stages of the design cycle.

\subsubsection{Key Fiscal Year 2014 Deliverables}

- MPACT Campaign Implementation Plan

- Electrochemical Process Monitoring for Enhanced Safeguards

- Radiation Signature Development for Electrochemical Processing

- Modeling and Simulation for Electrochemical Processing

- Cask Sabotage Gap Analysis

- Best Practices for Security of Used Fuel Dry Cask Storage

- Risk-Informed Security Analysis for Used Fuel Storage

- Field Test Demonstration Plans.

\subsection{Major Research and Development Activities}

\subsubsection{Safeguards and Security by Design - Electrochemical}

Safeguards and Security by Design is a methodology and discipline for integrating next generation MPACT considerations into the design of nuclear facilities from the very earliest stages. The goal is to identify innovative process and facility design features that maximize the effectiveness and efficiency of safeguards and security, and to work with the design team throughout the design process to introduce such features as appropriate, minimizing the need for costly retrofits. Electrochemical processing is being used as the test case for application to advanced fuel cycle technologies, in coordination with the Material Recovery and Waste Forms Campaign and the Joint Fuel Cycle Study. Advanced concepts and approaches, analysis tools, and instrumentation are being developed and applied in an integrated manner to optimize the overall system effectiveness.

Electrochemical Process Monitoring for Enhanced Safeguards, advanced process monitoring instruments (level/density using differential pressure sensors and a direct actinide measurement system using ion exchange) are being developed for electrochemical processing as part of the safeguards and security by design effort (Figure 43 and Figure 44). These sensors provide an opportunity to bring process 
monitoring into the realm of nuclear materials accounting to supplement and advance the current state-ofthe-art. In addition to the sensor development efforts, advanced statistical methods are being developed to formalize the usage of such data to enhance nuclear materials management.
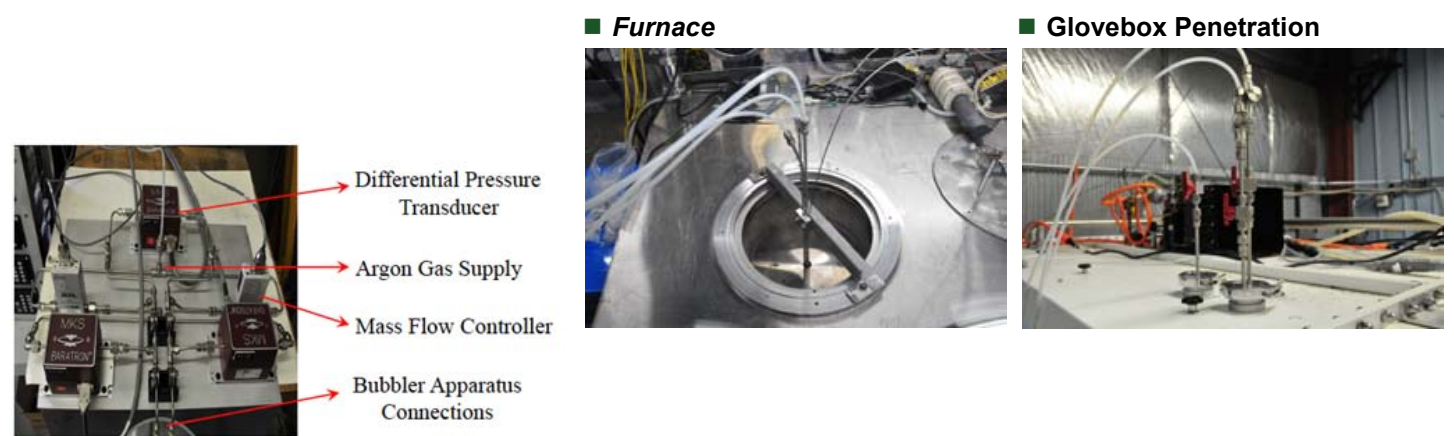

Figure 43. Level/density sensor testing equipment for molten salt tests have demonstrated the ability to measure density with $<1 \%$ accuracy, while level measurements were made with $2 \%$ accuracy.
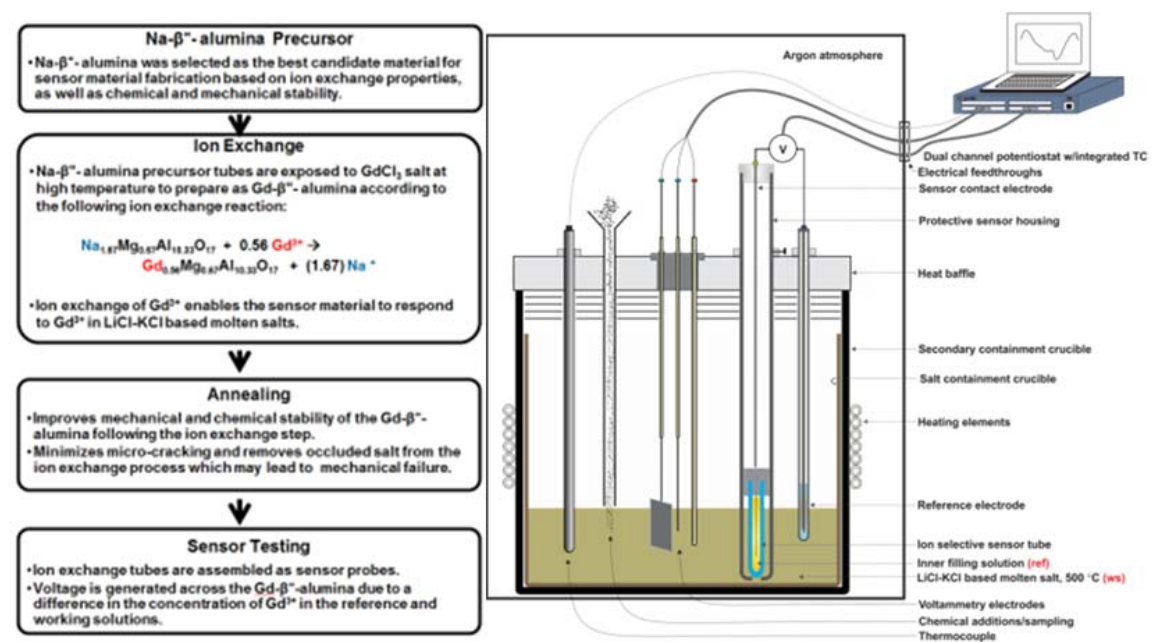

Figure 44. In-situ monitoring technology for prompt determination of actinide concentrations in a molten salt during treatment of used nuclear fuel.

Radiation Signature Development for Electrochemical Processing, advanced radiation transport calculations have been performed for a generic electrochemical processing facility to identify signatures for advanced monitoring instrumentation development (Figure 45). A parametric study was conducted with variable initial enrichments, burnups, and cooling times. Results of the study indicate that neutron and delayed gamma signatures may be exploitable to monitor deviations in the process. 
MCNP simulation from ER source

(top-gamma, bottom-neutron)

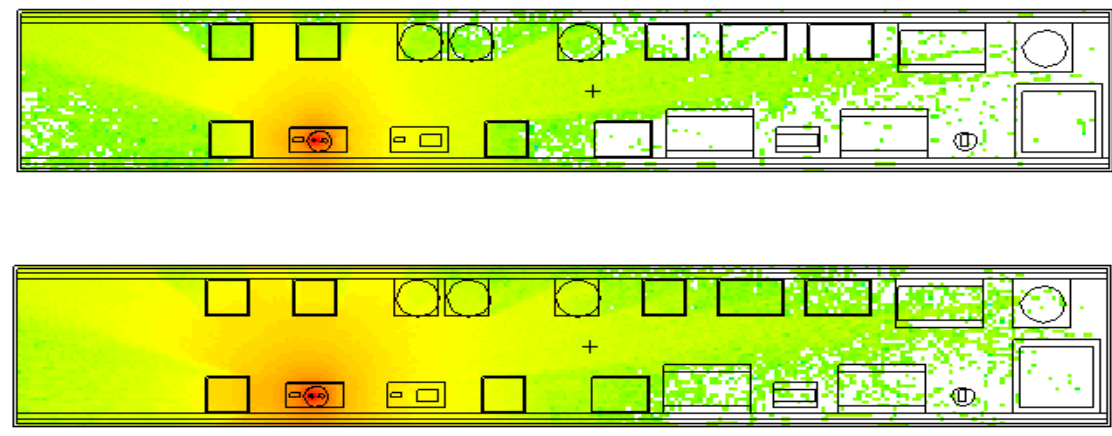

9. $107 \mathrm{E}-06$

4. $310 \mathrm{E}-07$

2. $040 \mathrm{E}-08$

9. $657 \mathrm{E}-10$

4. $571 \mathrm{E}-11$

2. $163 \mathrm{E}-12$

1. $024 \mathrm{E}-13$

4. $847 \mathrm{E}-15$

1. $450 \mathrm{E}-03$

6. $657 \mathrm{E}-05$

3. $055 \mathrm{E}-06$

1. $402 \mathrm{E}-07$

6. $437 \mathrm{E}-09$

2. $954 \mathrm{E}-10$

1. $356 \mathrm{E}-11$

6. $224 \mathrm{E}-13$

$2.856 \mathrm{E}-14$

2. $856 \mathrm{E}-14$

$3 \% 235$ U enrichment, 20GWD/MTU burnup, 3 yr cooling

Figure 45. Radiation signatures (neutron and gamma-ray) are being developed for electrochemical processing to enable advanced monitoring techniques.

Modeling and Simulation for Electrochemical Processing, a mass-balance flowsheet model for metal fuel processing has been developed with enhanced capability based on process chemistry. Dynamic materials flow is also captured allowing for a higher fidelity in predicting electrorefiner performance. The results of this model can be used to provide input to plant level simulations to evaluate overall nuclear material accounting and control performance.

\subsubsection{Used Fuel Extended Storage}

Concepts and approaches are being developed for integrated safeguards and security for used fuel extended storage. This includes the risk-informed security analysis (vulnerability and consequence), assessment of and addressing technology gaps, and providing leadership in the area of international best practices for security of dry storage. This effort is coordinated with the Used Fuel Disposition Campaign and the Nuclear Fuel Storage and Transportation Planning Project.

Cask Sabotage Gap Analysis, a key element for security requirements of used fuel dry storage is the source term and resultant consequence from sabotage, which depends on the spent fuel ratio to extrapolate surrogate testing results to actual spent fuel. Historical measurement data for this parameter is sparse and varies widely, leading to more conservative security requirements. A test plan to enable a more accurate determination of the spent fuel ratio has been developed to help inform regulatory requirements (Figure 46). 


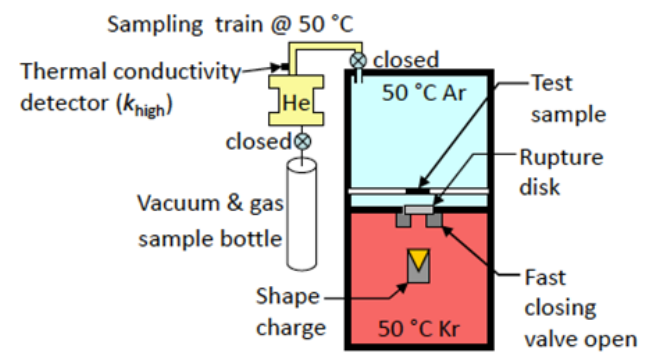

Figure 46. Experimental design for the determination of the spent fuel ratio, which is currently poorly understood and an important factor in evaluating security of interim storage concepts.

Best Practices for Security of Used Fuel Dry Cask Storage, an international workshop was sponsored by the MPACT Campaign and hosted by the World Institute for Nuclear Security (WINS) to address international best practices for security of used fuel dry cask storage. Thirty-seven participants from 17 countries, representing regulators, operators, industry, academia, and laboratories met June 10-12, 2014 in Vilnius, Lithuania. As part of the workshop, a site visit to the Ignalina Nuclear Power Plant was made, including the dry cask storage facility. The results of the workshop have been captured in a WINS best practices guidance document.

Risk-Informed Security Analysis for Used Fuel Storage, a Risk-Informed Management of Enterprise Security analysis of a generic Independent Spent Fuel Storage Installation was conducted based on the proposed design basis threat being considered by the Nuclear Regulatory Commission. Results of the study will be used to help refine design features of the generic storage facility.

\subsubsection{Demonstration Projects and Technical Support}

Advanced instruments are being developed with new capabilities that will significantly advance the state of the art in accounting and control. A focused, innovative, engineering-driven science-based R\&D program is being conducted to improve precision, accuracy, speed, sampling and monitoring methods, and scope of nuclear material accounting and control. As the technical readiness level of these technologies increases, we are planning and executing field tests in fuel cycle facilities to demonstrate their effectiveness. For FY 2014, the Multi-Isotope Process Monitor and the Microcalorimeter are developing field demonstration plans for deployment at H-Canyon as part of the NNSA-NE accountability project (Figure 47).
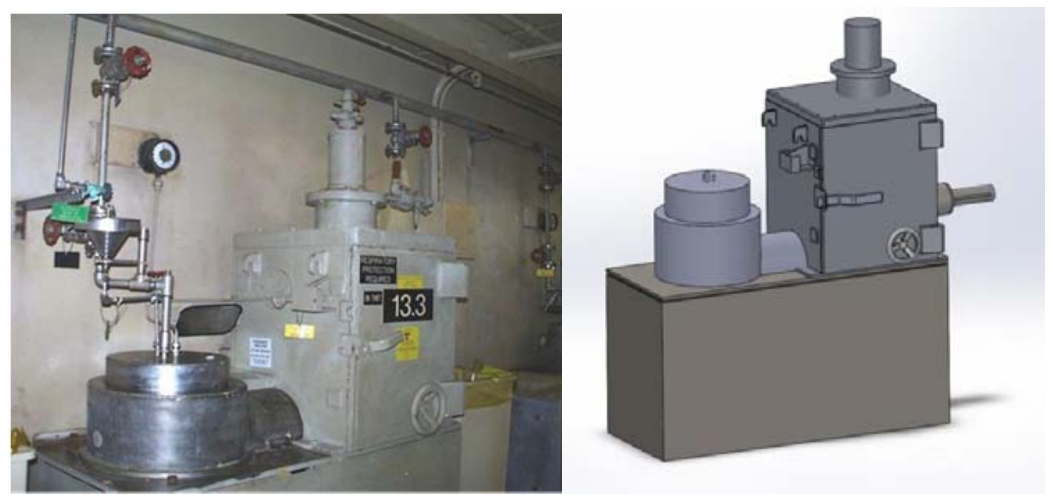

Figure 47. H-Canyon sampling hardware and associated model to support the field testing of the Multi-Isotope Process Monitor. 


\section{FUEL CYCLE OPTIONS CAMPAIGN}

\subsection{Overview}

\subsubsection{Mission}

The Fuel Cycle Options Campaign mission is to develop and implement analysis processes and tools and perform integrated fuel cycle evaluations to provide information that can be used to objectively and transparently inform DOE-NE as decisions are made about overall R\&D directions, mainly supporting R\&D Objective 3 in the Nuclear Energy Research and Development Roadmap (DOE 2010), and to contribute to integration of Fuel Cycle Technology (FCT) activities through R\&D efforts on common fuel cycle goals.

\subsubsection{Campaign Objectives}

1. Contribute to a broader understanding of the required characteristics of the promising fuel cycles capable of providing substantial improvements with respect to the current U.S. fuel cycle by communicating the results of the Nuclear Fuel Cycle Evaluation and Screening Study both within the FCT program and outside the program, and developing and improving communication tools such as the online Fuel Cycle Catalog to foster understanding of nuclear fuel cycles, their capabilities, and their limitations.

2. Develop understanding of the challenges and benefits associated with current and alternative nuclear fuel cycles, including transition, deployment, and options for managing fuel cycle issues, by performing analyses of complete integrated fuel cycles (mining through disposal) including consideration of specific existing and developing technologies and various deployment strategies including the use of modular facilities.

3. Develop understanding of the potential role of nuclear power in the domestic and global energy market considering alternative nuclear fuel cycles and the effects of economics and other external issues such as $\mathrm{CO}_{2}$ management and what aspects of fuel cycles can influence the use of nuclear power.

4. Develop enhanced fuel cycle economic analysis capability, providing results of greater credibility mainly by improving modeling capabilities and continuing improvement of supporting data.

5. Develop and manage processes and data for identifying sustainable alternative fuel cycle options for informing $R \& D$ prioritization, including documentation that supports transparent decision making for R\&D investments.

During FY 2014, the technical activities of the campaign were conducted in the areas of (1) Nuclear Fuel Cycle Evaluation and Screening; (2) Integrated Fuel Cycle Analysis, (3) Deployment and Implementation Issues, and (4) Fuel Cycle Catalog. 


\subsubsection{Key Fiscal Year 2014 Deliverables}

- Nuclear Fuel Cycle Evaluation and Screening Report

- Screening and Evaluation Tool (SET) software

- FY 2014 fuel cycle transition analyses

- Tradeoffs in fuel cycle performance

- Online public fuel cycle catalog

- Transition analysis methodology development and software assessment

- Identification and analyses of fuel cycle economics issues

- Exploration of alternative fuel cycles for U.S. and global nuclear energy use.

The major accomplishment was the completion of the Evaluation and Screening Study and the release of the final report. The study was chartered by DOE-NE in December 2011 in order to evaluate the potential performance of alternative fuel cycles in comparison to the current fuel cycle in the United States using nine evaluation criteria specified by DOE-NE. The nine criteria are nuclear waste management, proliferation risk, nuclear material security risk, safety, environmental impact, resource utilization, development and deployment risk, institutional issues, and financial risk and economics. The study considered the entire fuel cycle from mining to disposal. The set of alternative fuel cycles evaluated in the study was comprehensive with respect to nuclear fuel cycle performance. The results provided DOE-NE with information on the potential improvements associated with nuclear fuel cycle options as input to their decision-making process for R\&D directions and funding decisions. Additionally in FY 2014, the campaign started detailed investigations of the attributes of the most promising fuel cycles and the issues associated with transitioning to those fuel cycles from the current U.S. fuel cycle that uses light-water reactors (LWRs), enriched uranium fuel, and direct disposal of SNF.

The following sections describe representative highlights of work completed during the fiscal year.

\subsection{Fuel Cycle Evaluation and Screening}

\subsubsection{Complete the Fuel Cycle Evaluation and Screening Study}

The Nuclear Fuel Cycle Evaluation and Screening (E\&S) study focused on identifying promising fuel cycle options that could provide substantial improvements as compared to the current U.S. nuclear fuel cycle. These options were evaluated using a set of criteria provided by DOE-NE representing broadly defined economic, environmental, safety, non-proliferation, security and sustainability goals. The studies determined that substantial improvements were possible for reducing the amount of highly radioactive wastes per energy generated by about a factor of 10 and for reducing the amount of uranium and/or thorium requiring disposal per energy generated by about a factor of 100 through recycle using the uranium and/or thorium for fuel. This could also increase the percentage of the natural fuel resource used from about $0.6 \%$ today up to nearly $100 \%$. If these improvements are considered to be both important and substantial by decision-makers, then the required fuel cycle characteristics indicated in Table 1 are needed for the most promising options. The study also identified additional promising options which included continuous recycle using thorium fuel and once-through or limited recycle use in fast reactors of uraniumbased fuel in fast reactors to very high burnup. The link to the report is: 


\section{https://inlportal.inl.gov/portal/server.pt/community/nuclear_science_and_technology/337/nuclear} fuel cycle evaluation and screening final report.

Table 1. Identified attributes for the most promising fuel cycle options

- Continuous recycle - all irradiated fuel is reprocessed for recycle and no spent fuel is disposed

- Uranium-based fuel - fuel is uranium with either recycled plutonium or the transuranic (TRU) elements

- Fast neutron irradiation - greater neutron production per fission and more favorable fission-to-capture ratio

- Critical reactors - reactors capable of sustaining the fission chain-reaction

- High internal conversion - sufficient conversion of fertile isotopes are converted to fissile isotopes for the reactors to be self-sustaining without uranium enrichment.

Availability of Screening and Evaluation (SET) Tool: The SET tool computer software and associated User's Guide developed to support the E\&S study are also available on the report website (link provided above). The SET tool allows the user to explore the sensitivity of the identification of potentially promising fuel cycle options to variations in the importance of benefit criteria and metrics. An example result from the SET tool is provided in Figure 48, showing the 40 Evaluation Groups (EG) used in the study.

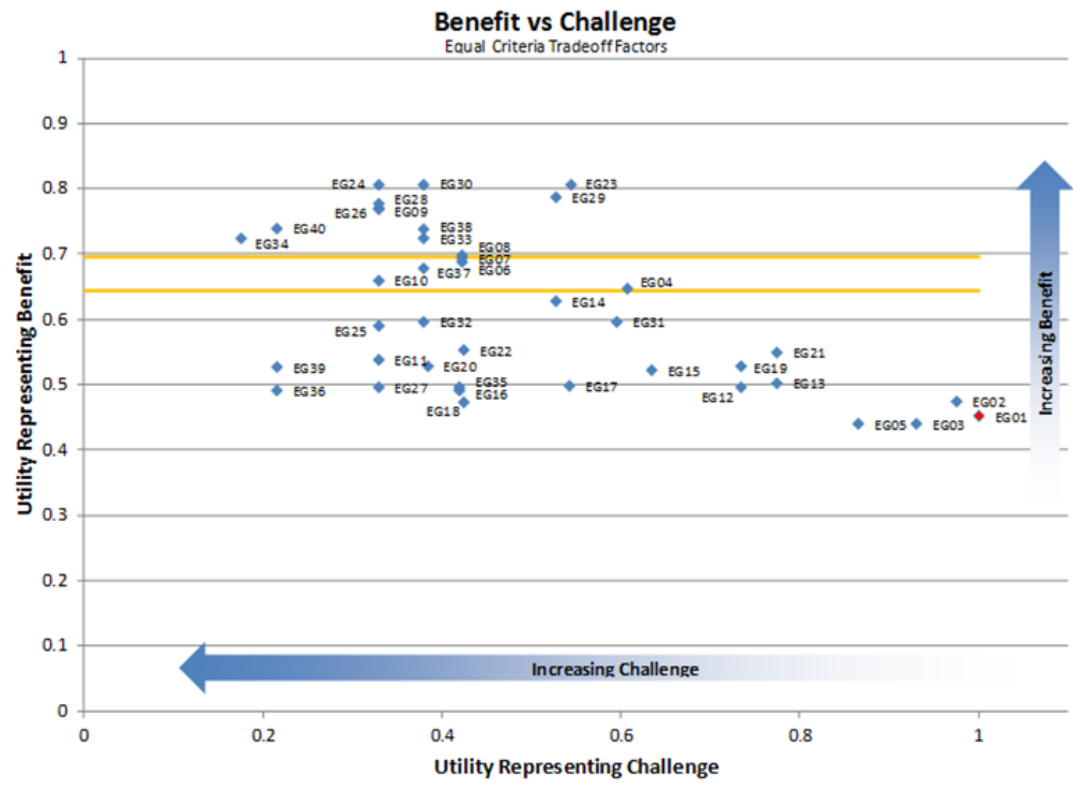

Figure 48. Benefit versus challenge using equal criteria tradeoff factors 


\subsection{Integrated Fuel Cycle Analysis}

Investigation of the Promising Fuel Cycle Groups: As the E\&S Study was conducted at the level of fuel cycle EGs that included many similar fuel cycle groups/options, an activity in FY 2014 reviewed the fuel cycle groups in the most promising and potentially promising EGs to determine the extent to which the individual fuel cycle groups in each EG could be identified as promising. Depending on the outcome of this examination, this may reduce the number of promising fuel cycle options identified as being promising in comparison to the current U.S. fuel cycle. The FY 2014 Integrated Fuel Cycle Analysis analyses also investigated the question of whether tradeoffs existed between the fuel cycle performance metrics and determined that such conflicts were minor or nonexistent and that fuel cycles exhibiting the best performance on all metrics were possible. The study also showed the lower performance potential of intermediate spectrum systems (which had been grouped with fast spectrum systems and part of the identified most promising EGs), and of those fuel cycles containing U/Th when considering U/Pu recycle. For example, the study indicated that of the many included groups in EG23, only those shown in Table 2 can be considered most promising.

Table 2. Included groups considered most-promising in Evaluation Group EG23

\begin{tabular}{|l|l|}
\hline Included Groups & \multicolumn{1}{c|}{ Description } \\
\hline SC-C-F-U-Pu-N & $\begin{array}{l}\text { Continuous recycle of U/Pu with new natural-U fuel in } \\
\text { fast critical reactors in single-stage fuel cycle }\end{array}$ \\
\hline $\mathrm{MC}-\mathrm{C}-\mathrm{F} / \mathrm{F}-\mathrm{U}-\mathrm{Pu}-\mathrm{N}$ & $\begin{array}{l}\text { Continuous recycle of U/Pu with new natural-U fuel in } \\
\text { fast critical reactors in multi-stage fuel cycle }\end{array}$ \\
\hline
\end{tabular}

\subsection{Deployment and Implementation Issues}

Deployment and Transition Trends: The Campaign has initiated analyses of transitions from the current U.S. fuel cycle to the much smaller set of most promising fuel cycles as defined by the E\&S study, including analysis of the transition from the current U.S. fuel cycle to two of the most promising fuel cycles involving continuous recycle in fast reactors. The analyses produced estimates of possible future deployment showing the time required for transition and identified constraining factors hindering deployment, such as availability of fuel materials for the fast reactors and the timing of deployment decisions. A typical plot of the electricity generated by different reactor types is shown in Figure 49 for the transition from the current LWRs to the advanced sodium-cooled reactors (SFRs).

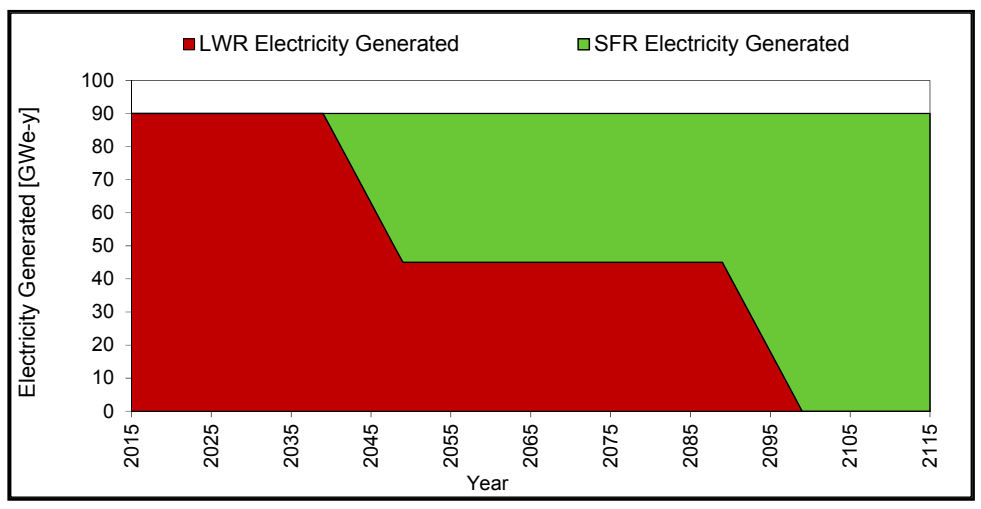

Figure 49. An Example of the timing of transition to a new fuel cycle using recycle in SFRs for a total generating capacity of $100 \mathrm{GWe}$ 
Identification and analysis of fuel cycle economics issues: Numerous issues arose during the E\&S study concerning the ability to perform credible economics analysis on alternative fuel cycles, including the accuracy or availability of supporting data, the interdependence of cost estimates between facilities, and a number of uncertainties (for an estimate, among multiple estimates, experience vs. variation, etc.). An activity was initiated to conduct a fundamental examination of what is needed to support credible fuel cycle cost estimates and evaluation of financial risk, starting from prior studies and approaches and introducing the necessary concepts to account for the issues that affect cost estimates. In the study, a preliminary examination of historical information on LWR reactor costs was conducted, identifying unavoidable and avoidable costs (Figure 50). The results showed consistency in unavoidable costs (e.g., design, construction, commodities), but large variation in avoidable costs (e.g., delays, licensing issues). Work will be continued in FY 2015 to refine the analysis methods for, and knowledge of, nuclear economics issues.

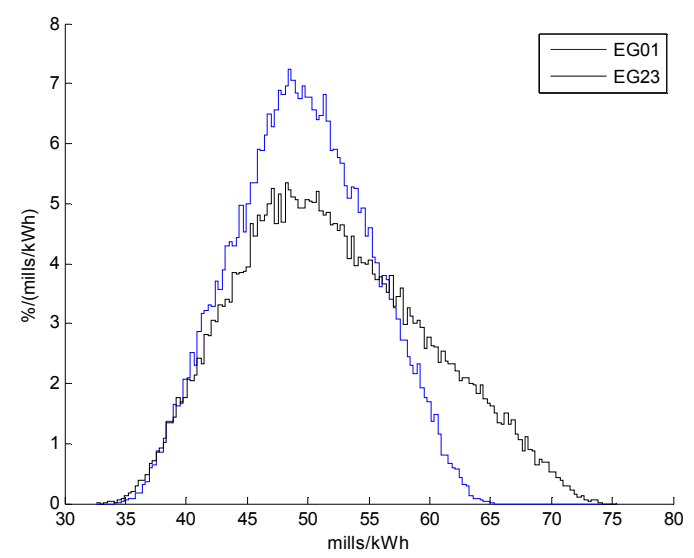

Figure 50. Comparison of the probability distributions for the levelized cost of electricity at equilibrium for EG01 (today's U.S. fuel cycle) and EG23 (one of the most promising groups) at a 5\% discount rate.

Stabilization of Atmospheric Greenhouse Gas Concentrations With Nuclear Electricity - Uncertainty remains as to the level of atmospheric greenhouse gas (GHG) concentrations that would avoid dangerous human interference with the climate. While there is no clear agreement on the level at which $\mathrm{CO}_{2}$ and other GHG concentrations should be stabilized, there has been greater focus in limiting atmospheric GHG concentration to $450 \mathrm{ppm} \mathrm{CO}_{2}$-eq (equivalent), the so-called 450 Scenario. This concentration has been estimated by the climate change community to have a high probability of limiting changes in the mean global temperature to approximately $2^{\circ} \mathrm{C}$ above pre-industrial levels. The impact of using nuclear energy to stabilize the level of GHG has been evaluated. Current results show that all technologies with low carbon emissions (fossil and biomass carbon capture and sequestration (CCS), renewables and nuclear) play a large role in contributing to electricity generation under the carbon policy of restricting carbon emissions. However, nuclear energy (EG01) with no direct carbon emissions plays a particularly large role in supplying the worldwide electricity needs of the 450 Scenario. The use of nuclear energy would need to grow over time with the rising carbon penalty on fossil fuel use. Electricity generation using CCS technologies, as a whole, that is applied to fossil as well as biomass fuels also has large contributions. Wind and solar technologies make significant gains but their contributions to electricity generation are less than nuclear and CCS technologies. The needed global shares of nuclear, CCS (fossil and biomass), and combined wind and solar are estimated to be 44,32 and $18 \%$ of the global electricity generation in 2095 (Figure 51). 


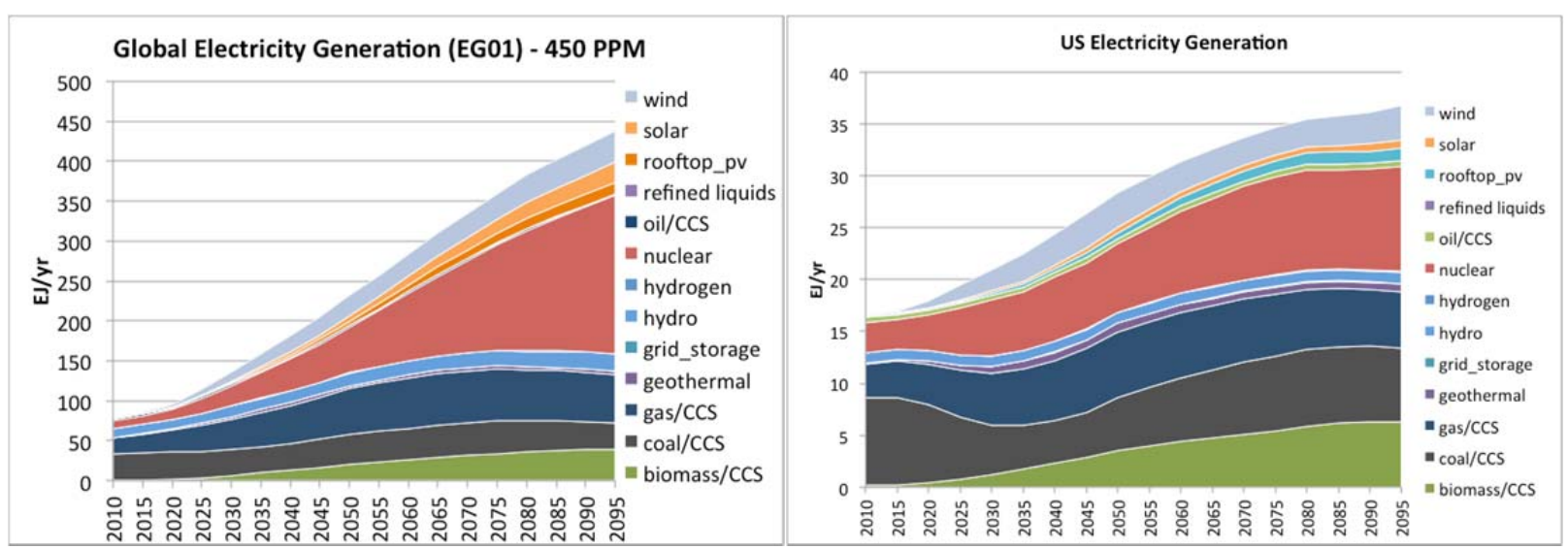

Figure 51. Global and U.S. electricity generation in the $450 \mathrm{ppm}$ scenarios (EJ/yr).

Transition Analysis Methodology Development - In FY 2014, effort was initiated for developing a transition analysis methodology, and assessing and developing the tools and skills needed to perform meaningful transition analysis activities on the scale needed to evaluate the promising EGs identified in the E\&S report. Definitions and strategies were developed and available codes were identified and tested along with the personnel and the administrative processes needed to move forward with this activity.

\subsection{Fuel Cycle Catalog}

Availability of Online Fuel Cycle Catalog: The initial version of the Fuel Cycle Catalog was completed and made publicly available online for the first time during FY 2014 (Figure 52). The activities included developing and operating a website that provides information about fuel cycles, their characteristics, and potential implementing technologies to facilitate communication about the capabilities of alternative fuel cycles. The interactive catalog allows users to explore a wide variety of fuel cycles, learn about fuel cycle technologies, and to take any fuel cycle and identify the fuel cycle in the Catalog that has similar performance characteristics. The Catalog is intended to be updated periodically to include results from the ongoing activities in Integrated Fuel Cycle Analyses.

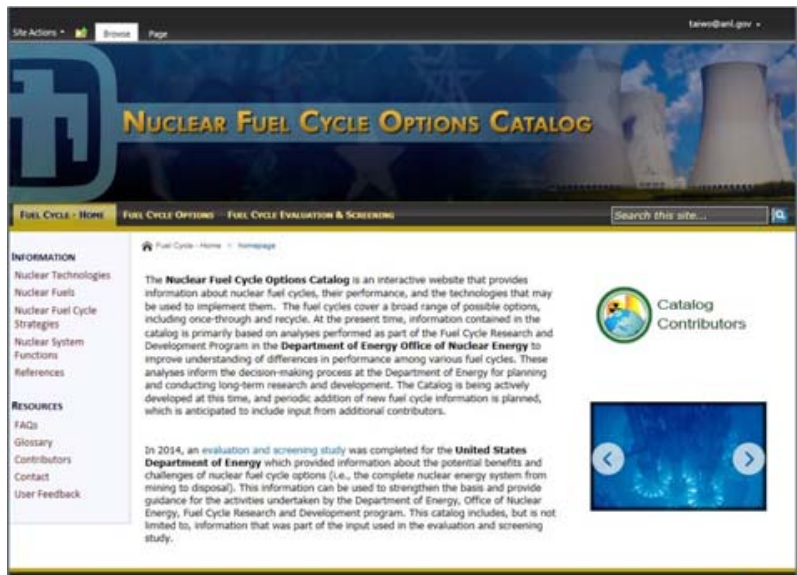

田 Sindo lational laborations

Q

Figure 52. Image of the home page of the Nuclear Fuel Cycle Catalog

(https://connect.sandia.gov/sites/NuclearFuelCycleOptionCatalog/SitePages/a/homepage.aspx) 


\section{Appendix A Acronyms}

AAR

AFC

ATF

ATR

ATRP

$\mathrm{BRC}$

CCS

DOE

DOE-NE

DPC

EPRI

EG

ESA

FCT

FOA

FY

GACS

GHG

HFEF

HLW

INL

IRT

ISF

JFCS

KAERI

KURT

LANL

LCC

LEU

LSFS

LWR

MFC

MOF

MPACT

NEAMS

NEUP
Association of American Railroads

Advanced Fuels Campaign

accident tolerant fuel

Advanced Test Reactor

atom transfer radical polymerization

Blue Ribbon Commission

carbon capture and sequestration

Department of Energy

DOE Office of Nuclear Energy

dual-purpose canister

Electric Power Research Institute

evaluation group

Execution Strategy Analysis

Fuel Cycle Technologies

Funding Opportunity Announcement

fiscal year

glovebox advanced casting system

greenhouse gas

Hot Fuel Examination Facility

high-level waste

Idaho National Laboratory

Integrated Recycling Test

interim storage facility

Joint Fuel Cycle Studies

Korean Atomic Energy Research Institute

KAERI Underground Research Tunnel

Los Alamos National Laboratory

liquid cadmium cathode

low-enriched-uranium

Laboratory-Scale Feasibility Study

light water reactor

Materials and Fuels Complex

metal-organic-framework

Materials Protection, Accounting and Control Technology

Nuclear Energy Advanced Modeling and Simulation

Nuclear Energy University Program 
NFST Nuclear Fuels Storage and Transportation (project)

NRC

Nuclear Regulatory Commission

NWPA

Nuclear Waste Policy Act

NWTRB

Nuclear Waste Technical Review Board

ODS

oxide dispersion strengthened

ORNL

Oak Ridge National Laboratory

PIE

postirradiation examination

PNNL

Pacific Northwest National Laboratory

R\&D

research \& development

RD\&D

research, development, and demonstration

RIGP

Radiation Induced Graft Polymerization

SET

Screening and Evaluation Tool

SFR

sodium-cooled fast reactor

SNF

spent nuclear fuel

SRG

state regional group

TCM

thermal conductivity microscope

TREAT

Transient Reactor Test (facility)

TRU

transuranic

UFD

Used Fuel Disposition Research and Development (campaign)

UNF

used nuclear fuel

UNF-ST\&DARDS Used Nuclear Fuel Storage, Transportation \& Disposal Analysis Resource and Data System

WINS World Institute for Nuclear Security 